\title{
Acceleration and Overturning of the Antarctic Slope Current by Winds, Eddies, and Tides
}

\author{
ANDREW L. STEWART \\ Department of Atmospheric and Oceanic Sciences, University of California, Los Angeles, Los Angeles, California
}

ANDREAS KLOCKER

Antarctic Climate and Ecosystems Cooperative Research Centre, University of Tasmania, Hobart, Australia

DimitRIS MENEMENLIS

Science Division, Jet Propulsion Laboratory, California Institute of Technology, Pasadena, California

(Manuscript received 26 October 2018, in final form 27 May 2019)

\begin{abstract}
All exchanges between the open ocean and the Antarctic continental shelf must cross the Antarctic Slope Current (ASC). Previous studies indicate that these exchanges are strongly influenced by mesoscale and tidal variability, yet the mechanisms responsible for setting the ASC's transport and structure have received relatively little attention. In this study the roles of winds, eddies, and tides in accelerating the ASC are investigated using a global ocean-sea ice simulation with very high resolution ( $1 / 48^{\circ}$ grid spacing). It is found that the circulation along the continental slope is accelerated both by surface stresses, ultimately sourced from the easterly winds, and by mesoscale eddy vorticity fluxes. At the continental shelf break, the ASC exhibits a narrow $(\sim 30-50 \mathrm{~km})$, swift $\left(>0.2 \mathrm{~m} \mathrm{~s}^{-1}\right)$ jet, consistent with in situ observations. In this jet the surface stress is substantially reduced, and may even vanish or be directed eastward, because the ocean surface speed matches or exceeds that of the sea ice. The shelfbreak jet is shown to be accelerated by tidal momentum advection, consistent with the phenomenon of tidal rectification. Consequently, the shoreward Ekman transport vanishes and thus the mean overturning circulation that steepens the Antarctic Slope Front (ASF) is primarily due to tidal acceleration. These findings imply that the circulation and mean overturning of the ASC are not only determined by near-Antarctic winds, but also depend crucially on sea ice cover, regionally-dependent mesoscale eddy activity over the continental slope, and the amplitude of tidal flows across the continental shelf break.
\end{abstract}

\section{Introduction}

The Antarctic Slope Current (ASC) is an approximately circumpolar, westward flow that tracks the continental shelf break and slope (see Fig. 1 and Thompson and Heywood 2008; Meijers et al. 2010; Chavanne et al. 2010; Armitage et al. 2018). A portion of the ASC is associated with the Antarctic Slope Front (ASF), a subsurface front that separates increasingly warm waters at middepth $(\sim 300 \mathrm{~m})$ offshore (Schmidtko et al. 2014) from the typically cold waters of the continental shelf (Jacobs 1991; Whitworth et al. 1998). The ASC and ASF therefore mediate exchanges of waters across the Antarctic continental slope and exert an outsized influence on local and global

Corresponding author: Andrew L. Stewart, astewart@atmos.ucla.edu ocean circulation and climate (Rintoul 2018; Thompson et al. 2018). For example, transfer of heat from the open ocean onto the continental shelf must cross the ASF (Heywood et al. 2016; Goddard et al. 2017; Palóczy et al. 2018) and directly contributes to the melt of Antarctica's floating ice shelves (Pritchard et al. 2012; Jenkins et al. 2016; Zhao et al. 2019). The production of dense shelf waters (DSW) supply the global volume of Antarctic Bottom Water (Gordon 2001; Orsi et al. 2001), which in turn ventilates the abyssal ocean (Sarmiento et al. 1988; Hotinski et al. 2001) and contributes to the baroclinicity and structure of the Antarctic Circumpolar Current (ACC) (Morrison and Hogg 2013; Stewart and Hogg 2017).

Despite the ASC's significance in the global ocean circulation, relatively little is understood about its 


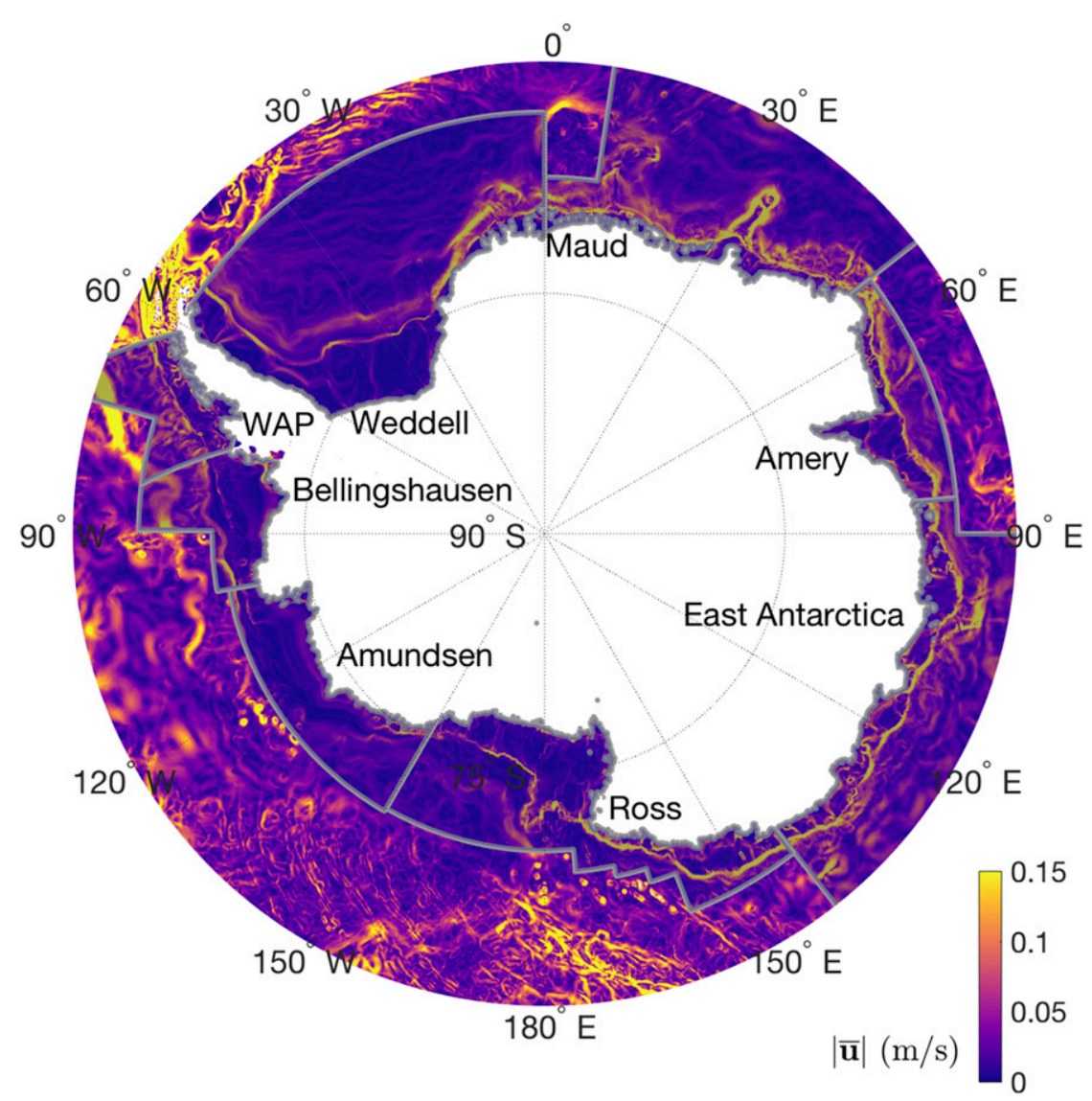

FIG. 1. Speed of the time-mean depth-averaged flow in the LLC_4320 simulation, highlighting the circumpolar structure of the Antarctic Slope Current's shelf break jet. The overlays and labels indicate our division of the Antarctic margins into regions, following Stewart et al. (2018).

circulation and dynamics compared, for example, to the ACC farther north (Rintoul 2018). The conception of the flow along the Antarctic shelf break as a wind-driven current was introduced by Gill (1973) and persists in modern descriptions of the ASC (Heywood et al. 2014). Process-oriented models of the ASF indicate that the wind-driven shoreward Ekman transport plays a central role in setting the slope of the pycnocline in the ASF and thus the overturning circulation across continental shelf and slope (Nøst et al. 2011; Stewart and Thompson 2015a; Hattermann 2018). This suggests that the near-Antarctic circulation, shoreward heat transport, and export of DSW to the global abyss should all be sensitive to changes in the near-Antarctic winds (Stewart and Thompson 2012; Spence et al. 2014, 2017; Goddard et al. 2017).

One way in which recent conceptions of the ASF/ ASC have advanced upon that of Gill (1973) is in their identification of the role of mesoscale variability, which we refer to as "eddies" throughout this article, in mediating cross-slope exchanges (Klinck and Dinniman 2010; Thompson et al. 2014). In parallel with the well-established paradigm for the ACC (Marshall and Radko 2003; Abernathey et al. 2011), eddies might be expected to counteract wind-induced steepening of isopycnals and thereby contribute to setting the baroclinicity of the ASF (Nøst et al. 2011; Stewart and Thompson 2013). Previous studies indicate that eddies efficiently transfer heat toward the coast via troughs in the continental shelf, particularly where circumpolar deep water (CDW) floods the shelf (St-Laurent et al. 2013; Couto et al. 2017) and where DSW is exported across the continental slope (Thompson et al. 2014; Stewart and Thompson 2015b). Stewart and Thompson (2016) examined the role of eddies in the momentum balance of the ASC, using idealized simulations, and found that they accelerated a series of jets along the continental slope, which in turn drifted offshore.

In addition to eddies, the ASC also experiences strong tidal flows, with average tidal velocities reaching $\mathscr{O}(1) \mathrm{m} \mathrm{s}^{-1}$ around localized stretches of the shelf break (e.g., Foldvik et al. 1990; Robertson 2001). Tides can contribute substantially to exchanges of CDW and 
DSW across the continental shelf and slope, particularly where the slope is relatively steep (Padman et al. 2009; Wang et al. 2013; Castagno et al. 2017). Tidal rectification can also directly contribute to the acceleration of along-slope mean flows, which are necessary to conserve momentum against the along-slope tidal "Stokes' drift" (Garreau and Maze 1992; Chen and Beardsley 1995), for example, around Georges Bank (Loder 1980) and the Yellow Sea (Lee and Beardsley 1999). Flexas et al. (2015) found that regional simulations integrated with tidal forcing alone could produce an ASF in the Weddell-Scotia confluence, suggesting that tides play a key role on driving the ASC there. However, it remains unclear whether this tidal acceleration of the ASC is ubiquitous around the Antarctic shelf or limited to specific "hot spots" such as the Weddell Sea.

In this article we use a global simulation with very high resolution (see Stewart et al. 2018) to examine the relative roles of wind forcing and transient flows (eddies and tides) in driving the ASC. In section 2 we discuss the model and our approach to analyzing it: we first review the model configuration (section $2 \mathrm{a}$ ), compare the structure of the simulated ASC against high-resolution hydrography and current measurements (section 2b), and provide diagnostics of the ASC's mean circulation and forcing (section 2c). We then describe our temporal decomposition of the model variables into approximate mean, eddy, and tidal components (section $2 \mathrm{~d}$ ), and discuss our transformation to coordinates that approximately follow the mean flow of the ASC (section 2e). In section 3 we present our main results: we first quantify the relative importance of different ASC circulation drivers via the integrated vorticity budget (section 3a) and energy budget (section 3b) in the combined Amery/ East Antarctica sector (see Fig. 1), which we use as a reference case because the ASC is approximately zonal there. We then examine the localization of the ASC forcing as a function of along-coast distance (section 3c) and depth (section 3d), and quantify variations in this forcing between different sectors of the continent (section 3e). Finally, we discuss our results and draw conclusions in section 4.

\section{The ASC in the LLC_4320 simulation}

This section describes the tools and methods required to distinguish different drivers of the ASC circulation in section 3. We first provide an overview of the simulation that serves as the basis of our analysis, referred to as the latitude-longitude-cap 4320 (LLC_4320) simulation (Rocha et al. 2016), and evaluate the simulated ASC against observations. We additionally present diagnostics of the mean zonal flow and surface/bottom forcing of the ASC. These diagnostics motivate a decomposition of the model variables into mean, eddy, and tidal components and a transformation into a coordinate system that follows isobaths (see Stewart et al. 2018).

\section{a. Model configuration}

We draw our results from a global ocean-sea ice simulation (the LLC_4320) run at very high horizontal resolution (Rocha et al. 2016), having a grid spacing of $1 / 48^{\circ}$, or $\sim 1 \mathrm{~km}$ over the Antarctic continental shelf and slope. In the vertical, the model is discretized into 90 levels, with spacings ranging from $1 \mathrm{~m}$ at the surface to $480 \mathrm{~m}$ at a depth of $7000 \mathrm{~m}$. Previous studies have found that this approximate model resolution is required to resolve eddy- and tidal-driven heat and volume exchanges across the continental slope (Padman et al. 2009; St-Laurent et al. 2013; Wang et al. 2013; Stewart and Thompson 2015b; Graham et al. 2016). At this time, no other model simulation that includes tidal forcing and spans the entire Antarctic margins has achieved comparable resolution. The LLC_4320 therefore offers a unique, albeit preliminary, insight into the role of high-frequency variability over the shelf and slope. Figure 1 shows depth-averaged, timemean flow speed in the portion of the model domain that we have analyzed in this study. The ASC is visible as a narrow jet, with depth-averaged mean flow speeds frequently exceeding $0.2 \mathrm{~ms}^{-1}$, that approximately tracks the entire Antarctic shelf break. The Amundsen and Bellingshausen sectors are an exception, likely due to the lack of data included in the model's bathymetry product, Smith and Sandwell (1997) version 14.1, as discussed by Stewart et al. (2018). The model is therefore not expected to accurately represent the ASC and ASF in these sectors.

For a detailed overview of the model configuration, readers are referred to Rocha et al. (2016). Salient properties of the simulation for the present study are as follows: The LLC_4320 simulation is a high-resolution refinement of the ECCO2 adjoint estimate, which was conducted on a global $1 / 6^{\circ}$ cubedsphere grid (CS_510; Menemenlis et al. 2008). A dataunconstrained continuation of the ECCO2 simulation was conducted on a latitude-longitude-cap (LLC) grid (Forget et al. 2015), first at $1 / 12^{\circ}$ (the LLC_1080, spanning January $2010-J u n e ~ 2012$ ), then at $1 / 24^{\circ}$ (the LLC_2160, spanning January 2011-April 2013), and finally at $1 / 48^{\circ}$ (the LLC_4320, spanning September 2011 to November 2012). Stewart et al. (2018) assessed the spinup of these simulations via time series of volume-averaged model properties in a portion of the Amery sector (Fig. 1) and found a drift in the mean 

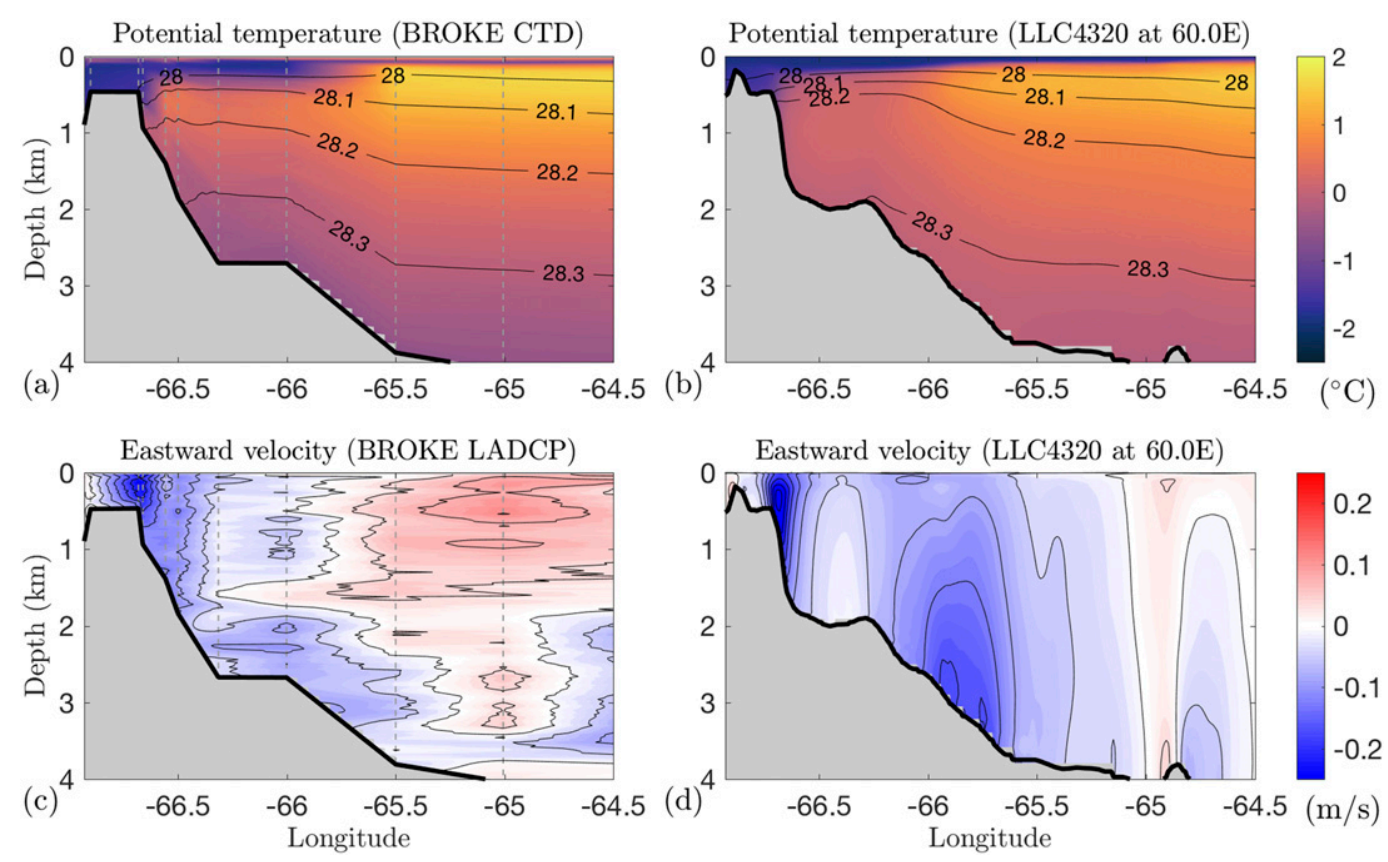

FIG. 2. Evaluation of the (b),(d) modeled annual-mean Antarctic Slope Front/Current against (a),(c) observations made between 8 and $11 \mathrm{Feb} 2006$ during the BROKE West Survey along 60 E (Meijers et al. 2010). (top) Potential temperature (colors) and neutral density (black contours) calculated following Jackett and McDougall (1997). Labels indicate neutral densities on each isopycnal $\left(\mathrm{kg} \mathrm{m}^{-3}\right)$. (bottom) Zonal velocity contoured every $0.01 \mathrm{~m} \mathrm{~s}^{-1}$ (colors) and $0.04 \mathrm{~m} \mathrm{~s}^{-1}$ (black contours). In (a) and (c), the dashed black lines indicate locations at which CTD cast and lowered ADCP measurements were taken.

potential temperature of $0.1^{\circ}-0.15^{\circ} \mathrm{C}$ over two years of LLC_2160 output. In contrast, the volume-averaged kinetic energy did not exhibit any drift, and in section 3 we similarly find that the tendency in the along-slope circulation is orders of magnitude smaller than the various terms contributing to its acceleration.

In all cases the model was forced by atmospheric fields derived from the $0.14^{\circ}$ ECMWF operational analysis (ECMWF 2011) and a tidal potential that includes the 16 frequencies corresponding to the largest global amplitudes (see Rocha et al. 2016). Continental runoff, including ice shelf melt and calving, is prescribed as a constant $1743 \mathrm{Gt} \mathrm{yr}^{-1}$ (Fekete et al. 2002), distributed in a 200-km band around the coastline of Antarctica, and applied to the uppermost geopotential grid level at each horizontal location. Apart from the prescribed timemean surface runoff, the above simulations do not include an explicit representation of ice shelf cavities or of bottom boundary layer processes, which likely inhibit the model's ability to realistically represent DSW formation and export. The results in the main text of this article are diagnosed exclusively from the LLC_4320 simulation. However, Stewart et al. (2018) found that the mean/eddy/tidal cross-slope heat fluxes exhibited only small quantitative differences between the LLC_4320 and LLC_2160 simulations, despite the larger $\sim 2 \mathrm{~km}$ grid spacing of the LLC_2160 simulation. Therefore, due to the very high computational cost of performing analysis on the LLC_4320 simulation, we perform supplementary tests (see appendixes B and C) using output from the LLC_2160 simulation.

\section{b. Evaluation of simulated ASF structure}

Before proceeding to our analysis of the LLC_4320 simulation, we first address the model's representation of the ASC and ASF. Our ability to perform quantitative evaluation of the model state is limited by the paucity of observations; we require in situ measurements of both hydrography and velocity that are able to resolve the narrow (tens of kilometers wide) core of the ASC. Here we focus on measurements from the Amery sector (see Fig. 1) because high-resolution velocity and hydrographic measurements are available. Additionally, we use the combined Amery/East Antarctica sector as a reference case throughout section 3 because the ASC, and thus its momentum forcing, are approximately zonal. In appendix A we present an additional model-observation comparison using measurements from the western Weddell Sea.

Figure 2 shows a comparison of the LLC_4320 model state with measurements made during the BROKE West survey along $60^{\circ} \mathrm{E}$ (Meijers et al. 2010). Here we have averaged the model fields over the $\sim 1$-year duration of 
the LLC_4320 simulation because the seasonal mean model state exhibits only relatively small quantitative differences from Figs. $2 \mathrm{~b}$ and $2 \mathrm{~d}$, and for consistency with the annually averaged model diagnostics discussed in section 3 . The modeled and observed hydrographies in Figs. $2 \mathrm{a}$ and $2 \mathrm{~b}$ are qualitatively similar despite inevitable sampling biases associated with temporal variability, and despite the model output having been annually averaged. Note that we have not attempted to evaluate the temporal variability in, for example, the transport of the ASC (Peña-Molino et al. 2016), because the LLC_4320 simulation contains only a single seasonal cycle. In particular, a strong front in the temperature field, characteristic of the ASF (Jacobs 1991; Whitworth et al. 1998), is present at the shelf break in both the model and the observations. A notable deficiency in the model is the absence of cold, dense water at the sea floor, indicating a lack of DSW production and export, likely due to the relatively short spinup from the ECCO2 adjoint estimate combined with the absence of ice shelf cavities. The model therefore likely omits eddy generation resulting from DSW export (LaneSerff and Baines 1998; Stewart and Thompson 2016); this should be regarded as a caveat to our analysis. The differences in hydrography are more pronounced in the western Weddell Sea, where DSW is present across the entire continental slope (see appendix A).

Figures $2 \mathrm{c}$ and $2 \mathrm{~d}$ show that the simulated and observed along-slope currents are also qualitatively similar to one another, though the quantitative differences are more evident than they are in the hydrography. Both the model and observations exhibit a narrow $(\sim 30-40 \mathrm{~km}$ wide) westward jet at the shelf break, though the modeled jet exhibits a somewhat larger maximum speed $\left(0.3 \mathrm{~m} \mathrm{~s}^{-1}\right)$ than the observed jet $\left(0.24 \mathrm{~m} \mathrm{~s}^{-1}\right)$. It is unclear whether the differences visible in Figs. $2 \mathrm{c}$ and $2 \mathrm{~d}$ are the result of model biases or whether they are largely a consequence of spatiotemporal sampling limitations (e.g., PeñaMolino et al. 2016). In either case, we conclude that the modeled ASF and ASC are at least representative of those in the ocean, with the exception of DSW influences.

\section{c. Mean circulation and forcing of the ASC}

In this study our primary aim is to distinguish different drivers of ASC circulation, so our diagnostics focus on the model momentum budget. The LLC_4320 is based on the Massachusetts Institute of Technology general circulation model (MITgcm; Marshall et al. 1997a,b) and solves the Boussinesq momentum equations in vectorinvariant form,

$$
\begin{aligned}
\frac{\partial \mathbf{u}}{\partial t}= & -f \hat{\mathbf{z}} \times \mathbf{u}-\zeta \hat{\mathbf{z}} \times \mathbf{u}-w \frac{\partial \mathbf{u}}{\partial z}-\nabla \phi-\nabla\left(\frac{1}{2} \mathbf{u}^{2}\right) \\
& +\frac{\partial \boldsymbol{\tau}^{(z)}}{\partial z}+\mathbf{G}_{\nu}+\mathbf{G}_{t} .
\end{aligned}
$$

Here $\mathbf{u}=(u, v)$ is the horizontal velocity vector, $w$ is the vertical velocity, $\phi$ is the dynamic pressure, $\zeta=\hat{\mathbf{z}} \cdot \nabla \times \mathbf{u}$ is the vertical component of relative vorticity, and $f$ is the Coriolis parameter. We denote the vertical stress as $\boldsymbol{\tau}^{(z)}$, defined such that positive values correspond to downward momentum transfer. The divergence of the lateral viscous stress tensor is denoted $\mathbf{G}_{\nu}$ and is prescribed via a modified Leith formulation (Fox-Kemper and Menemenlis 2008). Finally, $\mathbf{G}_{t}$ represents the tideproducing force, which is a sum of temporally oscillatory functions at each point in space, and so vanishes approximately under the long ( $\sim 1$ year) time averages considered in this paper.

To make explicit the role of surface and bottom momentum forcing, we perform most of our analysis on the depth integral of (1), defining

$$
\langle\bullet\rangle \equiv \int_{-h}^{0} d z \bullet,
$$

where $z=-h(x, y)$ is the sea floor elevation. To examine different drivers of the time-mean circulation, we additionally define a time averaging operator

$$
\overline{\boldsymbol{}} \equiv \frac{1}{T} \int_{t_{0}}^{t_{0}+T} d t \bullet
$$

where $t_{0}$ and $T$ denote the start and duration of the averaging period, respectively. This operator will be generalized to multiple time scales in section $2 \mathrm{~d}$. The depth-integrated time-mean momentum equation is therefore

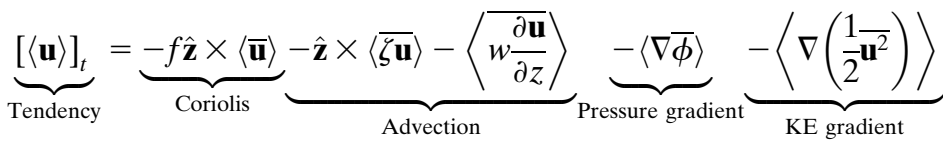

$$
\begin{aligned}
& \underbrace{+\left.\overline{\boldsymbol{\tau}}\right|_{z=0}}_{\text {Surface stress }} \underbrace{-\left.\overline{\boldsymbol{\tau}}\right|_{z=-h}}_{\text {Bottom stress }} \underbrace{+\left\langle\overline{\mathbf{G}_{\nu}}\right\rangle}_{\text {Viscosity }} \underbrace{+\left\langle\overline{\mathbf{G}_{t}}\right\rangle}_{\text {Tidal potential }},
\end{aligned}
$$


where we define $[\bullet]_{t} \equiv\left(\left.\bullet\right|_{t_{0}+T}-\left.\bullet\right|_{t_{0}}\right) / T$. Note that, following (1), the surface and bottom stresses are divided by the reference density, and so have units of meters squared per second squared $\left(\mathrm{m}^{2} \mathrm{~s}^{-2}\right)$. The ocean surface stress is calculated via standard quadratic bulk formulae for the atmosphere-ocean and sea ice-ocean stresses, weighted by the open water fraction and sea ice concentration, respectively. For further details, see Losch et al. (2010).

Figure 3 illustrates the mean circulation of the ASC in the combined Amery/East Antarctica sector (see Fig. 1). Figure $3 \mathrm{a}$ shows the potential temperature at $230-\mathrm{m}$ depth, highlighting variations in the sharpness of the ASF as it passes troughs in the continental shelf, visible in Fig. $3 \mathrm{a}$ as locations where the $500-\mathrm{m}$ isobath deviates toward the coastline. These troughs also guide the depthintegrated mean flow closer to the coast, as can be seen in the barotropic streamfunction in Fig. 3b. Here the barotropic streamfunction is defined as

$$
\Psi \equiv \int_{y_{s}}^{y}\langle\overline{\mathbf{u}}\rangle d y^{\prime},
$$

where $y_{s}$ is the southernmost latitude for which the ocean depth $h$ is nonzero and $y^{\prime}$ is a variable of integration. Figure $3 \mathrm{~b}$ also shows that most of the transport of the ASC occurs offshore of the ASF, at depths greater than $2000 \mathrm{~m}$, with only a few Sverdrups $\left(\mathrm{Sv} ; 1 \mathrm{~Sv} \equiv 10^{6} \mathrm{~m}^{3} \mathrm{~s}^{-1}\right)$, of alongslope transport at the shelf break (see Peña-Molino et al. 2016). However, the ASF consistently coincides with the strongest westward velocities in the ASC (Fig. 3c), which exhibits a jet with a meridional width of tens of kilometers and maximum speeds exceeding $0.3 \mathrm{~m} \mathrm{~s}^{-1}$ (see also Fig. 2).

As discussed in section 1, previous studies have typically characterized the ASC as a wind-driven circulation, so we first examine the role of wind in driving the model's ASC. In Figs. 4a and 4b we plot the zonal stress at the ocean surface over the same region as shown in Fig. 3. Note that throughout this article we plot all terms in the momentum budget in the more familiar units of newtons per square meter $\left(\mathrm{N} \mathrm{m}^{-2}\right)$ [i.e., multiplying (4) by $\rho_{0}$ ]. The surface stress is directed westward almost everywhere due to the easterly winds that encircle the Antarctic margins (see, e.g., Large and Yeager 2009; ECMWF 2011), with a zonal-mean maximum westward stress of around $0.06 \mathrm{~N} \mathrm{~m}^{-1}$ (Fig. 4b). However, there is a band of weak or zero westward stress, and in some places even weak eastward stress, tracking the shelf break. The meridional width of this feature is comparable to that of the shelfbreak jet shown in Fig. 3, and much smaller than the typical scales of variability in the local atmospheric circulation (Langlais et al. 2015).

Understanding the surface stress over the shelfbreak jet requires consideration of the sea ice, which covers the
ASC for most of the year (e.g., Cavalieri and Parkinson 2008). Figure $3 d$ shows that the sea ice also drifts westward due to the easterly winds, with a mean speed that is typically faster than that of the sea surface, such that the westward momentum input by the wind is transferred down to the ocean via ice-ocean drag (Losch et al. 2010; Meneghello et al. 2018). An exception occurs over the shelf break, where the mean sea ice speed exhibits a similar jet over the shelf break as the mean ocean surface speed (Fig. 3c), and the ice-ocean shear approximately vanishes (Fig. 3e). In contrast, Fig. $4 \mathrm{~b}$ shows that the zonal stress at the sea floor is elevated at the shelf break because the shelf break jet is largely barotropic (see Fig. 2). Longitudinal variations of the shelfbreak latitude obscure this elevated bottom stress in a zonal average, however, with typical zonal-mean bottom stresses of around $0.01 \mathrm{~N} \mathrm{~m}^{-1}$. Note that the time-mean flows and surface/bottom stresses discussed here also obscure the seasonal variations in the forcing of the ASC, which are discussed in appendix C.

\section{d. Temporal decomposition}

While the diagnostics presented in the preceding section indicate that the ASC is primarily forced by momentum transfer from the wind via the sea ice, the approximate vanishing of the surface stress in the core of the ASC (Fig. 4a) indicates that an alternative forcing mechanism must be present there. Lacking other inputs of mean momentum in (4), we anticipate that the ASC jet core may be the result of an interaction between mean and transient flows, as arise in a wide range of contexts in geophysical fluid dynamics (e.g., Andrews and McIntyre 1976; Bühler 2014).

As discussed in section 1, previous studies of the Antarctic shelf and slope emphasize both eddy and tidal variability. We therefore pose an approximate decomposition of the model variables into mean, eddy and tidal components to distinguish their relative roles in driving the ASC, following Stewart et al. (2018). For example, the model horizontal velocity field is written as a sum of mean $\mathbf{u}_{m}$, eddy $\mathbf{u}_{e}$, and tidal $\mathbf{u}_{t}$ components,

$$
\mathbf{u}=\mathbf{u}_{m}+\mathbf{u}_{e}+\mathbf{u}_{t} .
$$

We define the operator $\bar{\bullet}^{t}$ as an average over each consecutive model day, and we define tidal component of the flow $\mathbf{u}_{t}$ such that it vanishes under this tidalaverage operator. We then define the operator $\overline{\boldsymbol{\sigma}}^{e}$ as an average of daily-averaged quantities over the $\sim 1$-year duration of the simulation, and define the eddy component of the flow $\mathbf{u}_{e}$ such that it vanishes under this eddy-average operator. These components and averaging operators are related mathematically as follows, 


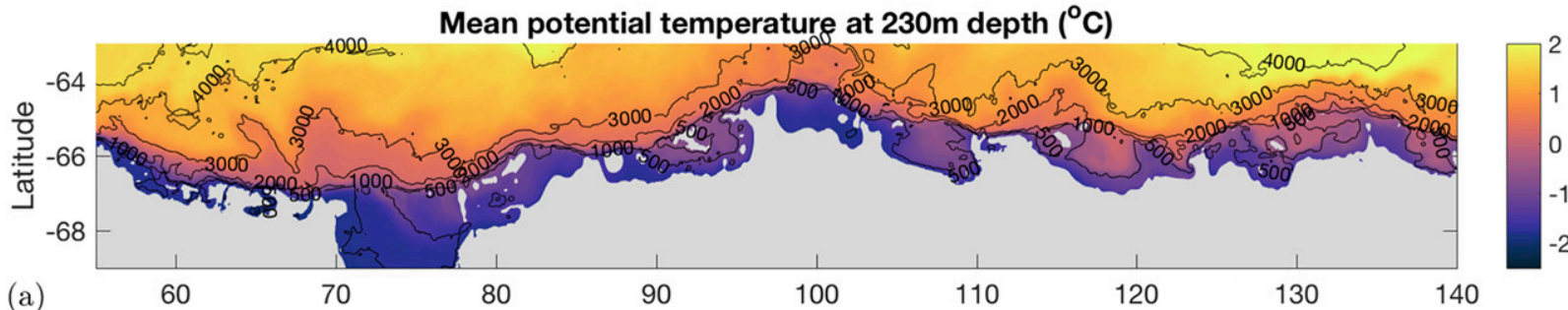

(a)

60

Barotropic streamfunction (Sv)

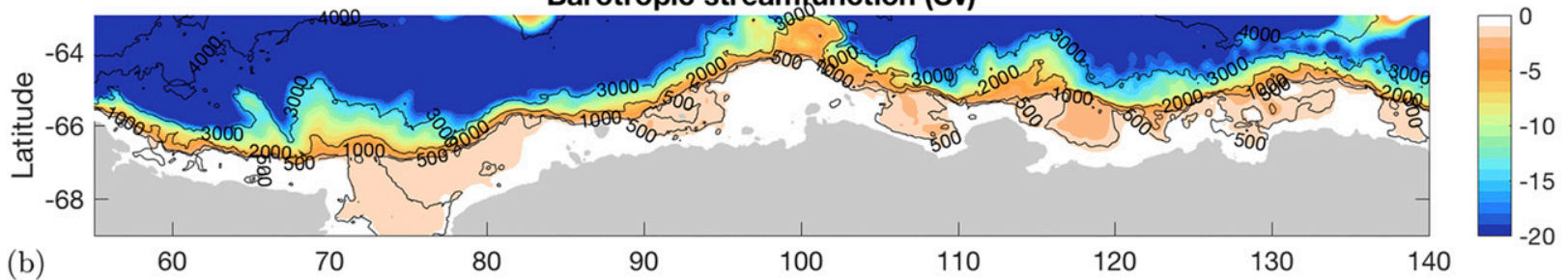

Mean surface zonal velocity $(\mathrm{m} / \mathrm{s})$

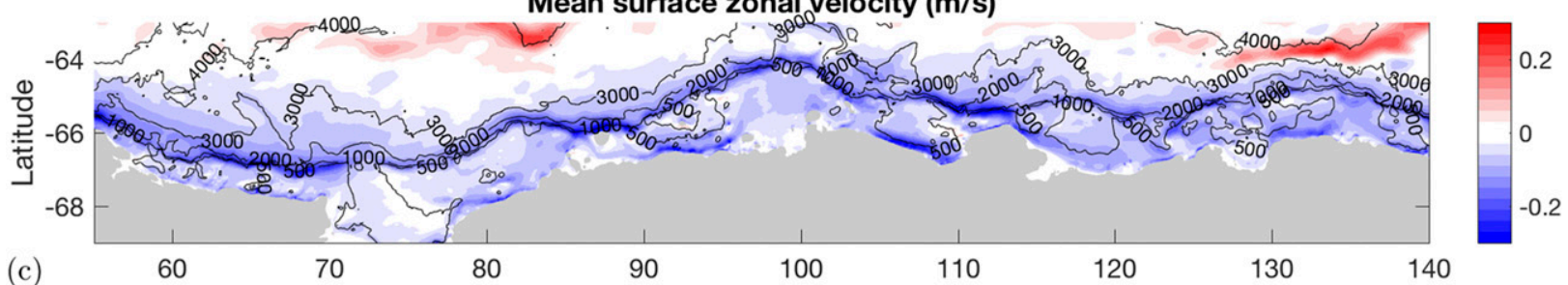

(c)

60

Mean sea ice zonal yelocity $(\mathrm{m} / \mathrm{s})$

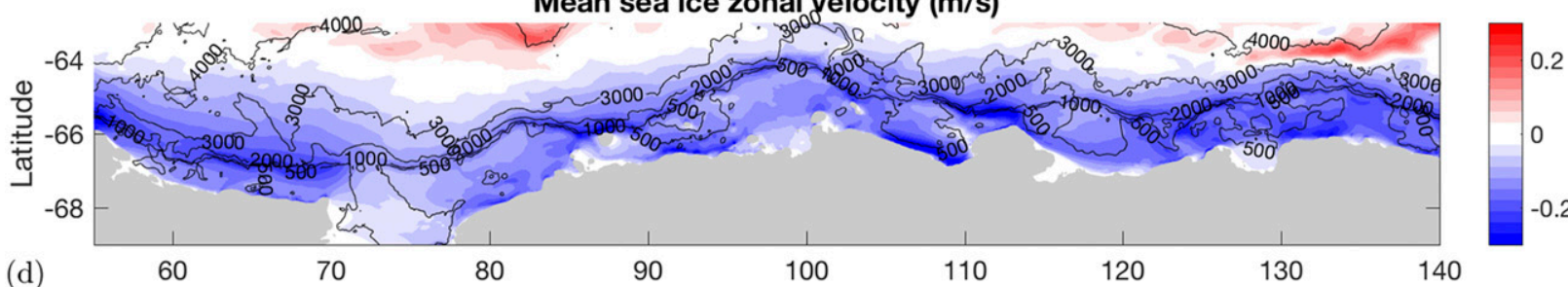

(d)

60

Mean sea ice-ocean shear $(\mathrm{m} / \mathrm{s})$

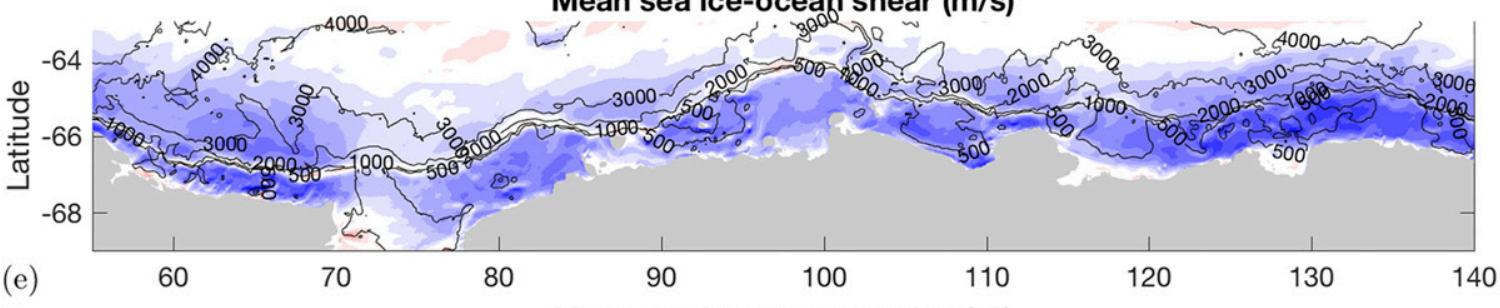

Mean sea ice concentration (\%)

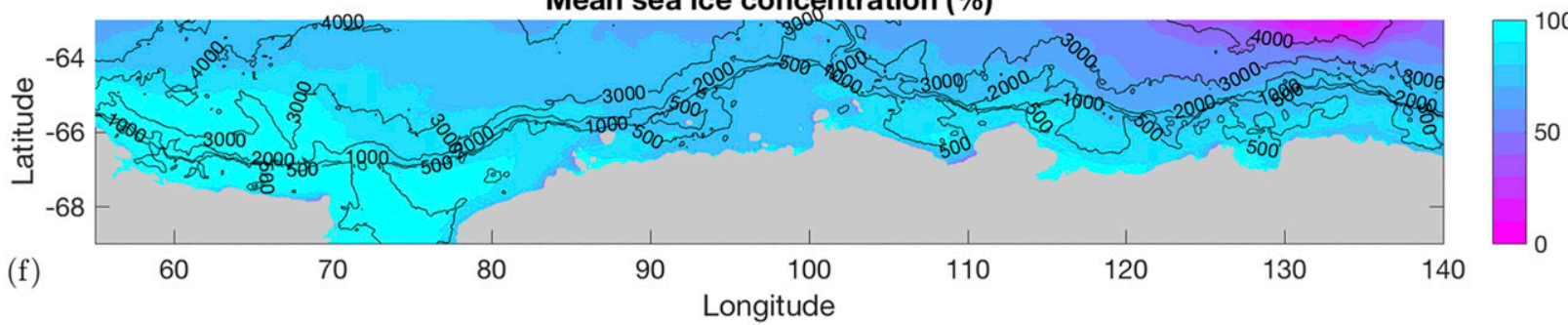

FIG. 3. Diagnostics of the time-mean Antarctic Slope Front structure and Antarctic Slope Current circulation in the combined Amery/ East Antarctic sector (see Fig. 1). (a) Mean potential temperature at 230-m depth, (b) barotropic streamfunction, (c) surface zonal velocity, (d) sea ice zonal velocity, (e) sea ice-ocean shear, and (f) sea ice concentration. In all panels black contours correspond to isobaths and are labeled with depths in meters. 


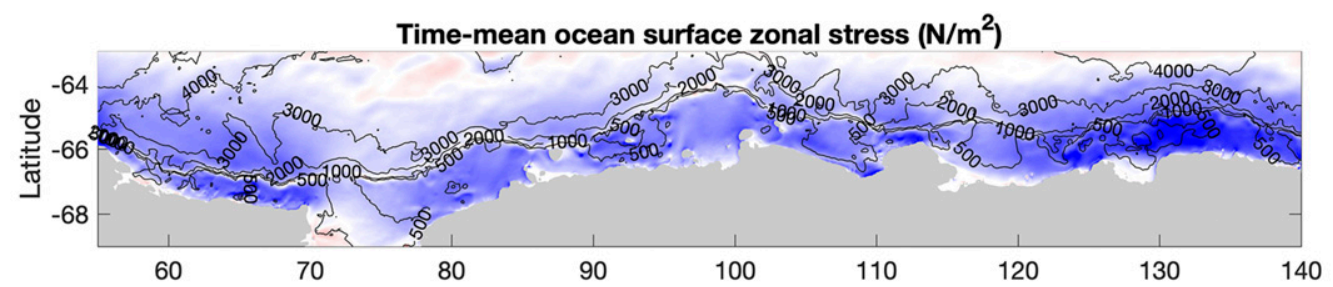

(a)

Time-mean zonal bottom frictional stress $\left(\mathrm{N} / \mathrm{m}^{2}\right)$

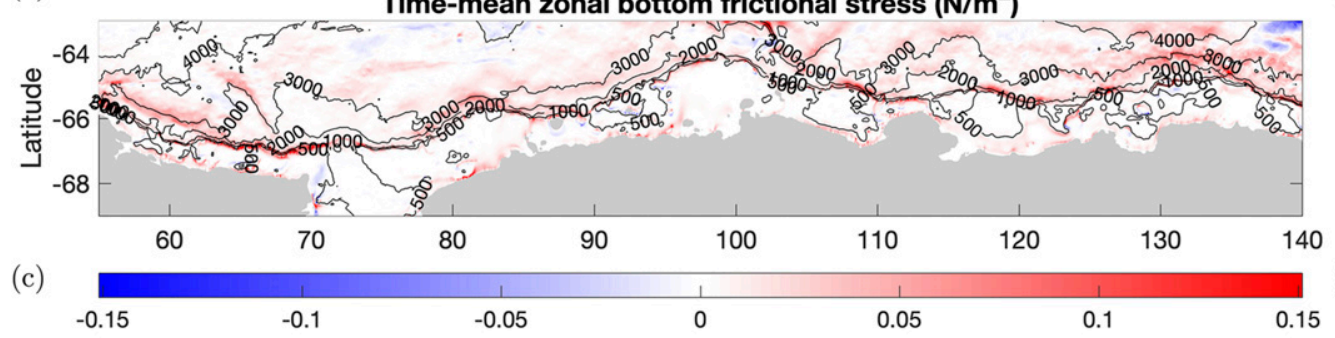

(b)
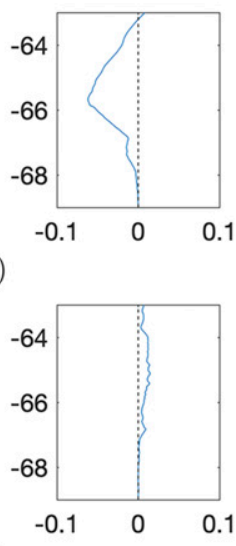

(d)
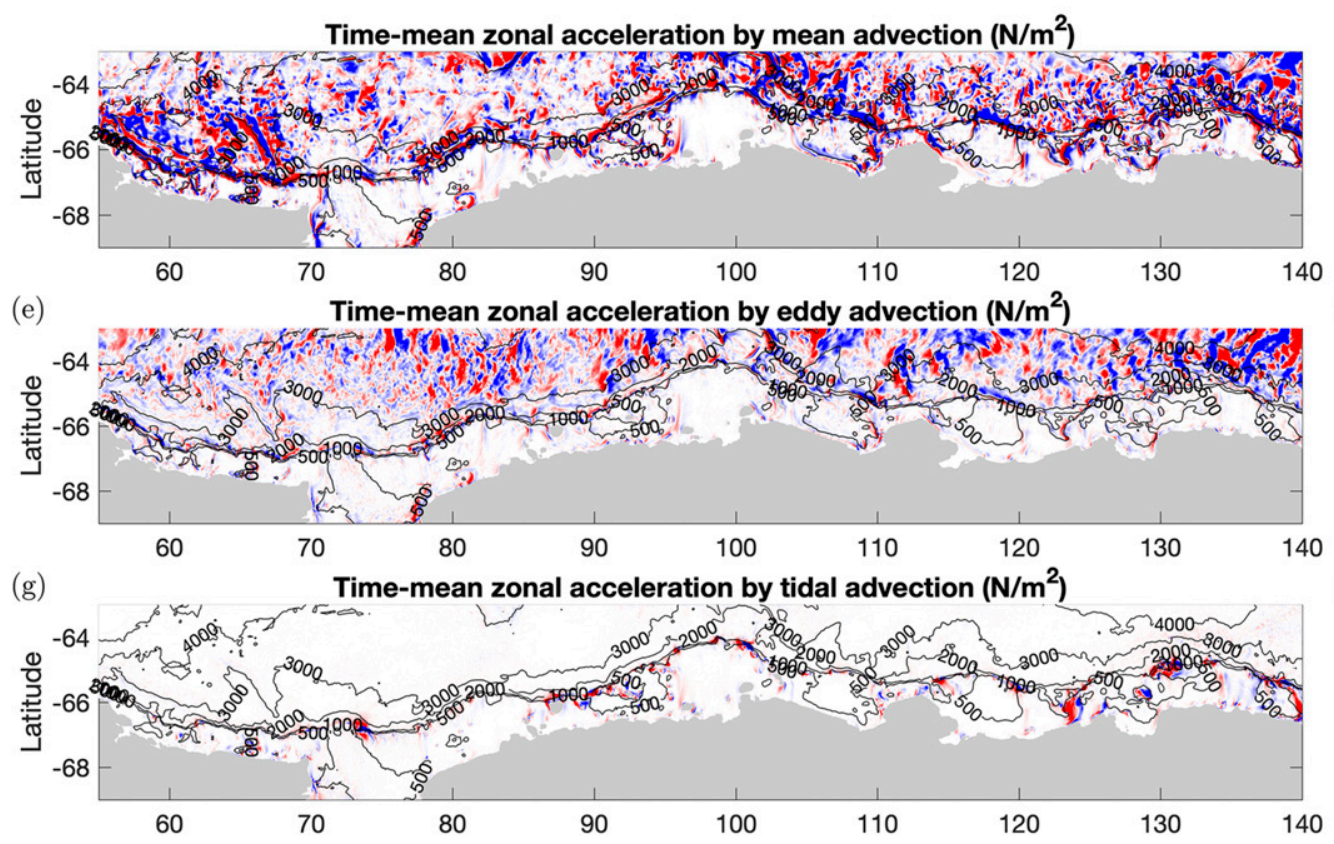

(i)

Longitude

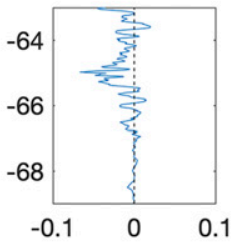

(f)

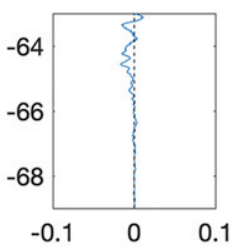

(h)

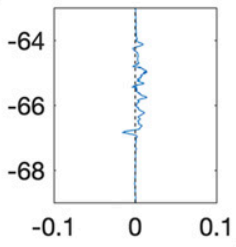

(j) Zonal mean $\left(\mathrm{N} / \mathrm{m}^{2}\right)$

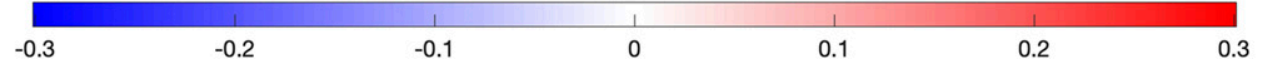

FIG. 4. Various terms from (4) contributing to zonal acceleration/deceleration of the Antarctic Slope Current in the combined Amery/ East Antarctica sector (see Fig. 1). (a),(b) Zonal ocean surface stress, (c),(d) zonal bottom frictional stress, (e),(f) zonal acceleration due to mean vorticity advection and vertical advection, $(\mathrm{g}),(\mathrm{h})$ zonal acceleration due to eddy vorticity advection and vertical advection, and (i),(j) zonal acceleration due to tidal vorticity advection and vertical advection. (left) Maps of the depth-integrated acceleration terms and (right) the corresponding zonal-mean accelerations as functions of latitude only. In all panels black contours correspond to isobaths and are labeled with depths in meters.

$$
\mathbf{u}_{m}=\overline{\mathbf{u}}^{t, e}, \quad \mathbf{u}_{e}=\overline{\mathbf{u}}^{t}-\overline{\mathbf{u}}^{t, e}, \quad \mathbf{u}_{t}=\mathbf{u}-\overline{\mathbf{u}}^{t} .
$$

Here we use $\boldsymbol{\bullet}^{t, e}$ as a shorthand for successive application of tidal and eddy averaging, that is, $\overline{\overline{\boldsymbol{\epsilon}}}^{e}$. Averages of quadratic products can also be written exactly as a sum of mean, eddy, and tidal components. For example, the kinetic energy can be decomposed as

$$
\underbrace{\frac{1-\overline{\mathbf{u}}^{t}, e}{2^{t, e}}}_{\mathrm{KE}}=\underbrace{\frac{1}{2} \mathbf{u}_{m}^{2}}_{\mathrm{MKE}}+\underbrace{\frac{1}{2^{\mathbf{u}_{e}^{2}}}}_{\mathrm{EKE}}+\underbrace{\frac{1 \overline{\mathbf{u}_{t}^{2}} t, e}{2^{t}}}_{\mathrm{TKE}} .
$$

The depth averages of the mean, eddy, and tidal kinetic energies (MKE, EKE, and TKE, respectively) are plotted in Fig. 5. Both the MKE and EKE are continuously 


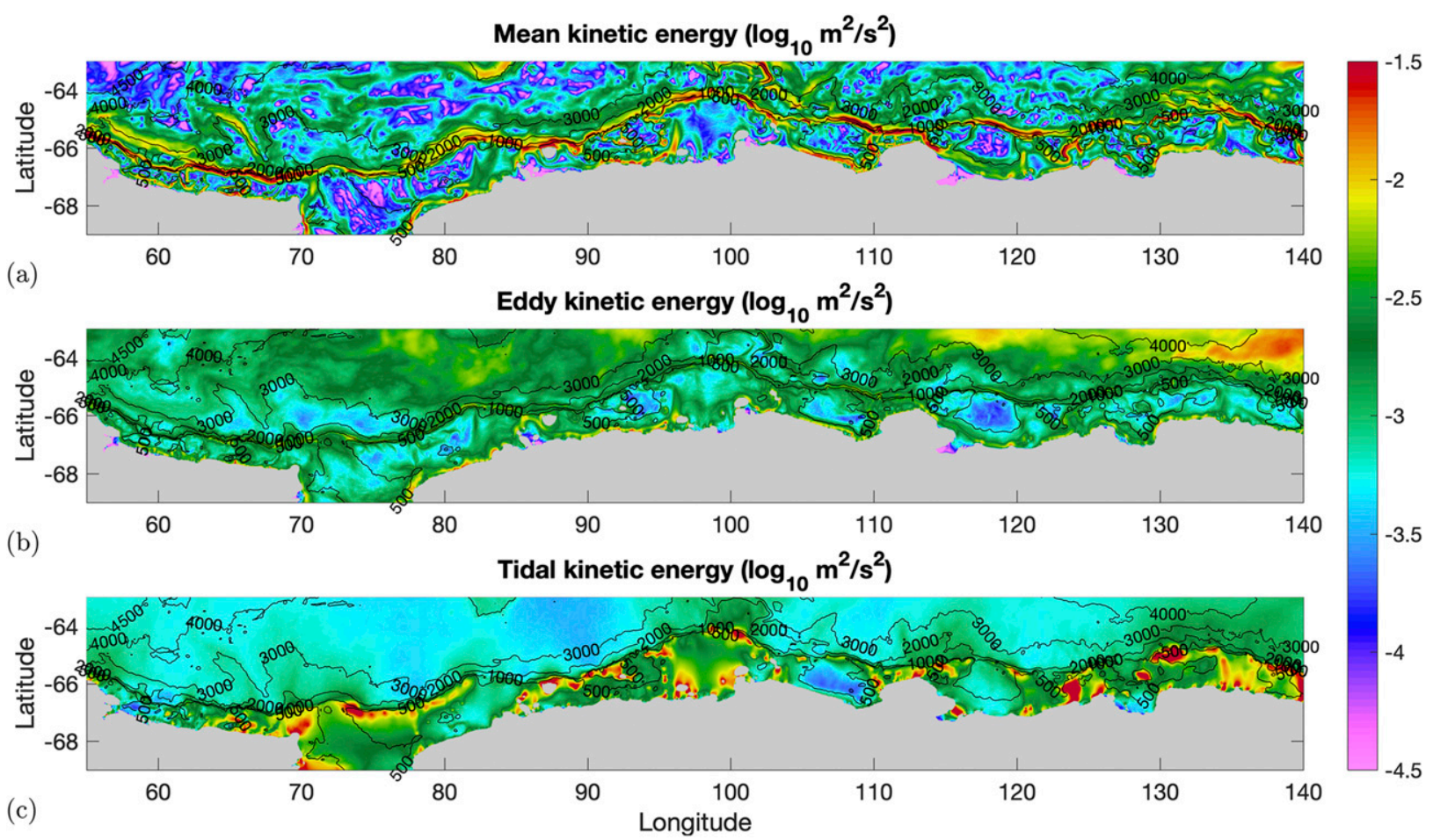

FIG. 5. An illustration of our mean/eddy/tidal decomposition using the depth-averaged kinetic energy [see (8)] in the combined Amery/East Antarctica sector (see Fig. 1). (a) Mean, (b) eddy, and (c) tidal components on a logarithmic scale. In all panels black contours correspond to isobaths and are labeled with depths in meters.

elevated along the continental slope (note the logarithmic color scale), while the TKE is elevated over localized regions of the shelf break. Thus, interactions between eddies and the mean flow may be expected to occur along the length of the ASC, while interactions between tides and the mean flow may be expected to be more spatially localized (see section 3c).

There are several caveats to this decomposition:

(i) A temporal separation into subdaily and superdaily frequencies does not exactly distinguish between tidal and eddy fluctuations. However, more accurate approaches such as tidal harmonic analysis (Foreman and Henry 1989) were impractical due to the very large volume of model output. For a more detailed discussion on this issue, the reader is referred to Stewart et al. (2018), who also quantify the effectiveness of the daily averaging as a tidal filter using spectral analysis. The qualitative differences in the distributions of EKE and TKE, and in the contributions of eddies and tides to the momentum budget (see section 3), also support our approximate decomposition.

(ii) In practice we compute $\mathbf{u}_{t}$ using 6-hourly snapshots of the model state. Output is available at hourly intervals, but using higher frequencies would impose a substantial additional computational burden, even for operations as simple as time averaging, again due to the very large volume of output data (Stewart et al. 2018). In appendix B we show that using higher-frequency output yields only small $(<10 \%)$ changes in the contributions to the momentum budget due to transient flows.

(iii) The eddy component includes all variability with frequencies longer than one day, including the seasonal cycle. In appendix $\mathrm{C}$ we show that the eddy momentum forcing terms discussed below are almost identical when averaged over different seasons.

We now apply our mean/eddy/tidal decomposition to the vorticity advection and vertical advection terms in the depth-integrated momentum equation (4) to perform a preliminary examination of their role in driving the ASC. We write each term as a sum of mean, eddy, and tidal components as follows:

$\underbrace{-\hat{\mathbf{z}} \times\langle\overline{\zeta \mathbf{u}}\rangle}_{\text {Vorticity advection }}=\underbrace{-\hat{\mathbf{z}} \times\left\langle\zeta_{m} \mathbf{u}_{m}\right\rangle}_{\text {Mean }} \underbrace{-\hat{\mathbf{z}} \times\left\langle\overline{\zeta_{e} \overline{\mathbf{u}}_{e}^{e}}\right\rangle}_{\text {Eddy }} \underbrace{-\hat{\mathbf{z}} \times\left\langle\overline{\left.\zeta_{t} \overline{\mathbf{u}}_{t}^{t, e}\right\rangle}\right.}_{\text {Tidal }}$, 


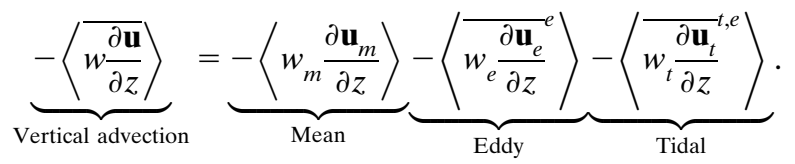

Figures $4 \mathrm{e}, 4 \mathrm{~g}$, and $4 \mathrm{i}$ show the total advective acceleration of the ASC due to mean flows, eddies, and tides, respectively. The qualitative spatial distributions of these terms resemble their counterparts in Fig. 5. However, the roles of these terms in accelerating the core of the ASC are difficult to discern. The zonal averages shown in Figs. 4f, $4 \mathrm{~h}$, and $4 \mathrm{j}$ also obscure the ASC because the latitude of the shelf break varies substantially across this sector.

\section{e. Transformation to an ASC-following coordinate system}

The mean/eddy/tidal decomposition of the advective acceleration terms (see section $2 \mathrm{~d}$ ) indicates that a zonal momentum budget is insufficient to explain the formation of the ASC core. This motivates an analysis of the momentum budget of the ASC in a coordinate system that approximately follows the mean flow. We consider two possible choices for this coordinate system: isobathfollowing coordinates, as in Stewart et al. (2018) (see also Palóczy et al. 2018), and barotropic streamline-following coordinates. In section 3 we use isobath-following coordinates exclusively, but we provide some additional diagnostics in barotropic streamline-following coordinates in appendix D for comparison.

Our coordinate transformation is built upon the following operator,

$$
[\bullet]_{h}=\iint_{h^{\prime}<h} \bullet d A .
$$

This simply calculates the area-integral of $\bullet$ for sea floor depths $h^{\prime}$ smaller than a specified depth $h$, where $h^{\prime}$ is a variable of integration. Thus the result, $[\bullet]_{h}$, is a function of $h$ only. To compute the average of scalar quantities we then take a derivative of the isobathintegral with respect to the area bounded by that isobath, that is,

$$
\frac{d}{d A}[\theta]_{h}, \quad A(h)=\iint_{h^{\prime}<h} d A .
$$

For example, in section $3 \mathrm{~b}$ we use (12) to compute areaaveraged energy conversion terms at different sea floor depths. We additionally use $A(h)$ to define a pseudooffshore distance $y^{\star}$,

$$
y^{\star}(h)=\frac{A(h)}{L},
$$

where $L$ is an approximate coastline length and is defined on a sector-by-sector basis (see Stewart et al. 2018). This approximate offshore coordinate serves only a cosmetic role in our figures, which are presented with both $y^{\star}$ and $h$ abscissas.

To quantify different contributions to the ASC momentum budget we will apply (11) to the curl of (4), that is, to the mean barotropic vorticity budget. Applying (11) to the curl of any vector $\mathbf{F}$ yields

$$
[\nabla \times \mathbf{F}]_{h}=\iint_{h^{\prime}<h} \nabla \times \mathbf{F} d A=\oint_{\mathscr{C}(h)} \mathbf{F} \cdot \hat{\mathbf{s}} d l,
$$

where $\hat{\mathbf{s}}$ is a contour-tangent unit vector. In (14) the second equality follows from Stokes's theorem and $\mathscr{C}(h)$ is the contour bounding the area defined by $h^{\prime}<h$. For example, if $\mathbf{F}=\langle\bar{u}\rangle$ is the depth-integrated mean velocity, then (14) corresponds to the depth-integrated mean circulation along isobath $h$. To provide diagnostics in familiar units, we typically normalize (14) by the contour length, that is,

$$
\frac{1}{\mathscr{L}(h)}[\nabla \times \mathbf{F}]_{h}, \quad \mathscr{L}(h)=\oint_{\mathscr{C}(h)} d l .
$$

We define a transformation to barotropic streamlinefollowing coordinates via an identical set of operators to (11)-(15), but replacing $h$ by $\Psi$ and modifying inequalities accordingly.

Figure 6 illustrates the result of applying (15) to the mean surface velocity, mean sea ice velocity, and surface and bottom stresses in the Amery/East Antarctica sector. Note that here a positive circulation corresponds to circulation counterclockwise around Antarctica, that is, approximately westward along the slope. The calculated along-contour averages are somewhat lower than one might expect based on visual inspection of Figs. 3 and 4 because the actual contour lengths $\mathscr{L}(h)$ typically exceed the zonal length of this sector by a factor of $\sim 2-3$. The along-slope jet is also spread across a larger range of isobaths/barotropic streamlines than one might expect based on visual inspection of Fig. 3, due to various points along the shelf break at which isobaths/barotropic streamlines converge (e.g., around $110^{\circ} \mathrm{E}$ ), which tend to coincide with elevated jet speeds. Thus, both coordinate transformations emphasize the shelfbreak jet, as intended, but Fig. 6 and subsequent plots should be interpreted with these clarifications in mind.

Both isobath-following coordinates (Fig. 6a) and barotropic streamline-following coordinate (Fig. 6b) capture a reduction of the surface stress on the shoreward flank of the shelfbreak jet, though the effect is more pronounced in the former case. The 

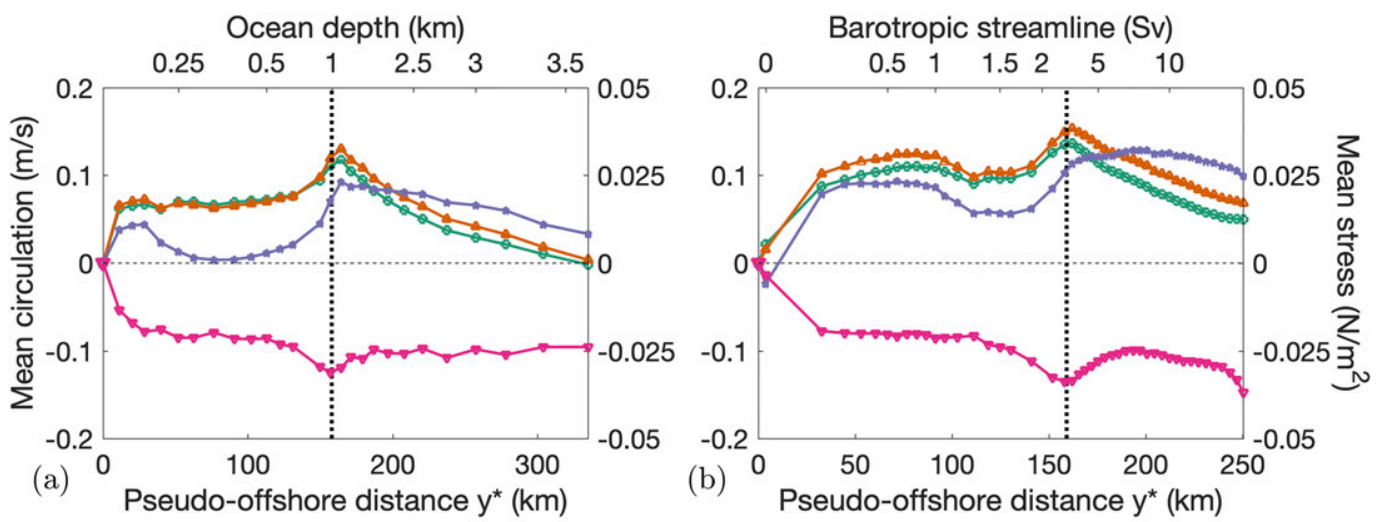

$\multimap$ Ocean surface circulation $\multimap$ Sea ice circulation $\multimap$ Ocean surface stress $\multimap$ Ocean bottom stress

FIG. 6. Circulation and forcing of the Antarctic Slope Current in the combined Amery/East Antarctica sector (see Fig. 1). The surface and sea ice circulation and the circulation tendency due to surface and bottom stresses, calculated in (a) isobath coordinates and (b) barotropic streamfunction coordinates. In each panel the lower abscissa corresponds to an approximate measure of distance from the coast (see section 2e), while the upper abscissa corresponds to isobaths/barotropic streamlines. In each panel the dashed black line corresponds to the 1-km isobath [calculated from the along-streamline averaged sea floor depth in (b)] and approximately separates the continental shelf break from the continental slope.

differences arise, in part, because the streamlines drift across the slope slightly, typically descending $\sim 200 \mathrm{~m}$ as the flow travels westward across this sector. Below we adopt isobath-following coordinates for our analysis because they better isolate the surface stress reduction on the shoreward flank of the shelfbreak jet and because barotropic streamline-following coordinates are not well defined in other sectors of the Antarctic margins. In appendix D we discuss these technical issues further and show that the along-streamline circulation budget yields qualitatively similar results to the along-isobath circulation budget discussed in section 3 a.

\section{Along-slope acceleration of the ASC}

In section 2 we described the LLC_4320 simulation and the analysis techniques required to diagnose the momentum balance of the ASC, namely our mean/ eddy/tidal decomposition of the LLC_4320 model output variables and a transformation to isobathfollowing coordinates. We now apply these techniques to distinguish different inputs to the ASC's circulation and energy budgets in the Amery/East Antarctica sector (see Fig. 1). We then examine the vertical and along-slope localization of these inputs and their variations between different sectors of the Antarctic margins.

\section{a. Circulation budget}

In section $2 \mathrm{e}$ we showed that a transformation to isobath-following coordinates captures the circulation and surface/bottom stresses along the shelfbreak jet. To distinguish different drivers of this circulation, we apply (14) to (4),

$$
\begin{aligned}
\underbrace{\left[\oint_{\mathscr{C}(h)}\langle\mathbf{u}\rangle \cdot \hat{\mathbf{s}} d l\right]_{t}}_{\text {Tendency }} \approx & \underbrace{-\oint_{\mathscr{C}(h)} f\langle\overline{\mathbf{u}}\rangle \cdot \hat{\mathbf{n}} d l}_{\text {Coriolis }} \underbrace{-\oint_{\mathscr{C}(h)}\langle\overline{\zeta \mathbf{u}\rangle \cdot \hat{\mathbf{n}} d l-\oint_{\mathscr{C}(h)}\left\langle w \frac{\partial \mathbf{u}}{\partial z}\right\rangle \cdot \hat{\mathbf{s}} d l} \underbrace{-\oint_{\mathscr{C}(h)}\left\langle\frac{\partial \bar{\phi}}{\partial l}\right\rangle \cdot \hat{\mathbf{s}} d l}_{\text {Pressure gradient }}}_{\text {Advection }} \\
& \underbrace{-\oint_{\mathscr{C}(h)}\left\langle\frac{\partial}{\partial l} \mathrm{KE}\right\rangle \cdot \hat{\mathbf{s}} d l}_{\text {KE gradient }} \underbrace{+\left.\oint_{\mathscr{C}(h)} \overline{\boldsymbol{\tau}}\right|_{z=0} \cdot \hat{\mathbf{s}} d l}_{\text {Surface stress }} \underbrace{-\left.\oint_{\mathscr{C}(h)} \overline{\boldsymbol{\tau}}\right|_{z=-h} \cdot \hat{\mathbf{s}} d l}_{\text {Bottom stress }},
\end{aligned}
$$

where $\hat{\mathbf{n}}$ is a contour-normal unit vector. This equation constitutes a budget for the circulation along the contour $\mathscr{C}(h)$ for each isobath $h$. This is mathematically equivalent to (and is calculated as) a mean barotropic vorticity budget integrated over the area bounded by the contour $\mathscr{C}(h)$. Here we have neglected the tidal potential term from (4) 
because it is a sum of oscillatory functions with periods on the order of one day, and so vanishes approximately under an average over the length of the simulation. Note that we have also neglected contributions due to viscosity under the assumption that they are small compared to the frictional bottom stress, formulated as a quadratic drag, but insufficient model diagnostics are provided to test this assumption directly.

Of the terms identified in (16), we are able to evaluate all except for the pressure gradient. As discussed in appendix $\mathrm{B}$, contributions of this term to the circulation budget did not converge even as the model output frequency was refined down to hourly frequency, perhaps due to aliasing of fast surface waves in the bottom pressure. However, neither this term nor the KE gradient term can contribute to the circum-Antarctic circulation budget; if $h$ is constant around the bounding contour $\mathscr{C}(h)$, for example, around the full Antarctic continent, then both the pressure gradient and $\mathrm{KE}$ gradient terms vanish,

$$
\oint_{\mathscr{C}(h)}\left\langle\frac{\partial \bar{\phi}}{\partial l}\right\rangle \cdot \hat{\mathbf{s}} d l=\oint_{\mathscr{C}(h)} \frac{\partial}{\partial l}\langle\bar{\phi}\rangle \cdot \hat{\mathbf{s}} d l=0 .
$$

Here the first equality follows from the fact that $\partial h / \partial l=0$ by definition. However, there are local contributions from these terms in different sectors of the continent that compensate for one another. We therefore provide an estimate of the pressure gradient term via a residual of the other terms in (16), while noting that the residual may also include contributions due to viscosity and discretization errors. Note also that because the sectors shown in Fig. 1 each span only a subset of continental shelf, the contour $\mathscr{C}(h)$ generally intersects the western and eastern boundaries, so the area-integrated curl of (4) includes accelerations along sections parallel to the western and eastern boundaries. However, the length of these portions of the contour are typically around 40 times smaller than the total contour length $\mathscr{B}(h)$.

In Fig. 7 we plot the terms in (16) for the combined Amery/East Antarctica sector (see Fig. 1). Figure 7a shows that the net deceleration of the along-isobath circulation by surface/bottom stresses is primarily balanced by an acceleration due to the advection terms, with an exception around the $h=1000-\mathrm{m}$ isobath where the KE gradient term accelerates the circulation. This acceleration coincides with a deceleration by the residual term, which serves as an estimate of the pressure gradient acceleration, and so may account for the slight offshore drift of mean barotropic streamlines in this sector. As discussed above, the KE gradient term cannot induce any net circumpolar along-isobath acceleration, so we focus on the advection terms. Figure $7 \mathrm{~b}$ shows that the advective acceleration of the flow is due to eddies offshore of the shelf break $(h \approx 1000 \mathrm{~m})$ and due to tides shoreward of the shelf break, while mean advection decelerates the flow along all isobaths. Figures $7 \mathrm{c}$ and $7 \mathrm{~d}$ show that the mean and eddy components of the advection terms are almost entirely due to vorticity advection, while the tidal component results from a compensation of acceleration by tidal vertical advection and deceleration by tidal vorticity advection. Taken together, the diagnostics shown in Figs. 6 and 7 indicate that the circulation shoreward of the shelf break is primarily a result of tidal acceleration (e.g., Chen and Beardsley 1995), whereas over the continental slope both eddy vorticity fluxes and surface stress accelerate the ASC.

\section{b. Energy budget}

While the circulation budget discussed in section 3a identified distinct roles for eddies and tides in accelerating the ASC, the partitioning of these accelerations between vorticity advection and vertical advection leaves their interpretation somewhat ambiguous. We therefore diagnose conversions to and from the mean, eddy, and tidal energy reservoirs [see (8)], which also serves to corroborate the results of our circulation budget.

In Fig. 8 we plot a limited subset of the energy sources and sinks that appear in the full mean/eddy/tidal energy budget, which is presented in appendix E. Motivated by the results of section $3 a$, we compare energy inputs due to surface forcing with conversions to and from the MKE and potential energy (PE) reservoirs. The vertical energy flux associated with the vertical stress term in (1) can be composed exactly as

$$
\begin{aligned}
& F_{\mathrm{MKE}}^{(\tau)}=\mathbf{u}_{m} \cdot \overline{\boldsymbol{\tau}}^{t, e}, \\
& F_{\mathrm{EKE}}^{(\tau)}=\overline{\mathbf{u}_{e} \cdot \overline{\boldsymbol{\tau}}^{t}}, \quad \text { and } \\
& F_{\mathrm{TKE}}^{(\tau)}=\overline{\mathbf{u}_{t} \cdot \boldsymbol{\tau}^{t, e} .}
\end{aligned}
$$

Figure 8a shows the result of evaluating these fluxes at both $z=0$ and $z=-h$, and then applying our alongisobath averaging operator (12) to the result. The mean, eddy, and tidal surface energy fluxes consistently serve to increase the MKE, EKE, and TKE, respectively, while the bottom energy fluxes decrease them. Unlike the mean along-slope stress (see Fig. 6), the mean component of the surface energy flux does not exhibit an obvious minimum shoreward of the shelf break. This implies a nonzero correlation between the mean along-isobath flow and the mean along-isobath stress as a function of $l$, the along-isobath coordinate (see section 3c).

In Figs. 8b-8d we plot the along-isobath average (12) of the energy conversions to and from the MKE and PE 


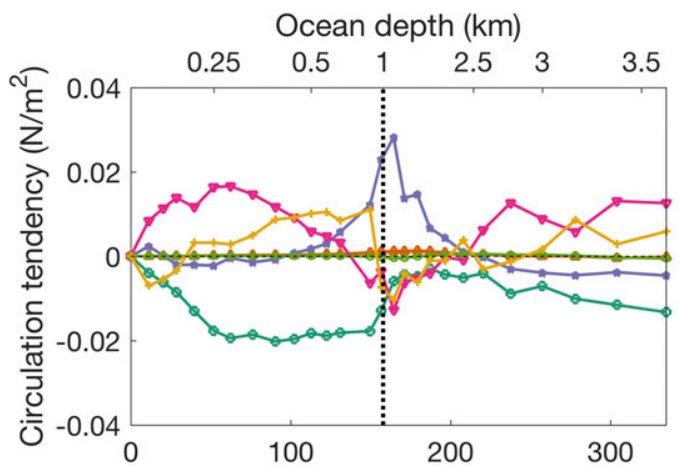

(a) Pseudo-offshore distance $\mathrm{y}^{\star}(\mathrm{km})$

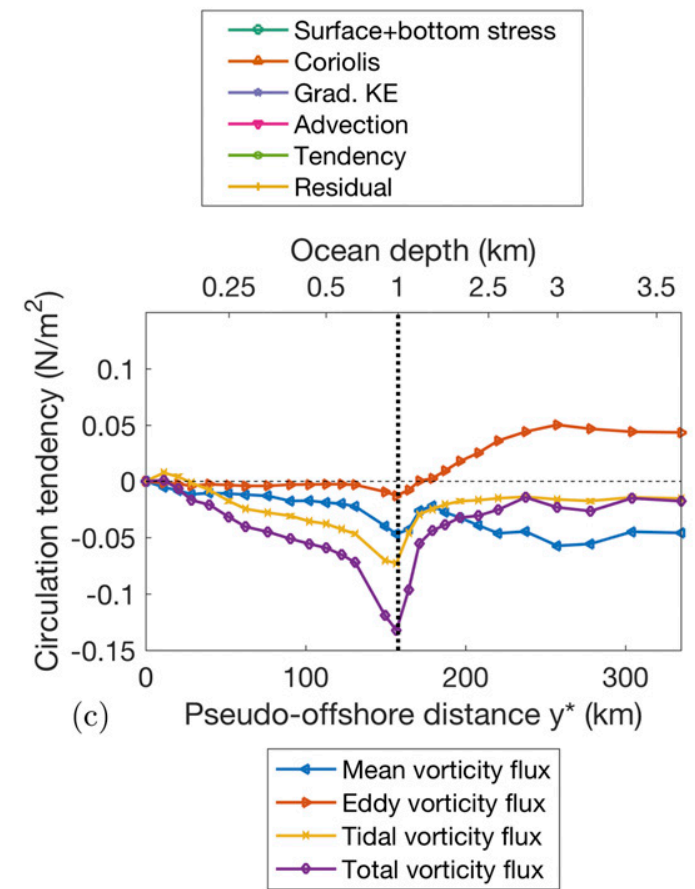

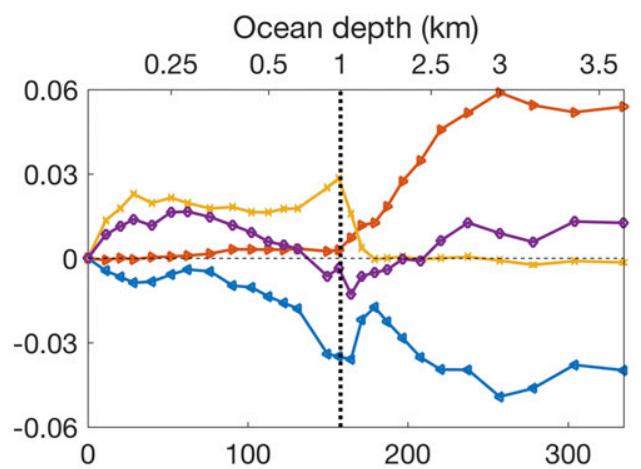

(b) Pseudo-offshore distance $\mathrm{y}^{*}(\mathrm{~km})$

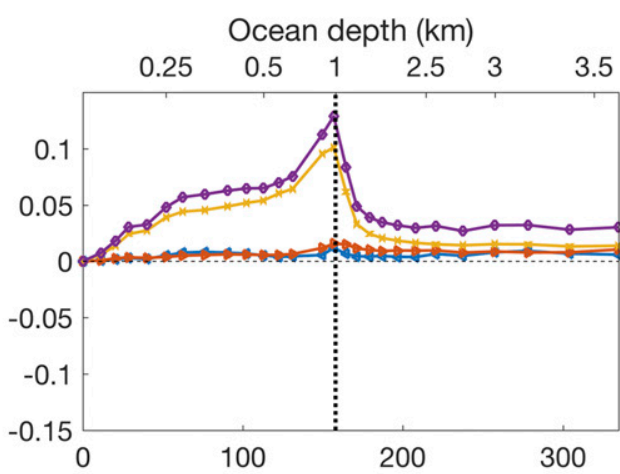

(d) Pseudo-offshore distance $\mathrm{y}^{*}(\mathrm{~km})$

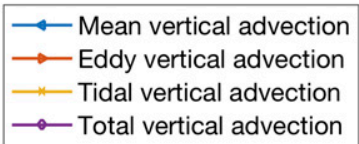

FIG. 7. Terms in the along-slope circulation budget [see (16)] in the combined Amery/East Antarctica sector (see Fig. 1). (a) Complete budget; (b) decomposition of the total advection into mean, eddy, and tidal components; (c) decomposition of the vorticity advection into mean, eddy, and tidal components; and (d) decomposition of the vertical advection into mean, eddy, and tidal components. In each panel the lower abscissa corresponds to an approximate measure of distance from the coast (see section 2e), while the upper abscissa corresponds to isobaths. In each panel the dashed black line corresponds to the $1-\mathrm{km}$ isobath and approximately separates the continental shelf break from the continental slope.

reservoirs. The rates of PE conversion to EKE and TKE are simply the eddy and tidal components of the vertical buoyancy flux,

$$
\begin{aligned}
& \mathrm{PE} \rightarrow \mathrm{EKE}={\overline{w_{e} b_{e}}}^{e}, \\
& \mathrm{PE} \rightarrow \mathrm{TKE}={\overline{w_{t} b_{t}^{b}}}^{t, e},
\end{aligned}
$$

where $b=-g\left(\rho-\rho_{0}\right) / \rho_{0}$ is the buoyancy and $\rho_{0}$ is the reference density. The rates of conversion from MKE to EKE and TKE result from eddy and tidal momentum fluxes directed along the gradient of the mean flow, that is,
$\mathrm{MKE} \rightarrow \mathrm{EKE}=\mathrm{MKE} \rightarrow \mathrm{EKE}_{\mathrm{horz}}+\mathrm{MKE} \rightarrow \mathrm{EKE}_{\mathrm{vert}}$,

$\mathrm{MKE} \rightarrow \mathrm{EKE}_{\mathrm{horz}}=-\overline{\mathbf{u}}_{e} \overline{\mathbf{u}}_{e}^{e} \cdot \nabla \mathbf{u}_{m}$,

$\mathrm{MKE} \rightarrow \mathrm{EKE}_{\mathrm{vert}}=-\overline{\mathbf{u}}_{e} w_{e}^{e} \cdot \frac{\partial \mathbf{u}_{m}}{\partial z}$,

and

$\mathrm{MKE} \rightarrow \mathrm{TKE}=\mathrm{MKE} \rightarrow \mathrm{TKE}_{\mathrm{horz}}+\mathrm{MKE} \rightarrow \mathrm{TKE}_{\mathrm{vert}}$, 


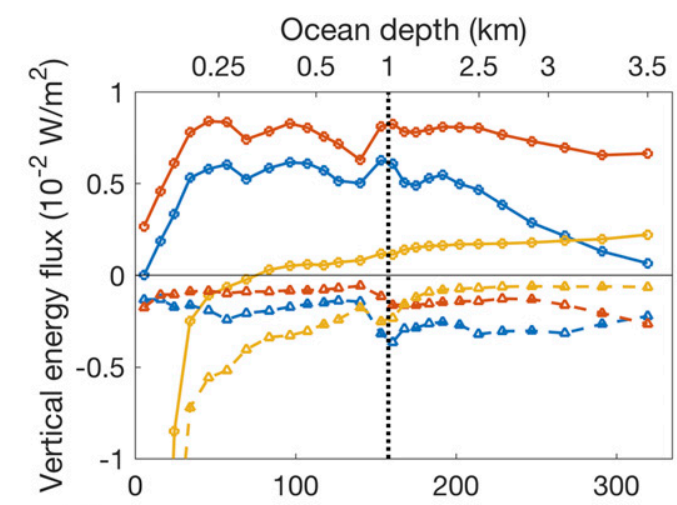

(a)
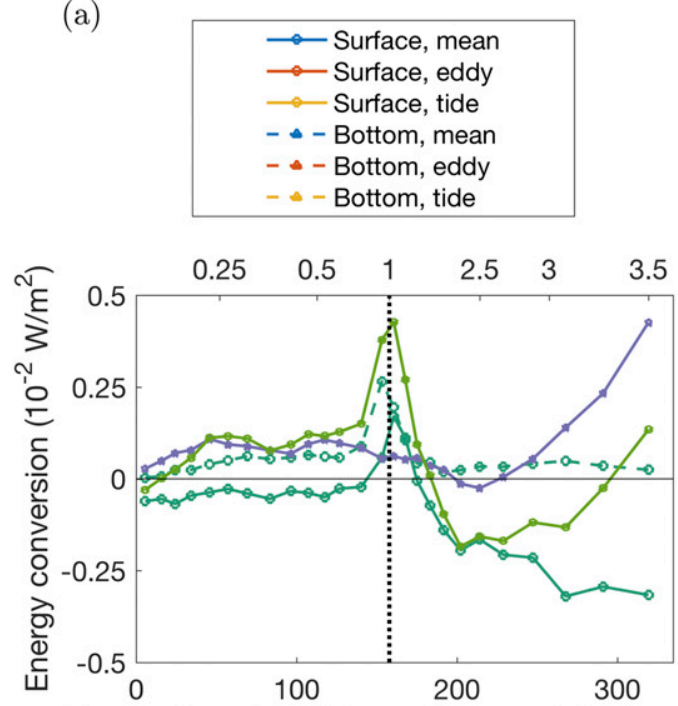

(c) Pseudo-offshore distance $\mathrm{y}^{*}(\mathrm{~km})$

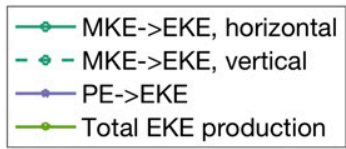

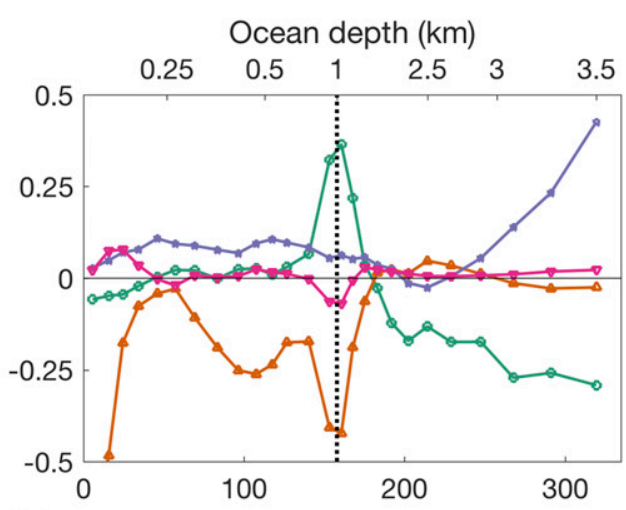

(b)
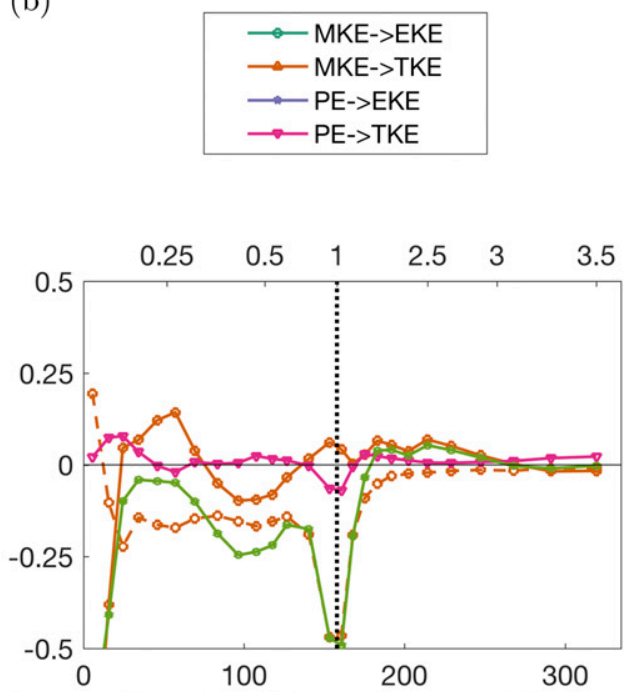

(d)

FIG. 8. Energy budget terms (see section 3b) averaged between isobaths in the combined Amery/East Antarctic sector (see Fig. 1). (a) Surface/bottom energy fluxes decomposed into mean, eddy, and tidal components. (b) EKE and TKE conversion from MKE and PE. (c) Decomposition of the MKE $\rightarrow$ EKE term into horizontal and vertical components. (d) Decomposition of the MKE $\rightarrow$ TKE term into horizontal and vertical components. In each panel, the lower abscissa corresponds to an approximate measure of distance from the coast (see section 2e) while the upper abscissa corresponds to isobaths. In each panel the dashed black line corresponds to the $1-\mathrm{km}$ isobath and approximately separates the continental shelf break from the continental slope.

$$
\begin{aligned}
\mathrm{MKE} \rightarrow \mathrm{TKE}_{\mathrm{horz}} & =-\overline{\mathbf{u}}_{t} \mathbf{u}_{t}^{t, e} \cdot \nabla \mathbf{u}_{m}, \\
\mathrm{MKE} & \rightarrow \mathrm{TKE}_{\mathrm{vert}}=-\overline{\mathbf{u}}_{t} w_{t}^{t, e} \cdot \frac{\partial \mathbf{u}_{m}}{\partial z} .
\end{aligned}
$$

We have separated these energy conversions into horizontal and vertical components, associated with the horizontal and vertical components of the eddy/tidal momentum fluxes.

Figure $8 \mathrm{~b}$ shows that the energy conversions are dominated by exchanges between the mean, eddy, and tidal
KE reservoirs: there is a relatively weak $\left(\sim 10^{-3} \mathrm{~W} \mathrm{~m}^{-2}\right)$ $\mathrm{PE} \rightarrow \mathrm{EKE}$ conversion across the continental shelf and slope, suggesting weak baroclinic eddy generation, while $\mathrm{PE} \rightarrow \mathrm{TKE}$ is negligibly small. Though MKE $\rightarrow$ EKE is positive at the shelf break itself, over the continental slope it is consistently large $\left(\sim 2.5 \times 10^{-3} \mathrm{~W} \mathrm{~m}^{-2}\right)$ and negative, corresponding to a transfer of energy from the eddy field to the mean flow that is consistent with the acceleration of the mean along-isobath circulation by eddy advection in Fig. $7 b$. Figure $8 c$ shows that this term is associated almost 
entirely with horizontal eddy momentum fluxes over the continental slope, lending support to our interpretation of the eddy forcing of the circulation as an eddy-momentum flux convergence in section $3 \mathrm{a}$. The MKE $\rightarrow$ TKE term in Fig. $8 \mathrm{~b}$ is consistently large $\left(\sim 2.5 \times 10^{-3} \mathrm{~W} \mathrm{~m}^{-2}\right)$ and negative over the continental shelf, consistent with the acceleration of the mean along-isobath circulation by tidal acceleration in Fig. 7b. Figure 8d shows that this tidal production of MKE is primarily associated with vertical momentum fluxes up the vertical gradient of the mean momentum.

\section{c. Along-slope localization}

The diagnostics presented in section $3 \mathrm{a}$ and section $3 \mathrm{~b}$ encompass the entire Amery/East Antarctica sector, yet Figs. 3 and 4 suggest that there are substantial along-slope variations in the structure and forcing of the ASC's shelfbreak jet. In Fig. 9 we plot along-slope variations of key terms in the circulation and energy budgets. We use longitude as an approximate measure of along-slope distance, exploiting the approximately zonal orientation of the continental slope in this sector. We focus on the $h=300-\mathrm{m}$ isobath, along which the reduction of the along-isobath surface stress and compensating along-isobath acceleration by tides are most pronounced. Performing the same calculation using other isobaths in the core of the ASC (e.g., the 400- and 500-m isobaths) yields qualitatively similar results. Similar to the method described by Stewart et al. (2018), we define a series of zonal "windows" of width $3^{\circ}$ and centered on longitudes separated by $0.5^{\circ}$. The $i$ th window defines an area $A_{i}(h)$ with bounding contour $\mathscr{C}_{i}(h)$ for our integration operator (11). However, the zonal boundaries of the contour $\mathscr{C}_{i}(h)$ are no longer negligible compared to its total length (see section 3a), so we have calculated and removed these contributions in Fig. 9.

Figure 9 shows that the along-isobath flow of the sea ice and ocean surface covary closely (Pearson's correlation coefficient $r=0.92$ ) as a function of longitude. The sea ice-ocean shear fluctuates around zero with zonal variations on a scale of around $10^{\circ}$, and very closely predicts the mean surface stress $(r=0.98),{ }^{1}$ despite substantial seasonal fluctuations in the monthly-mean velocities and stresses (see appendix C). The advective acceleration of the circulation (Fig. 9b) also exhibits substantial alongslope variations. This is primarily due to localized stretches of tidal advective acceleration, which are partially compensated by mean advective deceleration; the tidal and mean advective accelerations are anticorrelated

\footnotetext{
${ }^{1}$ Unless stated explicitly, the $p$ values corresponding to these correlation coefficients are all smaller than $10^{-3}$.
}

$(r=-0.54)$. While one might expect a relationship between stretches of reduced surface stress and alongslope advective acceleration, they are also only weakly correlated $(r=-0.28)$. Alternatively, advective acceleration may be expected to reduce the ice-ocean shear, and thus the surface stress, farther downstream, but the two are even more weakly correlated under a zonal lag.

Figures $9 \mathrm{c}$ and $9 \mathrm{~d}$ show that the net tidal advective acceleration results from relatively strong local accelerations due to tidal vertical advection that are partially compensated by local decelerations due to tidal vorticity advection $(r=0.90)$. Figure 9e shows that MKE $\rightarrow$ TKE is similarly localized, though there is not a clear visual correspondence between its amplitude and that of the net tidal advective acceleration of the circulation, and they are relatively weakly correlated $(r=-0.47)$. The net tidal advective acceleration may be expected to coincide with strong tidal flows and steep slopes (e.g., Garreau and Maze 1992; Chen and Beardsley 1995). While the tidal acceleration exhibits a relatively weak correlation with TKE $(r=0.46)$ and an insignificant correlation with topographic slope $(r=-0.18$, $p=0.02)$, it is strongly correlated with their product $(r=0.68)$, consistent with the scalings of Brink (2011) for topographically rectified flows. In summary, while tidal acceleration of the ASC is evidently strongly localized as a function of along-slope distance, the extent to which it controls along-slope variations in the ASC speed and ice-ocean shear remains somewhat ambiguous.

\section{d. Vertical structure and overturning}

Thus far we have only discussed depth-integrated contributions to the along-slope circulation and energy budgets. We now address the vertical structure of the along-isobath circulation forcing, focusing on the contribution of the advection terms in (1) on the crossisobath mean overturning circulation.

Figure 10 shows the Eulerian-mean overturning circulation diagnosed in our isobath-following coordinate system. We define the mean overturning streamfunction as

$$
\psi_{m}(h, z) \equiv \int_{z}^{0} d z^{\prime} \oint_{\mathscr{C}(h)} \mathbf{u}_{m} \cdot \hat{\mathbf{n}} d l
$$

where $z^{\prime}$ is a variable of integration. In Fig. 10 we plot eddy and tidal overturning streamfunctions estimated via an extended Transformed Eulerian Mean formulation, described by Stewart et al. (2018) and omitted here in the interest of brevity. Note that these streamfunctions are estimates of the overturning due to the 

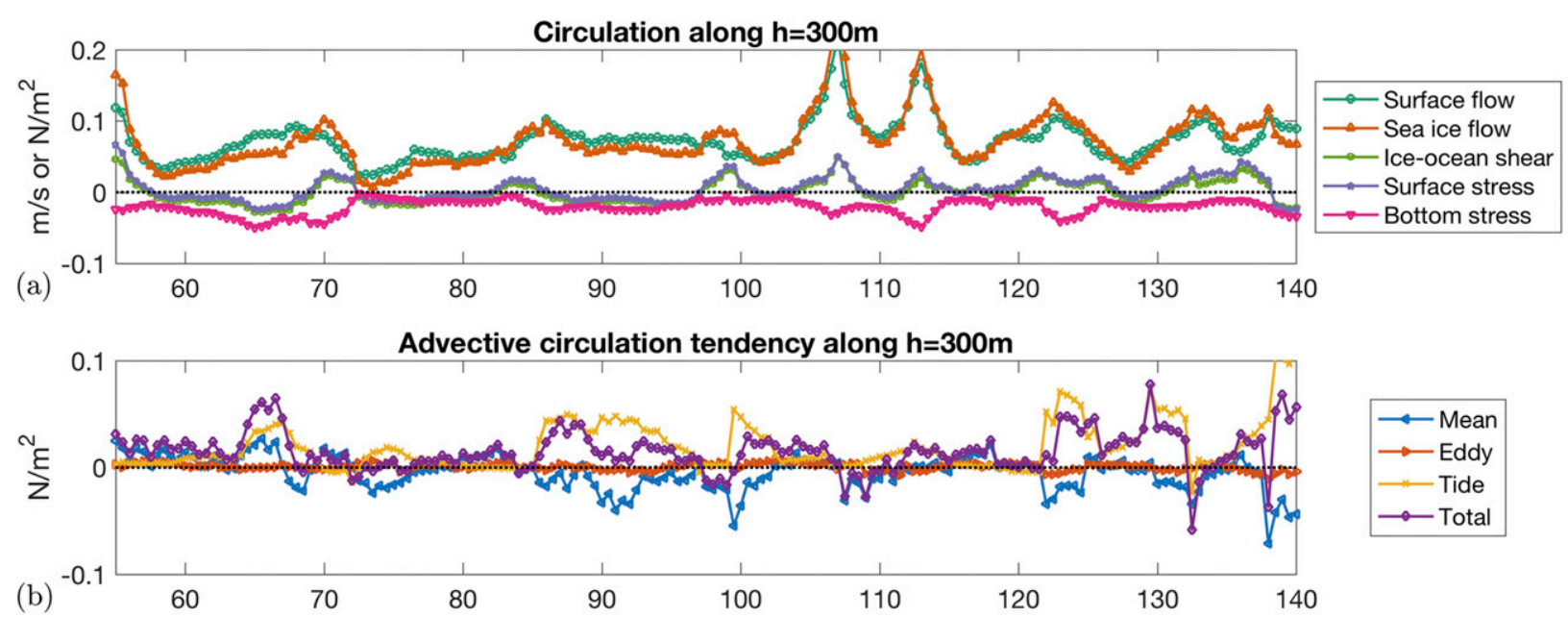

(b)
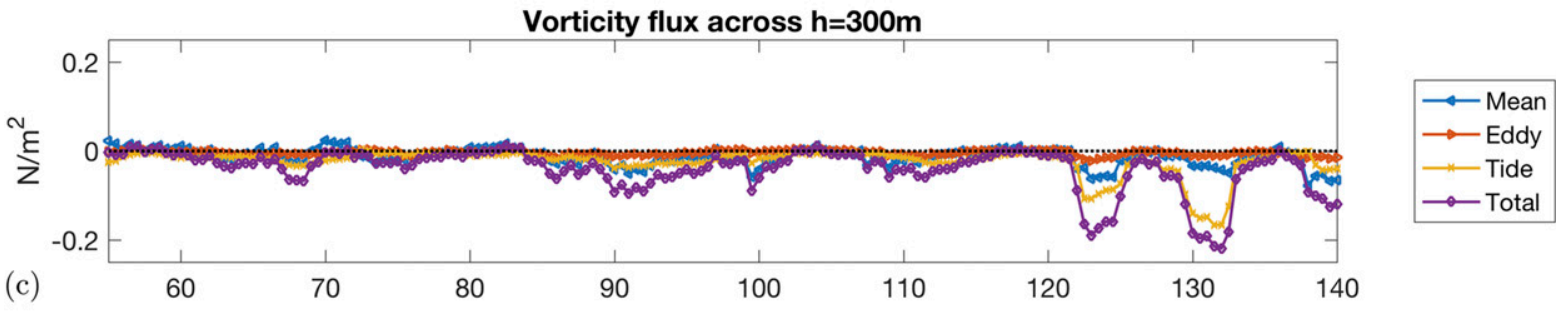

(c)

60

Vertical advection along $h=300 \mathrm{~m}$
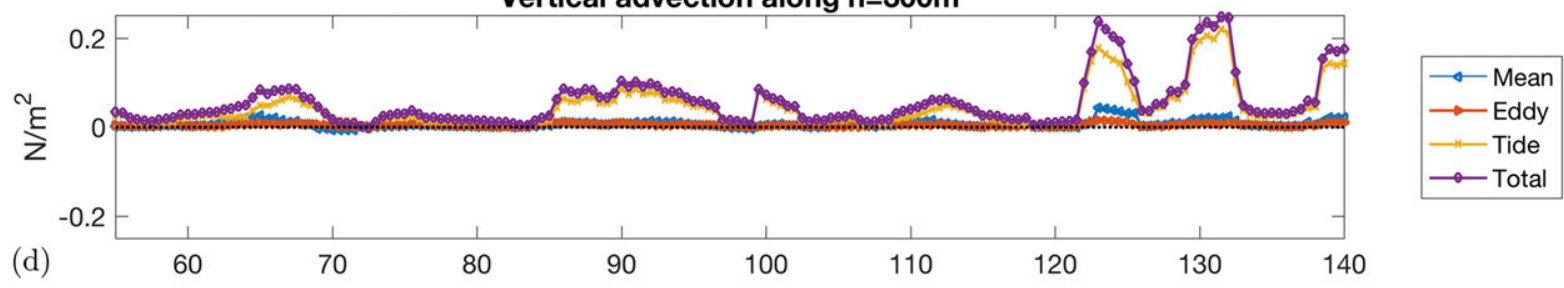

(d)

60

Energy conversion terms averaged between $h=300 m$ and $h=350 m$

(e)
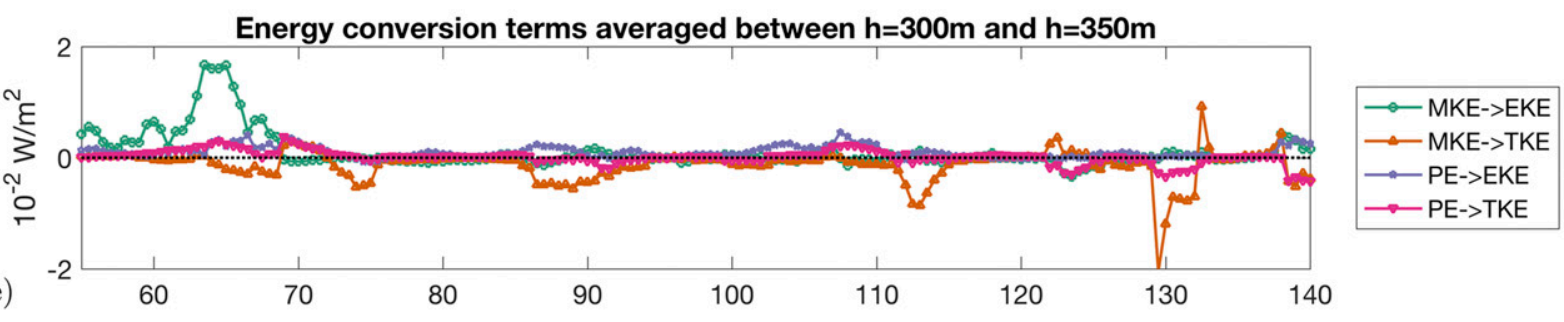

Sea floor depth $(\mathrm{m})$

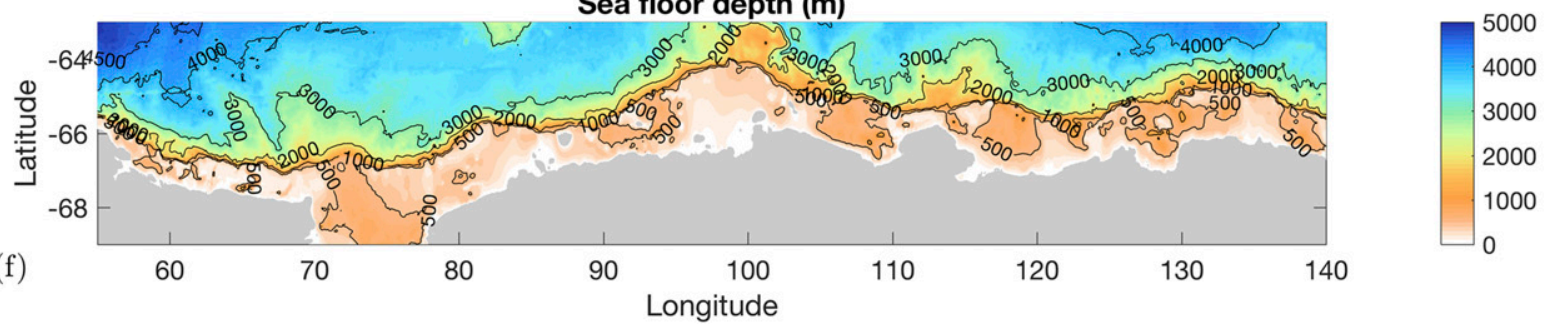

FIG. 9. Localization of mean flow forcing (see section 3c) along the 300-m isobath in the combined Amery/East Antarctica sector of the slope (see Fig. 1). (a) Surface/bottom stresses and resulting along-slope surface and sea ice circulation. (b)-(d) Circulation forcing due to total advection, vorticity advection, and vertical advection, respectively, in each case decomposed into mean, eddy, and tidal components. (e) Generation of EKE and TKE via conversion from MKE and PE. (f) Model bathymetry, plotted here to provide geographic context for the quantities plotted in (a)-(e). 


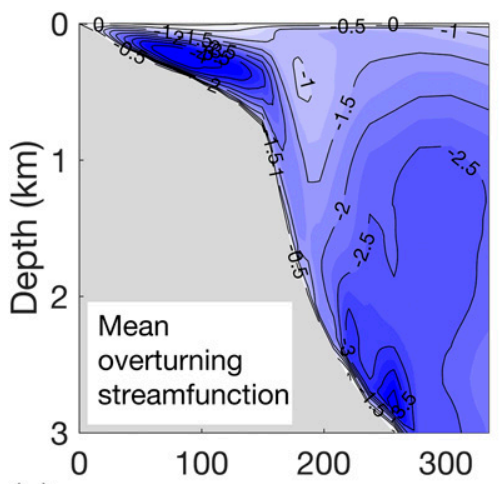

(a)

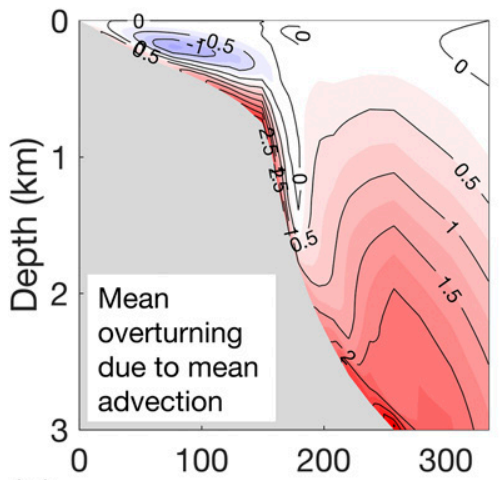

(d)

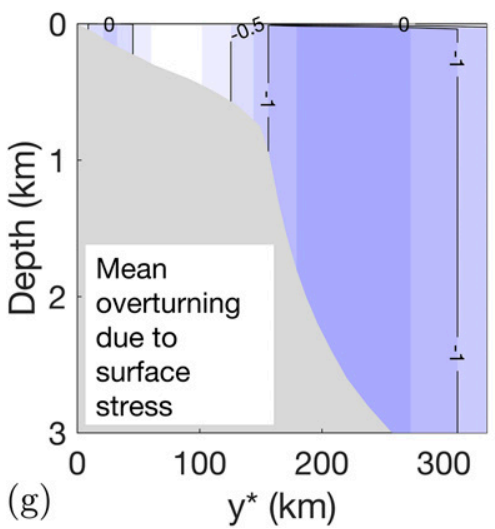

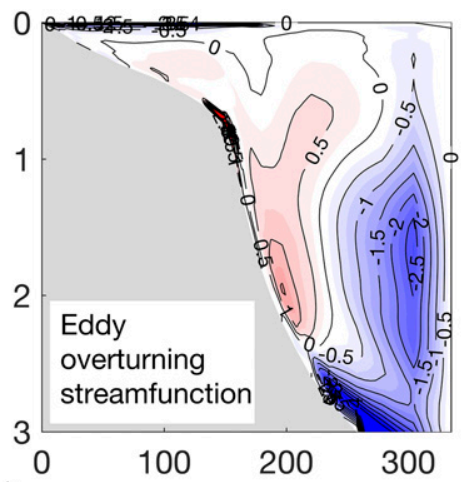

(b)

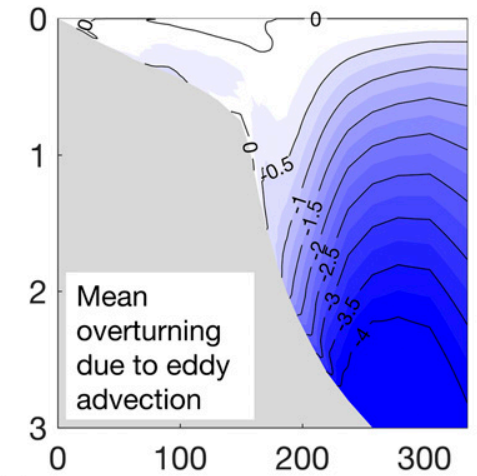

(e)

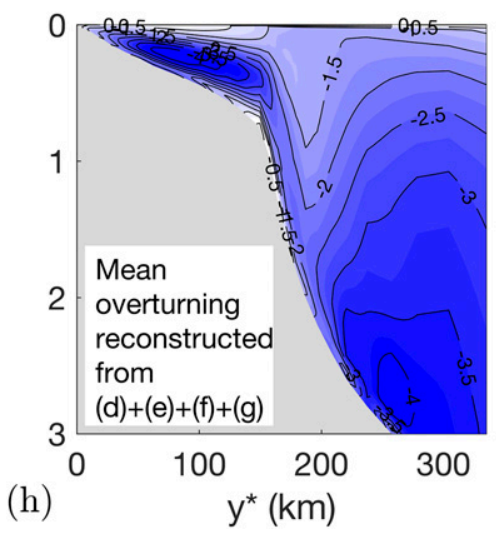

(h)

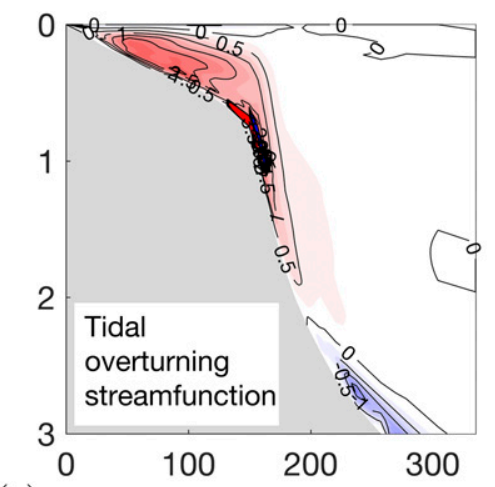

(c)
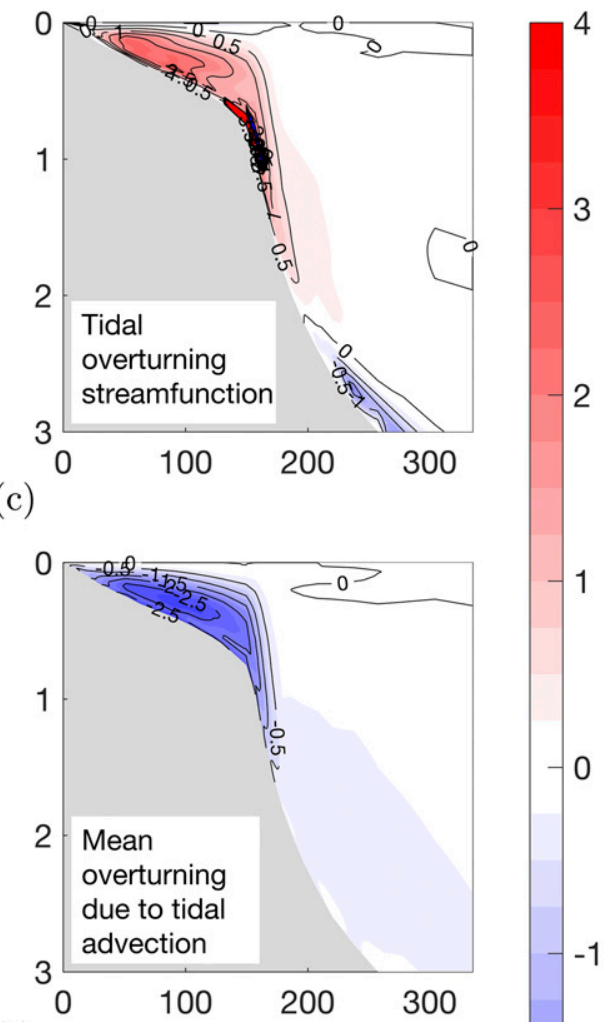

(f)

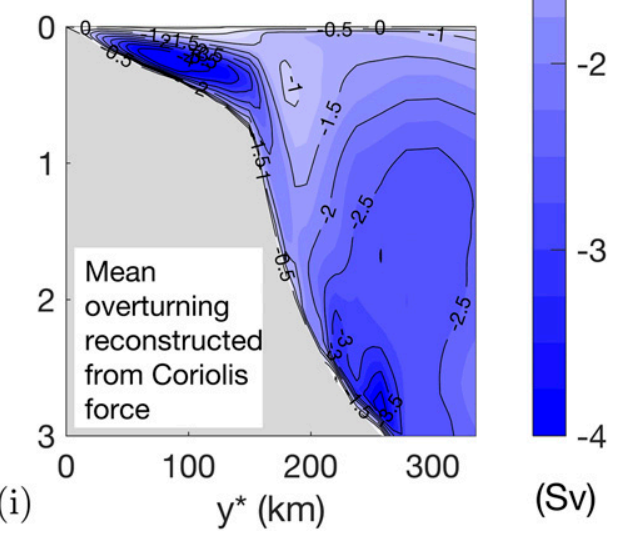

FIG. 10. Vertical structure of the along-slope circulation forcing (see section 3d), visualized via its contributions to the mean overturning circulation in the combined Amery/East Antarctica sector (see Fig. 1). (a)-(c) Components of the overturning circulation associated with the time-mean flow, approximate eddy Stokes' drift, and approximate tidal Stokes' drift, calculated following Stewart et al. (2018). (d)-(g) Estimated contributions to the mean overturning circulation due to mean advection, eddy advection, tidal advection, and surface stress, respectively. (h) An estimate of the total mean overturning circulation constructed from (d)-(g). (i) Mean overturning circulation calculated from the Coriolis force alone. By our definition of the overturning streamfunction (22), the flow follows streamlines clockwise around red-shaded regions and counterclockwise around blue-shaded regions.

generalized Stokes' drift associated with eddies and tides, and are distinguished from the eddy- and tidaldriven components of the mean overturning circulation discussed below. There is an approximate compensation between a relatively intense counterclockwise mean overturning across the shelf and shelf break in Fig. 10a, and clockwise tidal overturning of similar magnitude in Fig. 10c. Stewart et al. (2018) showed that advection of along-isobath mean potential temperature by these streamfunctions largely accounted for the diagnosed mean and tidal heat fluxes across the shelf and shelf break. 
The vanishing surface stress shoreward of the shelf break in Fig. 6 suggests that the intense mean shelf overturning in Fig. 10a cannot be explained by Ekman transport. We therefore now consider the possibility that this overturning results from advective acceleration by transient flows, which have been shown to produce mean overturning circulations, for example, in the ACC's jets (Li et al. 2016) and in idealized simulations of ASC jets (Stewart and Thompson 2016). Exploiting the approximately zonal orientation of the continental slope in the Amery/ East Antarctica sector, and correspondingly small variation in the Coriolis parameter $f$ over this region, we write

$$
\begin{aligned}
& \psi_{m} \approx \underbrace{\frac{1}{f_{0}} \int_{z}^{0} d z\left\{\oint_{\mathscr{C}(h)} f \mathbf{u}_{m} \cdot \hat{\mathbf{n}} d l\right\}}_{\text {Mean overturning reconstructed from Coriolis force }}=\underbrace{-\frac{1}{f_{0}} \int_{z}^{0} d z\left\{\oint_{\mathscr{C}(h)} \zeta_{m} \mathbf{u}_{m} \cdot \hat{\mathbf{n}} d l+\oint_{\mathscr{C}(h)} w_{m} \frac{\partial \mathbf{u}_{m}}{\partial z} \cdot \hat{\mathbf{s}} d l\right\}}_{\text {Mean overturning due to mean advection }}
\end{aligned}
$$

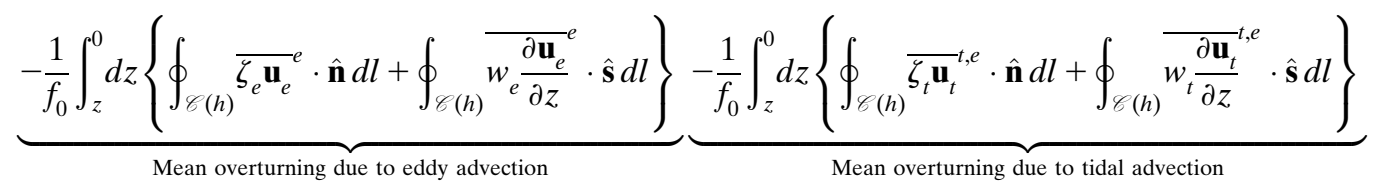

$$
\begin{aligned}
& \underbrace{+\left.\frac{1}{f_{0}} \oint_{\mathscr{C}(h)} \overline{\boldsymbol{\tau}}\right|_{z=0} \cdot \hat{\mathbf{s}} d l}_{\text {Mean overturning due to surface stress }}+\ldots
\end{aligned}
$$

Here the second equality follows from taking a vertical integral of (1) and rearranging, and $f_{0}=-1.32 \times 10^{-4} \mathrm{rad} \mathrm{s}^{-1}$ is approximately equal to the Coriolis parameter at $65^{\circ} \mathrm{S}$. Equation (23) states that the Coriolis force associated with the mean overturning circulation balances the along-isobath surface stress, the mean, eddy, and tidal advective accelerations, and other terms in the circulation budget.

In Figs. 10d-g, we use (23) to decompose the mean streamfunction into components driven by mean, eddy, and tidal advection, and due to the surface stress, respectively. The sum of these contributions, shown in Fig. 10h, is qualitatively and quantitatively similar to the diagnosed mean overturning streamfunction in Fig. 10a. The differences between Figs. 10a and $10 \mathrm{~h}$ are due to contributions from the pressure gradient and KE gradient terms in (4), which we have neglected in Fig. 10 because they cannot produce any net circumpolar acceleration. Figure $10 \mathrm{i}$ shows that reconstructing the mean overturning from the Coriolis force yields an almost identical result to computing $\psi_{m}$ directly from the model output. The dominant contribution to the mean overturning circulation across the shelf and shelf break is due to the along-isobath acceleration by tidal advection $(\sim 2.5 \mathrm{~Sv})$, with weaker contributions from eddy advection $(\sim 0.25 \mathrm{~Sv})$ and mean advection $(\sim 1 \mathrm{~Sv})$. While the surface stressdriven transport vanishes over the shelf, over the continental slope it produces a substantial $(\sim 1 \mathrm{~Sv})$ mean overturning. However, in this sector the mean overturning due to eddy advection $(\sim 4 \mathrm{~Sv})$ dominates over the lower slope (isobaths deeper than $h=2500 \mathrm{~m}$ ). Taken together, these diagnostics imply that the mean overturning across the continental shelf and slope is much stronger than might be expected due to the surface winds alone, being enhanced due to along-slope advective acceleration by transient flows.

\section{e. Circum-Antarctic regional variations}

The previous subsections have all described results diagnosed from the Amery/East Antarctica sector. To determine the generality of these results, we now extend our diagnostics to all of the regions identified in Fig. 1. The continental slope undergoes substantial meridional excursions in some sectors, particularly the Weddell and West Antarctic Peninsula (WAP). This makes an assessment of, for example, the along-slope localization of terms in the circulation and energy budgets more challenging at the circum-Antarctic scale. We therefore focus on the key circulation budget terms identified in section 3a. As discussed in section 2, we exclude the Amundsen and Bellingshausen sectors from our analysis due to qualitative differences between the model's bathymetry and the ocean's.

Figure 11 shows the along-isobath mean surface circulation, sea ice circulation, and ice-ocean shear, while Fig. 12 shows the along-isobath mean circulation forcing due to surface and bottom stresses, and due to mean, eddy, and tidal advection. Almost all sectors exhibit a transition at the shelf break: the 


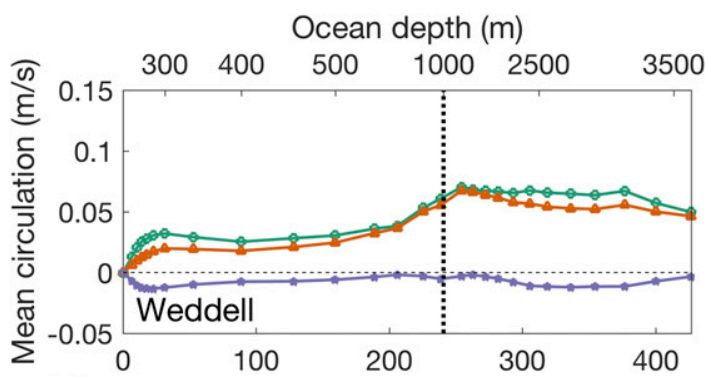

(a)

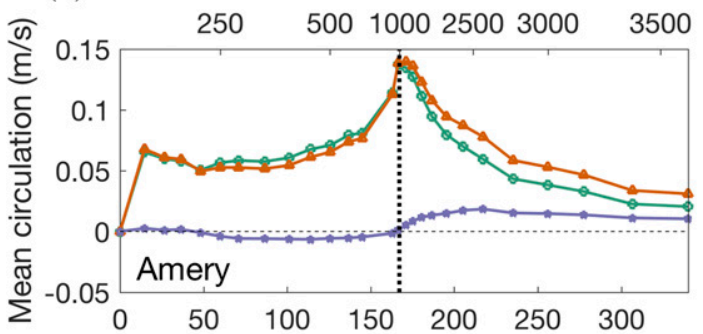

(c)

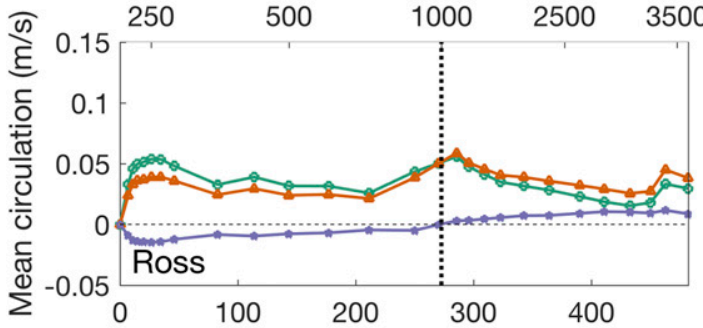

(d)

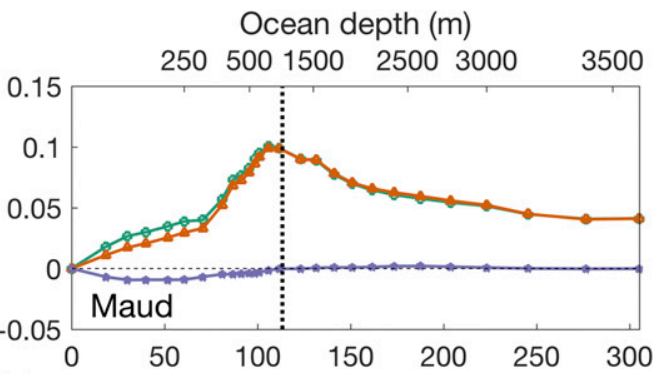

(b)

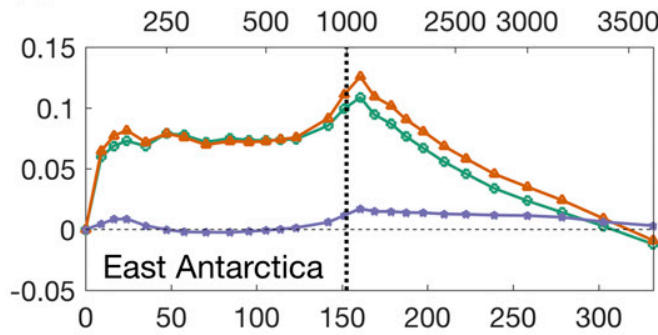

(e)
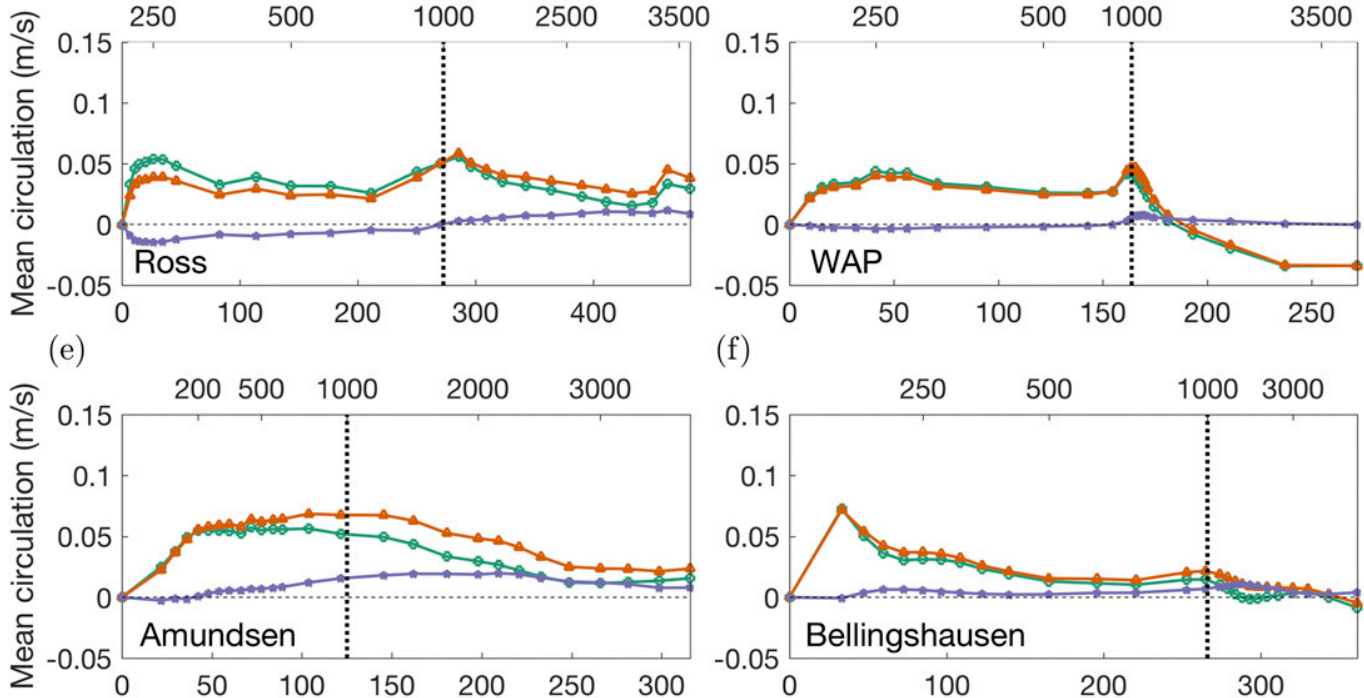

(g) Pseudo-offshore distance $\mathrm{y}^{*}(\mathrm{~km})$

(f)

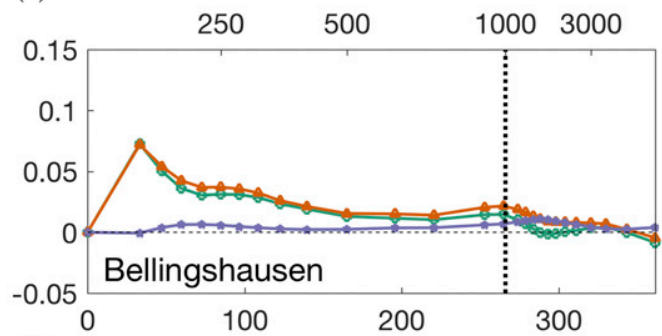

(h) Pseudo-offshore distance $\mathrm{y}^{\star}(\mathrm{km})$

$\because$ Ocean surface circulation $\longrightarrow$ Sea ice circulation $\longrightarrow$ Ice-ocean shear

FIG. 11. (a)-(h) Comparison of along-slope circulation in all eight sectors of the Antarctic margins identified in Fig. 1. In each panel the lower abscissa corresponds to an approximate measure of distance from the coast (see section 2e), while the upper abscissa corresponds to isobaths. Dashed lines are used in (g) and (h) to emphasize that the model's bathymetry differs qualitatively from the ocean's in these regions, as discussed in section 2 . In each panel the dashed black line corresponds to the $1-\mathrm{km}$ isobath and approximately separates the continental shelf break from the continental slope.

ice-ocean shear (Fig. 11) and surface stress (Fig. 12) vanish shoreward of the shelf break, where tides accelerate the ASC. An exception is the Weddell, in which the ASC experiences acceleration due to tidal advection and deceleration due to the surface stress across the entire continental shelf and slope. This is likely due to perennial ice cover and strong tides in this sector (Robertson 2001); our seasonal decomposition of the Amery/East Antarctic sector in appendix $\mathrm{C}$ also shows negative surface stresses in winter, when the ice cover is thick. Figure 12 also highlights that acceleration of the ASC by eddies over the continental slope varies widely between different sectors, with magnitudes ranging from around 

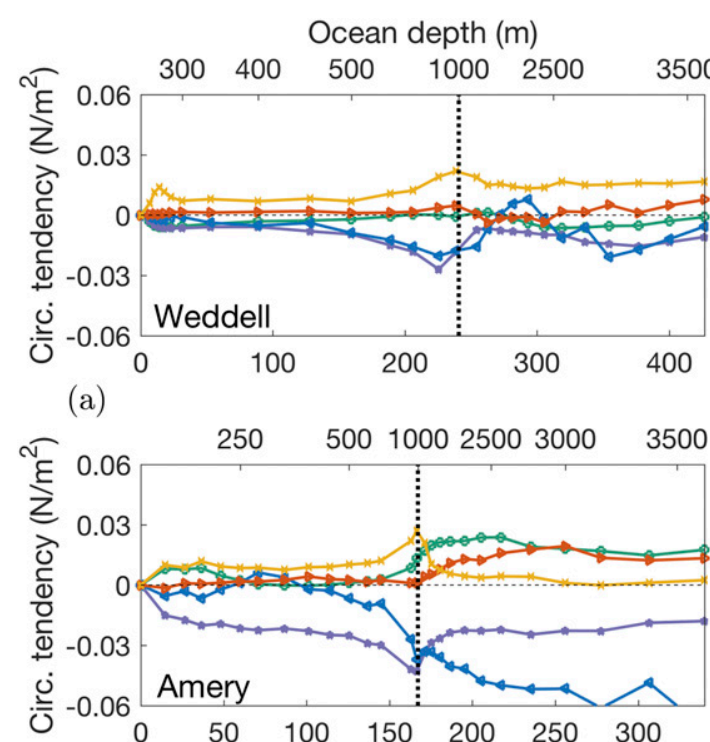

(c)

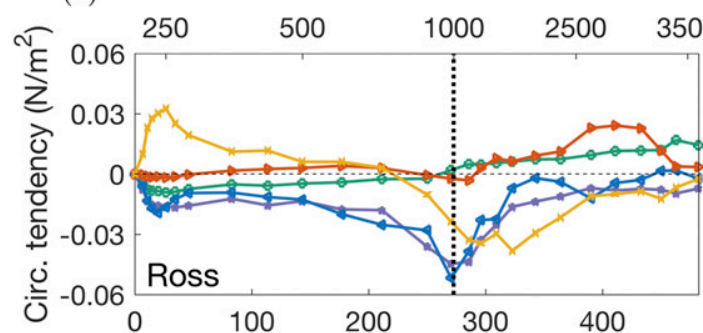

(e)

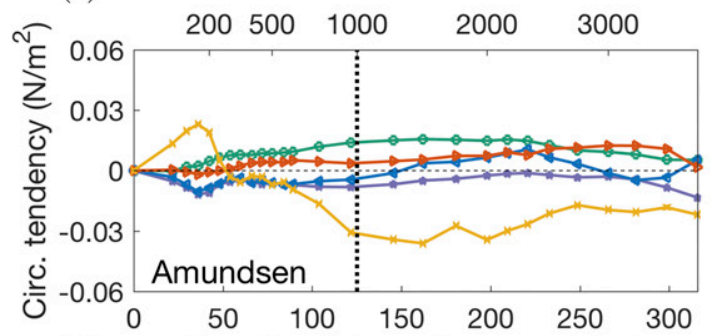

(g) Pseudo-offshore distance $\mathrm{y}^{\star}(\mathrm{km})$

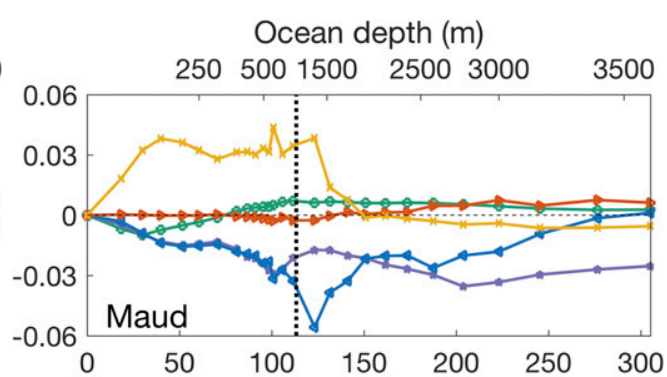

(b)

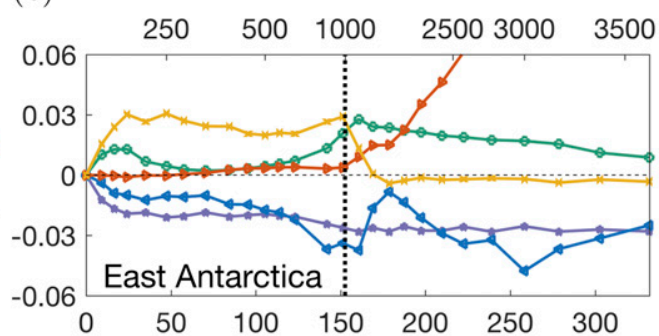

(d)

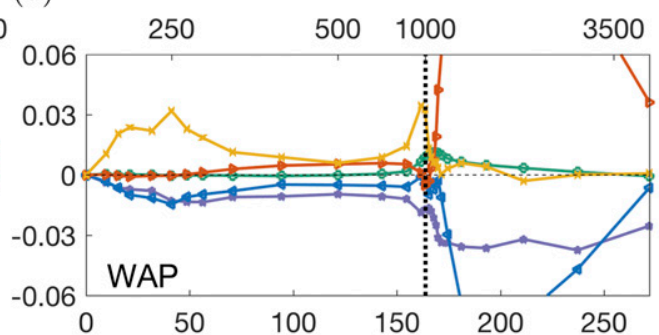

(f)

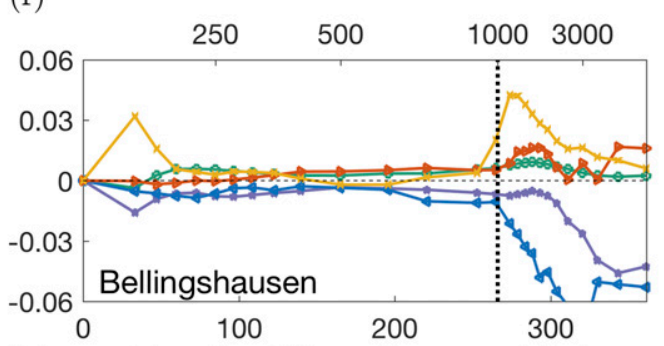

(h) Pseudo-offshore distance $\mathrm{y}^{*}(\mathrm{~km})$

$\multimap$ Surface stress $\longrightarrow$ Bottom stress $\longrightarrow$ Mean advection $\longrightarrow$ Eddy advection $\longrightarrow$ Tidal advection

FIG. 12. As in Fig. 11, but instead showing terms in the along-isobath circulation budget (see section 3a).

$0.14 \mathrm{~N} \mathrm{~m}^{-2}$ in the WAP sector to approximately zero in the Weddell.

\section{Discussion and conclusions}

\section{a. Summary of results}

In this study we have used a high-resolution global simulation, the LLC_4320, to investigate the role of transient flows in driving the ASC, and in particular the ASC's shelfbreak jet. The model ASC is accelerated by a westward surface stress that is ultimately input by the coastal easterly winds, but must be transferred to the ocean via the overlying sea ice over much of the year, consistent with previous studies (e.g., Mathiot et al. 2011; Heywood et al. 2014). The imbalance between surface zonal stress and bottom frictional stress (Fig. 4) suggests that the zonal surface momentum input is primarily balanced by topographic form stress, as in the ACC (e.g., Munk and Palmén 1951; Stewart and Hogg 2017). However, we are unable to verify this force balance directly from the model, as discussed in appendix B.

A central result of this study (summarized in Fig. 13) is that the shelfbreak jet, which is typically tens of 


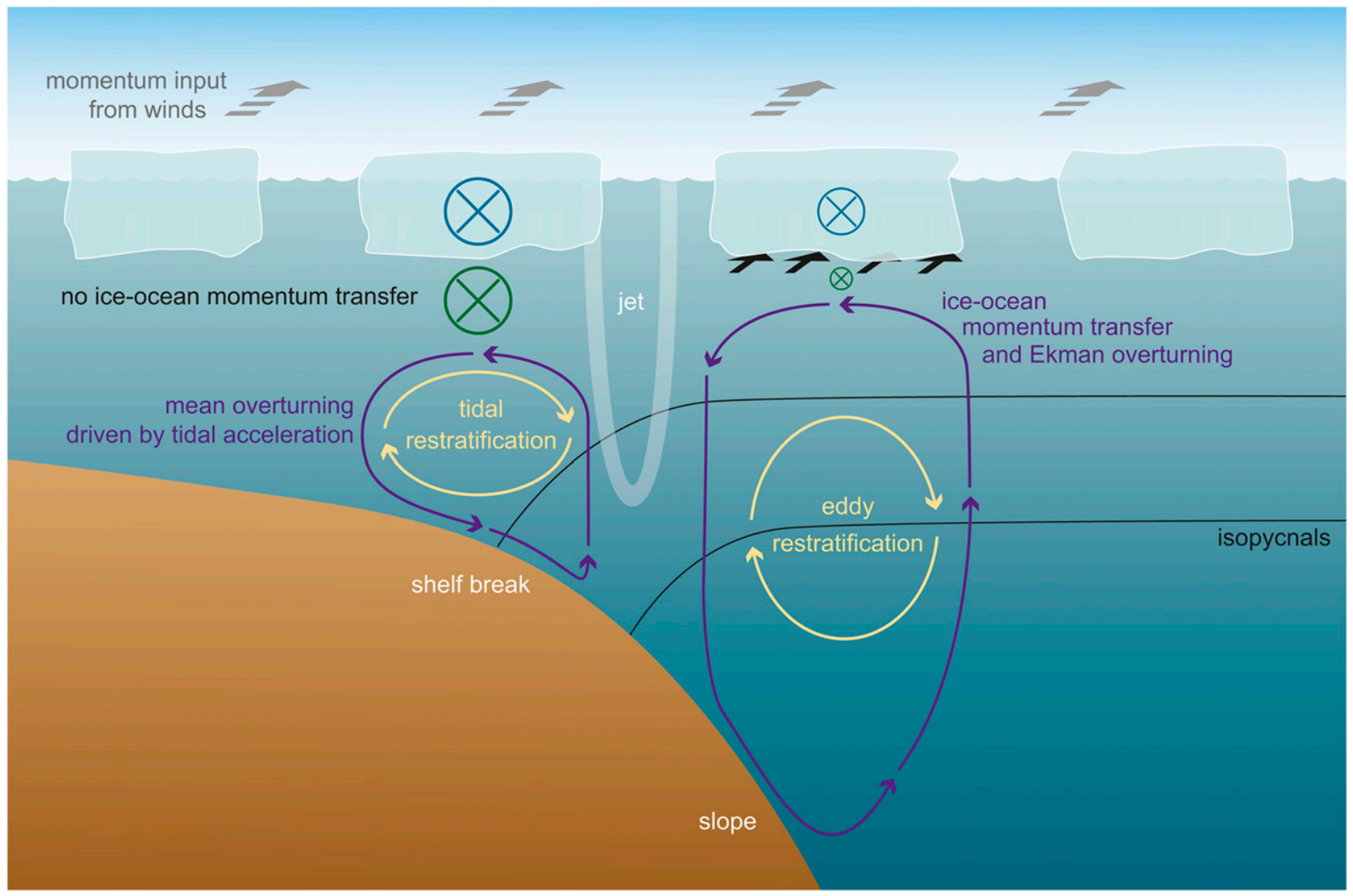

FIG. 13. Schematic illustrating the roles of wind, sea ice, eddies, and tides in accelerating the ASC. Over the continental slope, momentum is primarily sourced from the winds via the sea ice. The resulting shoreward Ekman transport and associated overturning circulation is compensated by an opposing eddy overturning circulation that serves to restratify the water column, analogous to the long-standing paradigm for the ACC (Karsten and Marshall 2002; Marshall and Radko 2003). At the shelf break, tides accelerate the ASC to the point that the surface speed is typically comparable to that of the overlying sea ice, resulting in an approximate vanishing of the surface momentum input. Consequently, tidal acceleration drives the mean shoreward surface transport and associated overturning circulation, with tidal Stokes' drift providing the opposing, restratifying overturning circulation.

kilometers wide and coincides with the ASF, is subject to a qualitatively different momentum balance from the rest of the ASC and continental shelf currents. Here the mean westward surface stress vanishes or even reverses (see Figs. 4 and 12). This occurs where the mean surface ocean flow speed approaches or exceeds that of the overlying sea ice (see Figs. 3, 6, and 9). This suggests that an additional source of along-slope acceleration, due, for example, to transient momentum flux convergence by eddies (e.g., Stewart and Thompson 2016; Li et al. 2016) or tides (Garreau and Maze 1992; Chen and Beardsley 1995). We therefore approximately decomposed the model output into mean, eddy, and tidal components (section 2d) to identify their relative contributions to driving the along-shelfbreak circulation, and posed our analysis in an isobath-following coordinate system that emphasizes the shelfbreak jet.
Applying this analysis framework to the LLC_4320 simulation in section 3 revealed that the shelfbreak jet is primarily accelerated westward by tidal vertical advection, partially compensated by deceleration due to tidal vorticity advection [see (4)]. This acceleration is collocated with a conversion from TKE to MKE via tidal vertical momentum fluxes (see Fig. 8), suggesting that this might be interpreted as the result of vertical momentum flux convergence by tides at the shelf break. The tidal acceleration is localized along the shelf break (Fig. 9), typically coinciding with stretches of steep continental slope and high TKE, consistent with the phenomenology of tidal rectification (Garreau and Maze 1992; Chen and Beardsley 1995). In section 3d we showed that the mean overturning circulation across the shelf break is also primarily driven by tidal acceleration (Fig. 10). Thus, while previous studies have highlighted the importance of tides for the ASC in specific regions 

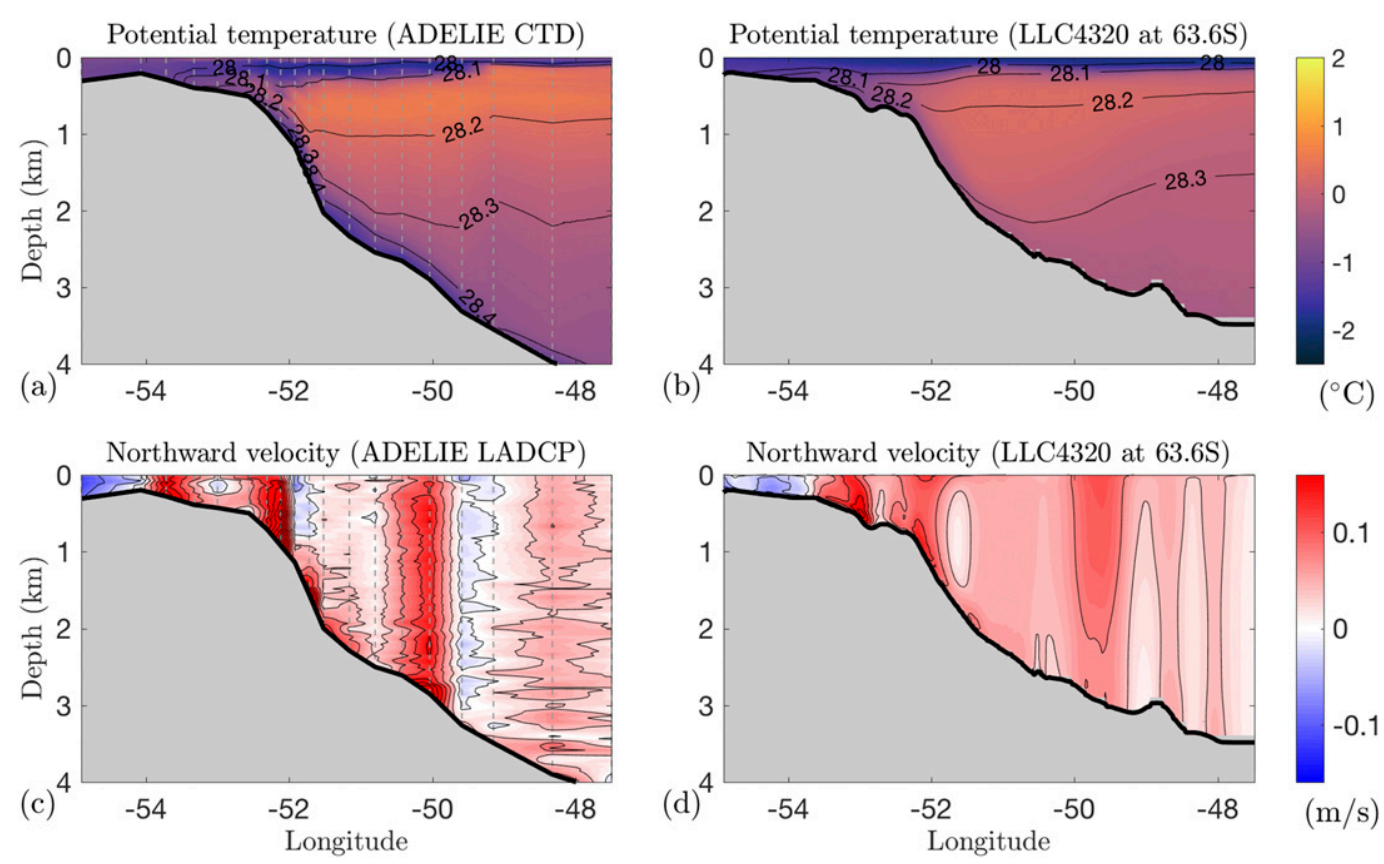

FIG. A1. Evaluation of (b),(d) the modeled annual-mean Antarctic Slope Front/Current against (a),(c) observations made in February 2007 during the ADELIE cruise in the northwestern Weddell Sea (see Thompson and Heywood 2008). (top) Potential temperature (colors) and neutral density (black contours) calculated following Jackett and McDougall (1997). Labels indicate neutral densities on each isopycnal $\left(\mathrm{kg} \mathrm{m}^{-3}\right.$ ). (bottom) Zonal velocity contoured every $0.01 \mathrm{~m} \mathrm{~s}^{-1}$ (colors) and $0.04 \mathrm{~m} \mathrm{~s}^{-1}$ (black contours). In (a) and (c) the dashed black lines indicate locations at which CTD cast and lowered ADCP measurements were taken.

(e.g., Robertson 2001; Flexas et al. 2015), our findings indicate that tides serve as a primary driver of the alongslope circulation and mean overturning of the ASF in all sectors of the Antarctic margins considered in this study (Fig. 12).

While we found a relatively minor role for eddies at the shelf break, in the Amery/East Antarctica sector they produce a substantial acceleration of the ASC over the continental slope. These accelerations coincide with conversion from EKE to MKE via horizontal momentum fluxes directed up the mean momentum gradient (Fig. 8), suggesting that they can be interpreted as eddy horizontal momentum flux convergence forcing the mean flow (e.g., Stewart and Thompson 2016; Li et al. 2016). It is not clear from our diagnostics why eddies drive the mean flow, rather than vice versa, but we speculate that the mechanism is topographic rectification of quasigeostrophic flows (e.g., Brink 2016; Wang and Stewart 2018). In contrast to the tidal acceleration of the shelfbreak jet, the eddy acceleration of the slope current is less consistent between different sectors of the Antarctic margins (Fig. 12). This may be a consequence of variations in the EKE over the continental slope, perhaps due to varying proximities of the continental slope to the energetic ACC to the north.

\section{b. Implications and outlook}

Together the above results imply that the ASC's shelfbreak current is accelerated by tidal rectification to the extent that the ocean is only weakly accelerated westward by the sea ice, if at all (e.g., Fig. 6). Indeed, our analysis in appendix $C$ suggests that over the course of a year, the shelfbreak jet may cycle through states in which it is accelerated by winds, weakly accelerated by the overlying sea ice, or acting to accelerate the sea ice, while in all seasons experiencing approximately the same tidal acceleration. Theoretical or comprehensive models of the ASC that exclude the effects of tides therefore likely underrepresent the strength of the shelfbreak jet associated with the ASF (Fig. 3), and so may underestimate ocean and sea ice transport around Antarctica. Furthermore such models would not capture the dominance of the tides in driving the cross-shelf overturning circulation (Fig. 10), which transports surface waters shoreward and acts to steepen isopycnals in the ASF. Various previous studies have emphasized the role of the wind in transporting surface waters across the continental shelf break (see, e.g., Nøst et al. 2011; Stewart and Thompson 2012; Spence et al. 2014; Zhou et al. 2014; Greene et al. 2017; Paolo et al. 2018). Further work will be required to 

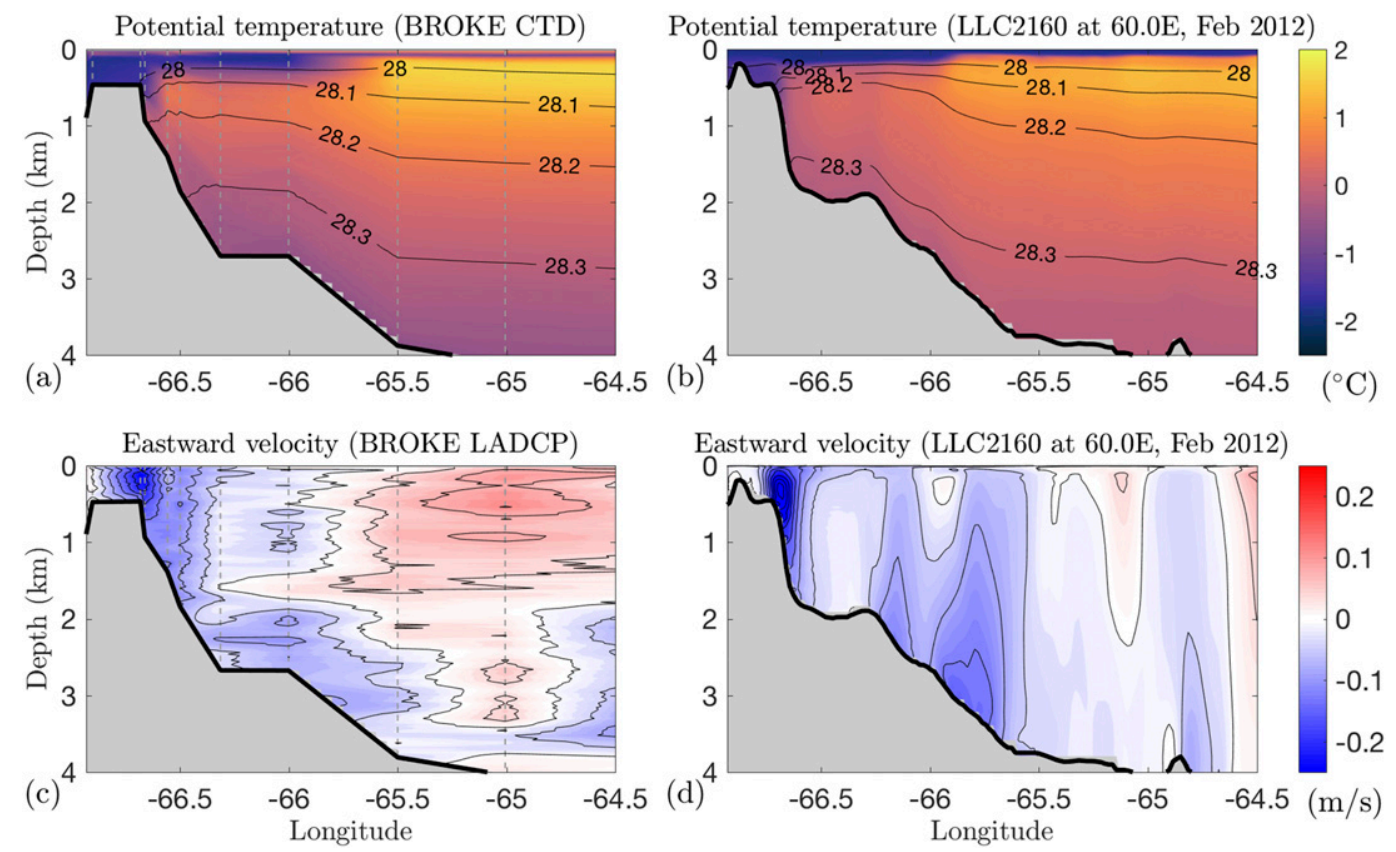

FIG. A2. As in Fig. 2, but showing the LLC_2160 temperature, neutral density, and zonal velocity fields averaged over the month of February 2012, rather than over a full annual cycle.

determine how tides modify the response of the ASC to wind variability (e.g., Armitage et al. 2018) and to historical and future wind trends (Hazel and Stewart 2019).

While the LLC_4320 simulation's high spatial resolution and output frequency make it well suited to the analysis of eddy and tidal dynamics at the Antarctic margins (Padman et al. 2009; Stewart and Thompson 2015b), it carries several substantial caveats. For example, we were unable to diagnose pressure forces directly, requiring that we infer them approximately as a residual of other terms (Fig. 7). While no net along-isobath pressure force is possible around the entire continent (see section 3a), we cannot completely exclude the possibility of local contributions that substantially influence the alongisobath circulation budget. We have also been unable to assess the effect of buoyancy forcing on the ASF, due, for example, to localized inputs of freshwater from floating ice shelves along the coast (Hattermann et al. 2014; Hattermann 2018), which are excluded by the LLC_4320 simulation's simplified distribution of continental runoff (see section 2). In addition to changing the baroclinic structure of the ASF/ASC, buoyancy forcing also serves to drive overturning circulations in density space and thereby indirectly enters the along-slope circulation budget, though its vertically integrated contribution is zero (Stewart and Thompson 2016).
The model's omission of dense shelf water (DSW) production is likely causing it to underestimate the effect of eddies in regions such as the western Ross and Weddell Seas, where eddies may receive more of their energy as a result of buoyancy forcing than wind forcing (Lane-Serff and Baines 1998; Stewart and Thompson 2016). The export and DSW, and the return flow of CDW and other water masses onto the continental shelf, are therefore also absent from our diagnostics of the overturning circulation in Fig. 10. Due to the model's high horizontal resolution, it would likely simulate DSW overflows if the integration could practically be continued for a longer period (Newsom et al. 2016; Dufour et al. 2017), though this also raises the possibility of the stratification and circulation drifting far from observations. The simulation also only represents one annual realization of the Antarctic atmospheric forcing sampled from substantial interannual variability (e.g., Gordon et al. 2015; Langlais et al. 2015). The 1-yr duration of the simulation appears to be sufficient to avoid distortion of the eddy and tidal statistics, based on the consistency of the eddy/tidal acceleration between seasons (see appendix C) and the eddy/tidal heat transports between the 1-yr LLC_ 4320 and 2-yr LLC_2160 simulations (Stewart et al. 2018). However, longer simulations at higher resolution will be required to quantify drivers of seasonal and interannual variations in the ASF and ASC. 

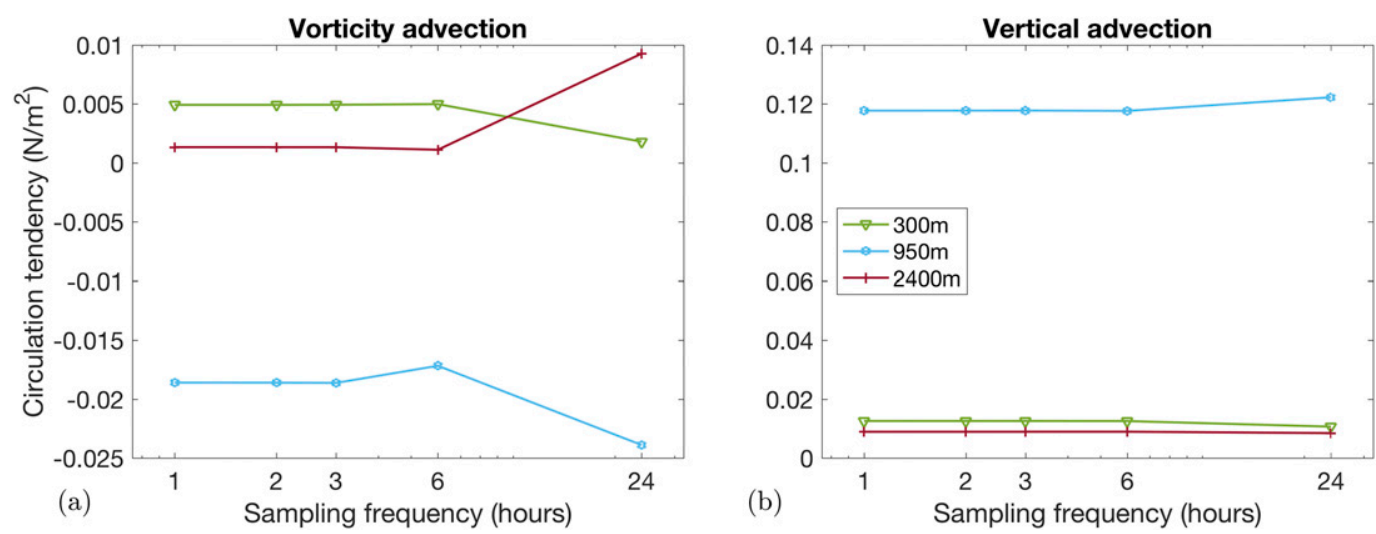

FIG. B1. Sensitivity of circulation forcing due to (a) vorticity advection and (b) vertical advection to model output frequency. For each panel the circulation tendency was calculated as described in section $2 \mathrm{e}$ for a subdomain of the Amery region (see Fig. 1), between $70.7^{\circ}$ and $79.0^{\circ} \mathrm{E}$ and between $68.3^{\circ}$ and $65.1^{\circ} \mathrm{S}$. In each case we calculated the total circulation tendency due to all transient flows, using the LLC_2160 simulation for computational efficiency.

Finally, the model's bathymetry product (Smith and Sandwell 1997) differs qualitatively from the real continental shelf and slope in the Amundsen and Bellingshausen sectors, precluding an accurate diagnosis of the ASC's dynamics in these sectors (see Stewart et al. 2018).

There are also various caveats to our analysis approach. Both of the coordinate transformations (isobath-following and barotropic streamline-following) discussed in section 2e produce somewhat distorted representations of the average structure and forcing of the shelfbreak jet and should be interpreted accordingly. As emphasized in section 2 d, our "eddy" and "tidal" components only approximately correspond to their representative flow phenomena, and include other flows that evolve on comparable time scales. For example, the effect of tides could be more accurately isolated via tidal harmonic analysis (Foreman and Henry 1989) and the "eddy" component may also include phenomena such as lowfrequency coastal-trapped waves (Kusahara and Ohshima 2014; Spence et al. 2017) and the oceanic response to synoptic wind variability (e.g., Davis et al. 2018). Our analysis options were strongly constrained by the computational cost of performing operations on the very large volume of model output (see Stewart et al. 2018), a problem that might be ameliorated in future by improved computational infrastructure and tools for working with large datasets. The computational burden could further be reduced by conducting regional simulations of the full Antarctic margins, which would also allow for inclusion of ice shelf cavities and updated continental shelf bathymetry.
In summary, the circum-Antarctic acceleration of the ASC's shelfbreak jet by tides leads to a qualitatively different momentum balance and mean overturning of the ASF than would be expected due to winds alone (e.g., Nøst et al. 2011; Stewart and Thompson 2016), while eddies contribute substantially to the acceleration of the ASC in specific sectors of the continental slope. However, the various caveats attached to the LLC_4320 simulation and the limitations of our analysis leave many open questions to be addressed in future studies. In particular, the combined impact of DSW export and tides on the ASC may

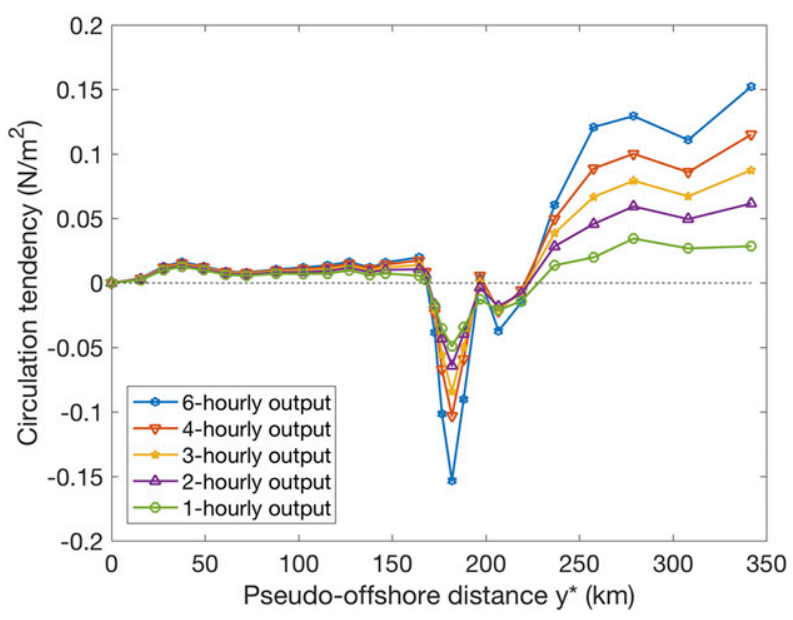

FIG. B2. Sensitivity of circulation forcing due to pressure gradients to model output frequency. For each frequency the circulation tendency was calculated as described in section 2e for the combined Amery/East Antarctica region (see Fig. 1). These results have been calculated using the LLC_2160 simulation for computational efficiency. 


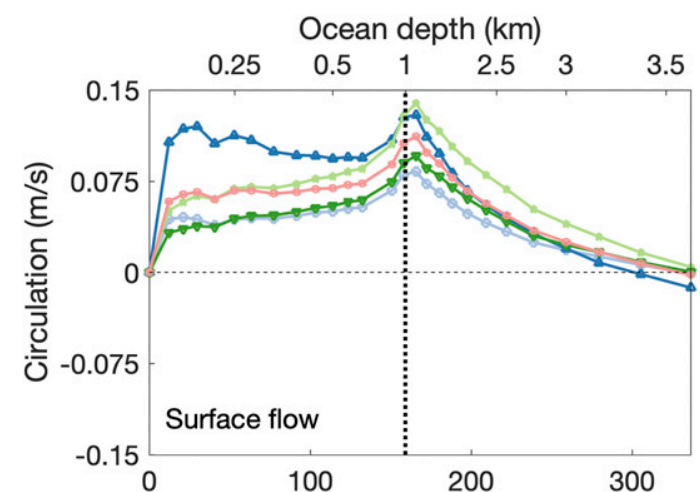

(a)

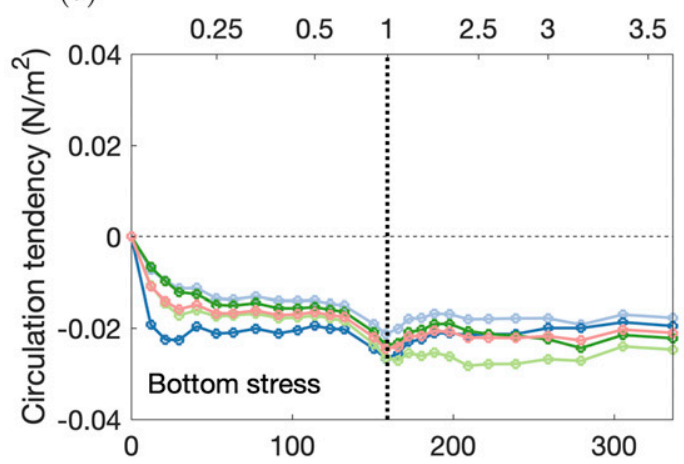

(c)

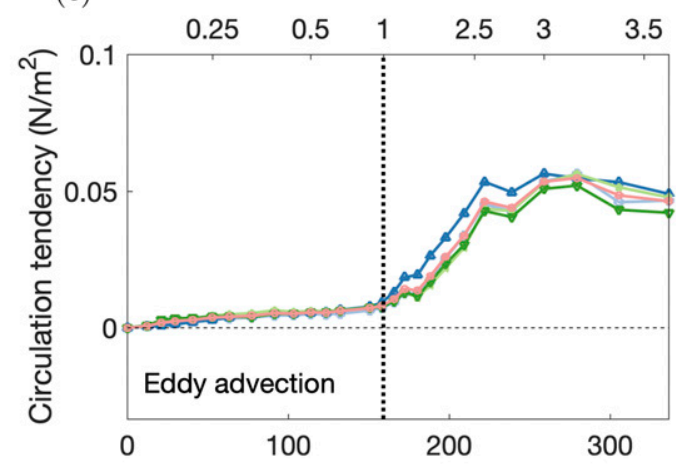

(e)

Pseudo-offshore distance $\mathrm{y}^{\star}(\mathrm{km})$

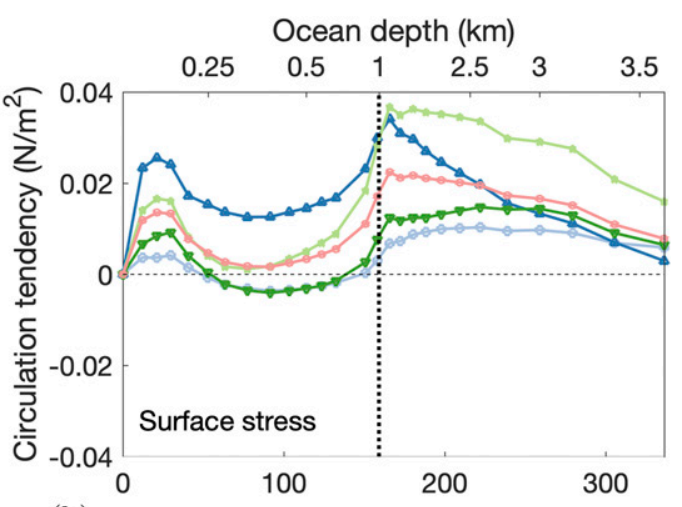

(b)

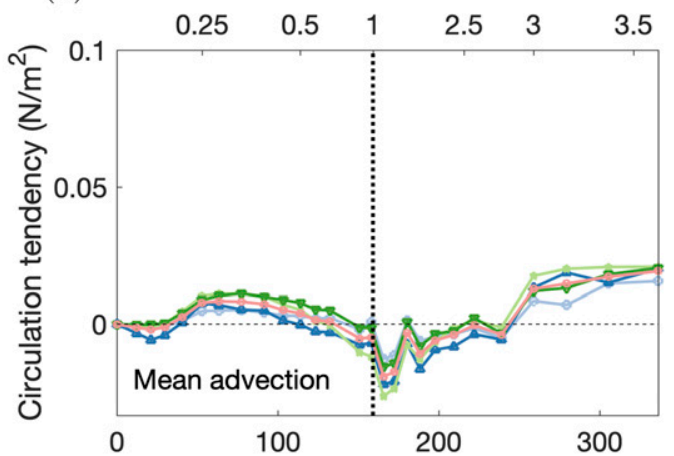

(d)

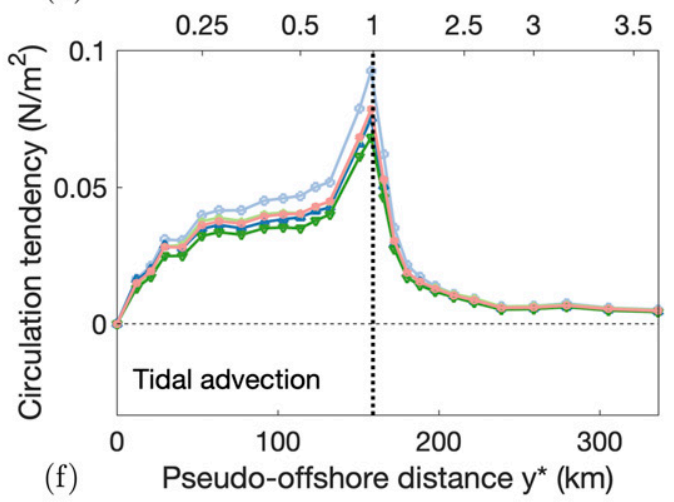

$$
\because \text { OND } \multimap \text { JFM } \multimap \text { AMJ } \multimap \text { JAS } \multimap \text { Annual }
$$

FIG. C1. Seasonal variations in (a) circulation and (b)-(f) forcing of the Antarctic Slope Current in the combined Amery/East Antarctica sector (see Fig. 1). Shown are the along-slope circulation tendency due to surface stress in (b), bottom stress in (c), mean advection in (d), eddy advection in (e), and tidal advection in (f). In each panel the lower abscissa corresponds to an approximate measure of distance from the coast (see section 2e), while the upper abscissa corresponds to isobaths. These seasonal diagnostics were performed using output from October 2011 to September 2012 in the LLC_2160 simulation for computational efficiency. In each panel the dashed black line corresponds to the $1-\mathrm{km}$ isobath and approximately separates the continental shelf break from the continental slope.

introduce qualitative changes in the dynamics, albeit likely confined to localized regions (Baines and Condie 1998). Figure 11 indicates that the mean along-isobath flow of the ASC varies substantially between different sectors of the continent, but the dynamical processes responsible for these variations remains to be explored. Our results also highlight the importance of mechanical interaction between the ocean and the sea ice in the ASC's shelfbreak jet but the implications of oceanic acceleration on sea ice drift around Antarctica remain 


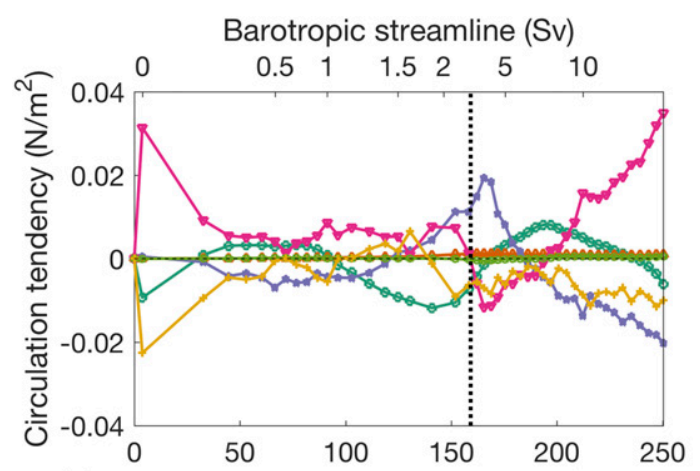

(a) Pseudo-offshore distance $\mathrm{y}^{*}(\mathrm{~km})$
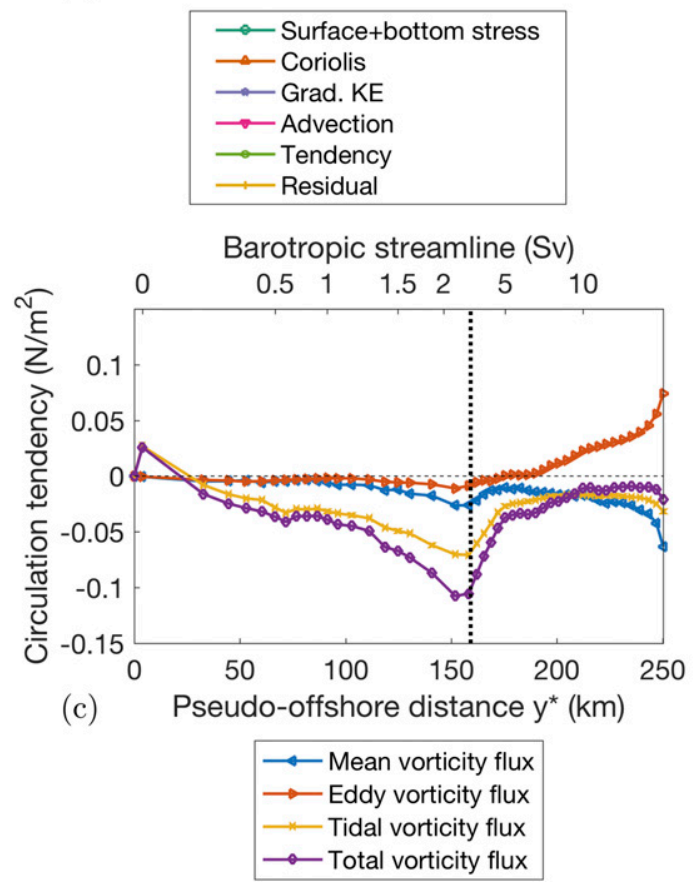
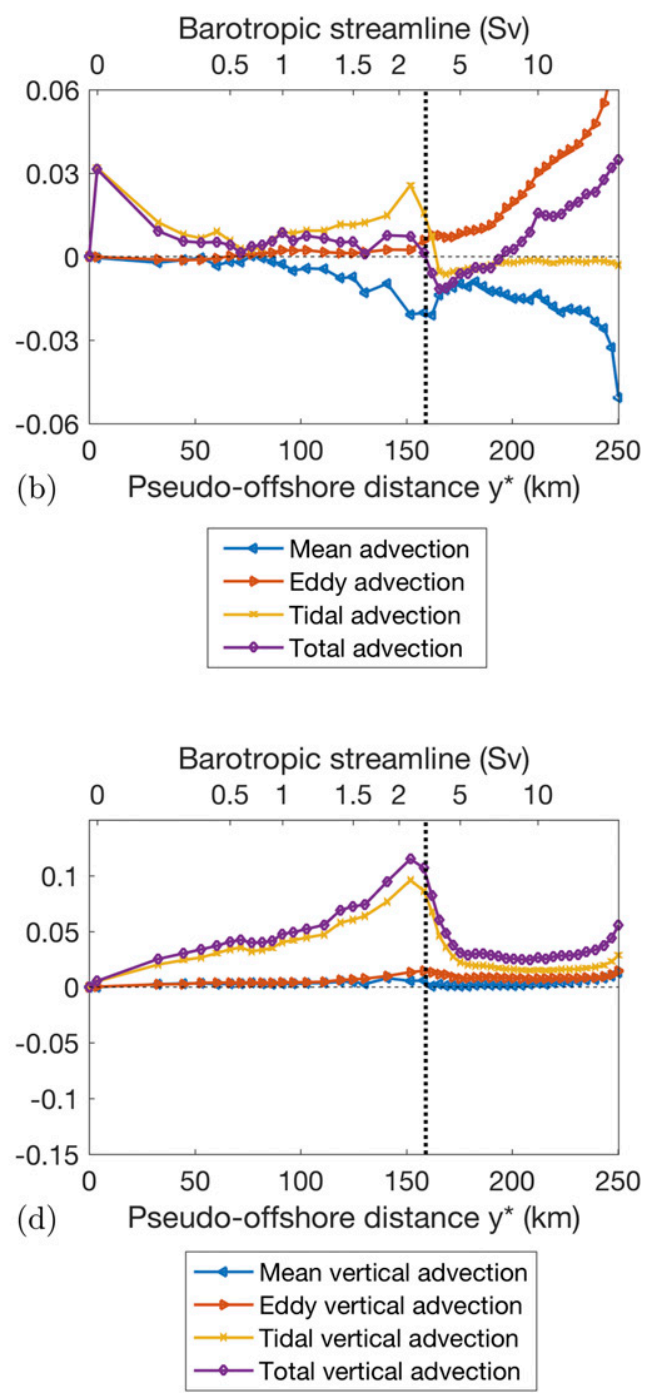

FIG. D1. Terms in the along-flow circulation budget in the combined Amery/East Antarctica sector (see Fig. 1). (a) Complete budget; (b) decomposition of the total advection into mean, eddy, and tidal components; (c) decomposition of the vorticity advection into mean, eddy, and tidal components; and (d) decomposition of the vertical advection into mean, eddy, and tidal components. In each panel the lower abscissa corresponds to an approximate measure of distance from the coast (see section 2e), while the upper abscissa corresponds to barotropic streamlines. In each panel the dashed black line corresponds to the 1-km isobath (calculated via the along-streamline averaged sea floor depth) and approximately separates the continental shelf break from the continental slope.

to be explored. Finally, our results offer little insight into the sensitivity of the ASC to the modeled tidal amplitudes, atmospheric forcing, ambient offshore stratification, and sea floor geometry, and thus little insight into past and potential future changes in the ASC. We suggest that progress on these fronts will require high-resolution circum-Antarctic regional modeling, process-oriented simulations to more clearly isolate different ASC drivers, and additional observational deployments in regions of strong tidal and eddy ASC forcing.
Acknowledgments. The authors thank Andrew Thompson and Mar Flexas for helpful comments on an earlier draft of this manuscript. The authors thank Ed Doddridge and an anonymous reviewer for many detailed recommendations that improved the manuscript. This material is based in part upon work supported by the National Science Foundation under Grant Numbers OCE-1538702, ANT-1543388, and OCE-1751386. This research was supported under the Australian Research Council's Special Research Initiative Antarctic Gateway Partnership (Project ID 
SR140300001). DM carried out this work at the Jet Propulsion Laboratory (JPL), California Institute of Technology, under a contract with the National Aeronautics and Space Administration (NASA). The authors thank Andrew Thompson and Karen Heywood for providing the observational data used to create Fig. A1. High-end computing resources were provided by the NASA Advanced Supercomputing (NAS) Division of the Ames Research Center. The authors thank the MITgcm development team, NAS computer scientists, and SGI engineers for their contributions to producing and making available the high-resolution model output used in this study. The model configuration files can be downloaded from: http://wwwcvs.mitgcm.org/ viewvc/MITgcm/MITgcm_contrib/llc_hires/llc_4320/. The raw model output data are stored on NASA's Pleiades supercomputer and may be accessed via request to DM. The model analysis used the Extreme Science and Engineering Discovery Environment (XSEDE; Towns et al. 2014), which is supported by National Science Foundation Grant ACI-1548562. The time-averaged model output fields used to derive the results presented in this manuscript can be downloaded from: https://doi.org/10.4226/77/ 5a37035ea15b2.

\section{APPENDIX A}

\section{Additional Model Evaluation}

Here we discuss additional evaluation of the LLC_4320 simulation, which is limited by the paucity of simultaneous high-resolution hydrographic and velocity measurements across the ASC. In Fig. A1 we present plots analogous to those shown in Fig. 2, but using observations from the ADELIE deployment (Thompson and Heywood 2008) in the western Weddell Sea. Both the modeled and observed meridional velocities exhibit multiple, northward, primarily barotropic jets. In this section, however, the absence of $\mathrm{AABW}$ in the model leads to more substantial differences in the stratification over the slope and shelf break, compared to Fig. 2.

As emphasized in section $2 \mathrm{~b}$, quantitative agreement between the model and observations should not be expected because the former is an annual mean and the latter an approximately instantaneous snapshot. In Fig. A2 we replicate Fig. 2 using output from the LLC_2160 simulation averaged over the month of February 2012, rather than over a full annual cycle. Despite comparing the model output with observations taken in the same calendar month, Fig. A2 does not exhibit discernibly better agreement between the modeled and observed ASC states than Fig. 2.

\section{APPENDIX B}

\section{Sensitivity to Model Output Frequency}

As discussed in section $2 \mathrm{~d}$, all diagnostics from the LLC_4320 simulation were calculated using 6-hourly instantaneous model output for computational efficiency, though hourly output is available. In Fig. B1 we test the sensitivity of the computed accelerations due to vorticity advection and vertical advection to the frequency of the model output in a subset of the Amery sector (see Stewart et al. 2018) in the LLC_2160 simulation. In each case we have subtracted the corresponding accelerations associated with the time-mean, so the curves in Fig. B1 correspond to the total acceleration due to all transient flows. While there are $\sim 100 \%$ differences in the result between output frequencies of 24 and $6 \mathrm{~h}$, higher frequencies yield only small $(\sim 10 \%)$ changes in the computed accelerations. This is consistent with similar results presented by Stewart et al. (2018) for the cross-slope heat fluxes.

In section $3 \mathrm{a}$ we noted that we could not directly calculate the pressure gradient term in (16). This is because, unlike all other terms in (16), the calculated pressure gradient term does not converge under refinement of the model output frequency. Figure B2 shows the along-isobath circulation over the entire Amery/East Antarctica sector in the LLC_2160 simulation, calculated using several different output frequencies. The differences in the acceleration between hourly and 2-hourly output frequencies are comparable to those between 4- and 6-hourly output frequencies, so evidently convergence has not been achieved. While it appears that the magnitude of the acceleration is becoming progressively smaller, it is not possible to accurately extrapolate to the actual circulation forcing. We speculate that high-frequency surface waves may be the source of this issue, which highlights the need for online averaging in future model studies of Antarctic tides, particularly for the pressure field.

\section{APPENDIX C}

\section{Seasonal Cycle}

The ASC and the near-Antarctic winds exhibit a pronounced seasonal cycle (Mathiot et al. 2011; 
Su et al. 2014; Peña-Molino et al. 2016) that could, in principle, comprise part of the "eddy" component of the flow as defined in this study. To distinguish the role of seasonal variability we recalculated our circulation budget diagnostics for 12 months of the LLC_2160 simulation in the Amery/East Antarctica sector. Specifically, for each month from October 2011 to September 2012, we reproduced the analysis discussed in section 2 and section 3 but defining the long-time average $\overline{\boldsymbol{c}}^{e}$ as an average over that month. In Fig. C1 we plot key diagnostics of the along-slope circulation and forcing, averaging the monthly diagnostics into 3-month seasonal periods: October-December (OND), January-March (JFM), April-June (AMJ), and JulySeptember (JAS).

Figures $\mathrm{C} 1 \mathrm{a}-\mathrm{c}$ show that the surface flow of the ASC and the surface stress exhibit large seasonal variations across the shelf break and shelf, with the flow speed varying by a factor of $\sim 2$ and the stress varying from negative (eastward) values in winter to positive (westward) values in summer, with an annual-mean of approximately zero on the shoreward flank of the ASC jet. It is therefore somewhat surprising that the shear between the annual-mean sea ice flow and annualmean surface flow so closely predicts the annual-mean stress in Fig. 9. In contrast, the advective accelerations in Figs. C1d-f show very little (up to $\sim 20 \%$ ) variation between seasons. We conclude that the eddy component is primarily associated with submonthly variability.

\section{APPENDIX D}

\section{Barotropic Streamfunction Coordinates}

In section 2e we discuss two coordinate systems: one following isobaths and one following mean barotropic streamlines. We prefer the former because the latter introduces some practical complexities: the sectors shown in Fig. 1 were constructed to remove offshore seamounts and plateaus that would otherwise lend spurious contributions to the calculated along-isobath circulation (Stewart et al. 2018). However, to perform the analysis in barotropic streamline-following coordinates we additionally found it necessary to exclude all areas deeper than $3000 \mathrm{~m}$, in order to exclude localized offshore recirculations. Even with these modifications, there remain some local recirculations over the shelf that manifest as negative streamfunction coordinates in Figs. $6 \mathrm{~b}$ and D1.

Figure D1 is identical to Fig. 7 but posed in barotropic streamline-following coordinates rather than isobath-following coordinates. In this alternative coordinate system the circulation budget yields qualitatively similar results, in that the surface stress is suppressed in the core of the ASC jet as a result of tidal advective acceleration along streamlines. However, there are also some notable differences between Figs. D1 and 7; for example, surface stress exceeds the bottom stress on the shoreward and offshore sides of the ASC jet when diagnosed in streamline-following coordinates, but not in isobath-following coordinates (see also Fig. 6). Such discrepancies likely result from deviations of barotropic streamlines from isobaths, which become more pronounced away from the shelfbreak jet (Fig. 3).

\section{APPENDIX E}

\section{Mean/Eddy/Tidal Energy Budget Decomposition}

In section 3 we used the transfer of energy between the mean and transient components of the flow to complement our circulation budget analysis, facilitating interpretation of the diagnosed eddy and tidal accelerations of the ASC. While decomposition of the energy reservoirs into mean and transient components is common practice in the study of geophysical fluids (e.g., Vallis 2006), we could not find an explicit decomposition appropriate to flows across three different time scales. We therefore provide the full mean/eddy/tidal energy budget here for completeness, though we only use a small subset of these equations in our analysis (see section 3b).

The MKE, EKE, and TKE reservoirs are defined in (8). In addition to these, we define the potential energy,

$$
\mathrm{PE} \equiv-b z
$$

By extending standard derivations (e.g., Vallis 2006), we write equations for the time evolution of the depthintegrated MKE,

$$
\begin{aligned}
& \frac{\partial}{\partial t}\langle\mathrm{MKE}\rangle+\nabla \cdot\left\langle\mathbf{F}_{\mathrm{MKE}}\right\rangle \approx-\langle\mathrm{MKE} \rightarrow \mathrm{EKE}\rangle-\langle\mathrm{MKE} \rightarrow \mathrm{TKE}\rangle-\langle\mathrm{MKE} \rightarrow \mathrm{PE}\rangle \\
& \quad+\left.F_{\mathrm{MKE}}^{(\tau)}\right|_{z=0}-\left.F_{\mathrm{MKE}}^{(\tau)}\right|_{z=-h}-\left\langle\frac{\partial \mathbf{u}_{m}}{\partial z} \cdot \overline{\boldsymbol{\tau}}^{t, e}\right\rangle+\left\langle\mathbf{u}_{m} \cdot \overline{\mathbf{G}}_{\nu}^{t, e}\right\rangle
\end{aligned}
$$


the depth-integrated EKE,

$$
\begin{aligned}
& \frac{\partial}{\partial t}\langle\mathrm{EKE}\rangle+\nabla \cdot\left\langle\mathbf{F}_{\mathrm{EKE}}\right\rangle=\langle\mathrm{MKE} \rightarrow \mathrm{EKE}\rangle \\
& +\langle\mathrm{PE} \rightarrow \mathrm{EKE}\rangle-\langle\mathrm{EKE} \rightarrow \mathrm{TKE}\rangle+\left.F_{\mathrm{MKE}}^{(\tau)}\right|_{z=0} \\
& \quad-\left.F_{\mathrm{MKE}}^{(\tau)}\right|_{z=-h}-\left\langle\overline{\left.\frac{\partial \mathbf{u}_{e}}{\partial z} \cdot \overline{\boldsymbol{\tau}}^{t}\right\rangle}\right. \\
& +\left\langle\overline{\mathbf{u}_{e} \cdot \overline{\mathbf{G}}_{\nu}^{t}}\right\rangle+\left\langle\overline{\mathbf{u}_{e} \cdot \overline{\mathbf{G}}_{t}^{t}}\right\rangle
\end{aligned}
$$

the depth-integrated TKE,

$$
\begin{aligned}
\frac{\partial}{\partial t}\langle\mathrm{TKE}\rangle+\nabla \cdot\left\langle\mathbf{F}_{\mathrm{TKE}}\right\rangle=\langle\mathrm{MKE} \rightarrow \mathrm{TKE}\rangle+\langle\mathrm{PE} \rightarrow \mathrm{TKE}\rangle \\
\quad+\langle\mathrm{EKE} \rightarrow \mathrm{TKE}\rangle+\left.F_{\mathrm{MKE}}^{(\tau)}\right|_{z=0}-\left.F_{\mathrm{MKE}}^{(\tau)}\right|_{z=-h} \\
\quad-\left\langle\frac{{\overline{\partial \mathbf{u}_{t}}}_{\partial z} \cdot \boldsymbol{\tau}}{t, e}\right\rangle+\left\langle{\overline{\mathbf{u}_{t} \cdot \mathbf{G}_{\nu}}}^{t, e}\right\rangle+\left\langle{\overline{\mathbf{u}_{t} \cdot \mathbf{G}_{t}}}^{t, e}\right\rangle,
\end{aligned}
$$

and the depth-integrated PE,

$$
\begin{aligned}
& \frac{\partial}{\partial t}\langle\mathrm{PE}\rangle+\nabla \cdot\left\langle\mathbf{F}_{\mathrm{PE}}\right\rangle=\langle\mathrm{MKE} \rightarrow \mathrm{PE}\rangle \\
& \quad-\langle\mathrm{PE} \rightarrow \mathrm{EKE}\rangle-\langle\mathrm{PE} \rightarrow \mathrm{TKE}\rangle-\left\langle\begin{array}{ll}
\bar{b}^{t, e} & z
\end{array} .\right.
\end{aligned}
$$

Here (E2) is approximate because we have neglected the time-mean tidal forcing $\overline{\mathbf{G}}_{t}^{t, e}$, and in (E6) we denote nonconservative sources and sinks of buoyancy as $\dot{b}$.

In $(\mathrm{E} 2)-(\mathrm{E} 6)$ the conversion terms $\mathrm{MKE} \rightarrow \mathrm{EKE}$, $\mathrm{MKE} \rightarrow \mathrm{TKE}, \mathrm{PE} \rightarrow \mathrm{EKE}$, and $\mathrm{PE} \rightarrow \mathrm{TKE}$ are given by (20a), (21a), (19a), and (19b), respectively. We additionally define the rate of energy conversion from MKE to PE as

$$
\mathrm{MKE} \rightarrow \mathrm{PE}=-w_{m} b_{m},
$$

and the conversion from EKE to TKE as

$$
\mathrm{EKE} \rightarrow \mathrm{TKE}=-{\overline{\overline{\mathbf{u}}_{t}{ }_{t}^{t} \cdot \nabla \mathbf{u}_{e}}}^{e}-\overline{{\overline{\mathbf{u}_{t} w_{t}}}^{t} \cdot \frac{\partial \overline{\mathbf{u}}_{e}}{\partial z}} .
$$

Finally, we define the flux of MKE,

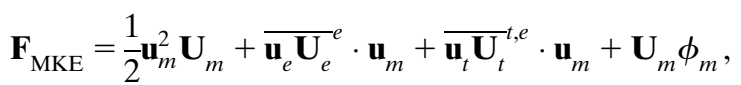

the flux of EKE,

$$
\mathbf{F}_{\mathrm{EKE}}=\overline{\frac{1}{2} \mathbf{u}_{e}^{2}\left(\mathbf{U}_{m}+\mathbf{U}_{e}\right)}+{\overline{\overline{\mathbf{u}}_{t} \mathbf{U}_{t}^{t} \cdot \mathbf{u}_{e}}}^{e}+{\overline{\mathbf{U}_{e} \phi_{e}}}^{e},
$$

the flux of TKE,

$$
\mathbf{F}_{\mathrm{TKE}}={\overline{\frac{1}{2} \mathbf{u}_{t}^{2} \mathbf{U}}}^{t, e}+{\overline{\mathbf{U}_{t} \phi_{t}}}^{t, e}
$$

and the flux of PE

$$
\mathbf{F}_{\mathrm{PE}}=\overline{\mathbf{U P E}}^{t, e}
$$

Here $\mathbf{U}=(u, v, w)$ is the three-dimensional velocity vector.

\section{REFERENCES}

Abernathey, R., J. Marshall, and D. Ferreira, 2011: The dependence of Southern Ocean meridional overturning on wind stress. J. Phys. Oceanogr., 41, 2261-2278, https://doi.org/ 10.1175/JPO-D-11-023.1.

Andrews, D. G., and M. E. McIntyre, 1976: Planetary waves in horizontal and vertical shear: The generalized Eliassen-Palm relation and the mean zonal acceleration. J. Atmos. Sci., 33, 2031-2048, https://doi.org/10.1175/1520-0469(1976)033<2031: PWIHAV $>2.0 . \mathrm{CO} ; 2$.

Armitage, T. W. K., R. Kwok, A. F. Thompson, and G. Cunningham, 2018: Dynamic topography and sea level anomalies of the Southern Ocean: Variability and teleconnections. J. Geophys. Res. Oceans, 123, 613-630, https://doi.org/10.1002/ 2017JC013534.

Baines, P. G., and S. Condie, 1998: Observations and modelling of Antarctic downslope flows: A review. Ocean, Ice, and Atmosphere: Interactions at the Antarctic Continental Margin, S. S. Jacobs and R. F. Weiss, Antarctic Research Series, Vol. 75, Amer. Geophys. Union, 29-49.

Brink, K. H., 2011: Topographic rectification in a stratified ocean. J. Mar. Res., 69, 483-499, https://doi.org/10.1357/002224011799849354.

_ 2016: Cross-shelf exchange. Annu. Rev. Mar. Sci., 8, 59-78, https://doi.org/10.1146/annurev-marine-010814-015717.

Bühler, O., 2014: Waves and Mean Flows. Cambridge University Press, https://doi.org/10.1017/CBO9781107478701.

Castagno, P., P. Falco, M. S. Dinniman, G. Spezie, and G. Budillon, 2017: Temporal variability of the Circumpolar Deep Water inflow onto the Ross Sea continental shelf. J. Mar. Syst., 166, 37-49, https://doi.org/10.1016/j.jmarsys.2016.05.006.

Cavalieri, D. J., and C. L. Parkinson, 2008: Antarctic sea ice variability and trends, 1979-2006. J. Geophys. Res., 113, C07004, https://doi.org/10.1029/2007JC004564.

Chavanne, C. P., K. J. Heywood, K. W. Nicholls, and I. Fer, 2010: Observations of the Antarctic slope undercurrent in the southeastern Weddell Sea. Geophys. Res. Lett., 37, L13601, https://doi.org/10.1029/2010GL043603.

Chen, C., and R. C. Beardsley, 1995: A numerical study of stratified tidal rectification over finite-amplitude banks. Part I: Symmetric banks. J. Phys. Oceanogr., 25, 2090-2110, https://doi.org/ 10.1175/1520-0485(1995)025<2090:ANSOST>2.0.CO;2.

Couto, N., D. G. Martinson, J. Kohut, and O. Schofield, 2017: Distribution of Upper Circumpolar Deep Water on the warming continental shelf of the West Antarctic Peninsula. J. Geophys. Res. Oceans, 122, 5306-5315, https://doi.org/ 10.1002/2017JC012840.

Davis, P. E. D., and Coauthors, 2018: Variability in basal melting beneath Pine Island Ice Shelf on weekly to monthly timescales. 
J. Geophys. Res. Oceans, 123, 8655-8669, https://doi.org/ 10.1029/2018JC014464.

Dufour, C. O., A. K. Morrison, S. M. Griffies, I. Frenger, H. Zanowski, and M. Winton, 2017: Preconditioning of the Weddell Sea polynya by the ocean mesoscale and dense water overflows. J. Climate, $\mathbf{3 0}$, 7719-7737, https://doi.org/10.1175/JCLI-D-16-0586.1.

ECMWF, 2011: ECMWF's Operational Model Analysis, starting in 2011. Research Data Archive at the National Center for Atmospheric Research, Computational and Information Systems Laboratory, accessed 24 October 2013, https://doi.org/ 10.5065/D6ZG6Q9F.

Fekete, B. M., C. J. Vörösmarty, and W. Grabs, 2002: High-resolution fields of global runoff combining observed river discharge and simulated water balances. Global Biogeochem. Cycles, 16, https://doi.org/10.1029/1999GB001254.

Flexas, M. M., M. P. Schodlok, L. Padman, D. Menemenlis, and A. H. Orsi, 2015: Role of tides on the formation of the Antarctic Slope Front at the Weddell-Scotia Confluence. J. Geophys. Res. Oceans, 120, 3658-3680, https://doi.org/ 10.1002/2014JC010372.

Foldvik, A., J. H. Middleton, and T. D. Foster, 1990: The tides of the southern Weddell Sea. Deep-Sea Res., 37A, 1345-1362, https://doi.org/10.1016/0198-0149(90)90047-Y.

Foreman, M. G. G., and R. F. Henry, 1989: The harmonic analysis of tidal model time series. Adv. Water Resour., 12, 109-120, https://doi.org/10.1016/0309-1708(89)90017-1.

Forget, G., J.-M. Campin, P. Heimbach, C. N. Hill, R. M. Ponte, and C. Wunsch, 2015: ECCO version 4: An integrated framework for non-linear inverse modeling and global ocean state estimation. Geosci. Model Dev., 8, 3071-3104, https:// doi.org/10.5194/gmd-8-3071-2015.

Fox-Kemper, B., and D. Menemenlis, 2008: Can large eddy simulation techniques improve mesoscale rich ocean models? Ocean Modeling in an Eddying Regime, Geophys. Monogr., Vol. 177, Amer. Geophys. Union, 319-338.

Garreau, P., and R. Maze, 1992: Tidal rectification and mass transport over a shelf break: A barotropic frictionless model. J. Phys. Oceanogr., 22, 719-731, https://doi.org/10.1175/15200485(1992)022<0719:TRAMTO >2.0.CO;2.

Gill, A. E., 1973: Circulation and bottom water production in the Weddell Sea. Deep-Sea Res. Oceanogr. Abstr., 20, 111-140, https://doi.org/10.1016/0011-7471(73)90048-X.

Goddard, P. B., C. O. Dufour, J. Yin, S. M. Griffies, and M. Winton, 2017: $\mathrm{CO}_{2}$-induced ocean warming of the Antarctic continental shelf in an eddying global climate model. J. Geophys. Res. Oceans, 122, 8079-8101, https://doi.org/10.1002/2017JC012849.

Gordon, A. L., 2001: Bottom water formation. Encyclopedia of Ocean Sciences, Academic Press, 334-340, https://doi.org/ 10.1006/rwos.2001.0006.

_ B. A. Huber, and J. Busecke, 2015: Bottom water export from the western Ross Sea, 2007 through 2010. Geophys. Res. Lett., 42, 5387-5394, https://doi.org/10.1002/2015GL064457.

Graham, J. A., M. S. Dinniman, and J. M. Klinck, 2016: Impact of model resolution for on-shelf heat transport along the West Antarctic Peninsula. J. Geophys. Res. Oceans, 121, 7880-7897, https://doi.org/10.1002/2016JC011875.

Greene, C. A., D. D. Blankenship, D. E. Gwyther, A. Silvano, and E. van Wijk, 2017: Wind causes Totten Ice Shelf melt and acceleration. Sci. $A d v$., 3, e1701681, https://doi.org/10.1126/ sciadv.1701681.

Hattermann, T., 2018: Antarctic thermocline dynamics along a narrow shelf with easterly winds. J. Phys. Oceanogr., 48, 24192443, https://doi.org/10.1175/JPO-D-18-0064.1.
L. H. Smedsrud, O. A. Nøst, J. M. Lilly, and B. K. GaltonFenzi, 2014: Eddy-resolving simulations of the Fimbul Ice Shelf cavity circulation: Basal melting and exchange with open ocean. Ocean Modell., 82, 28-44, https://doi.org/10.1016/ j.ocemod.2014.07.004.

Hazel, J. E., and A. L. Stewart, 2019: Are the near-Antarctic easterly winds weakening in response to enhancement of the Southern Annular Mode? J. Climate, 32, 1895-1918, https:// doi.org/10.1175/JCLI-D-18-0402.1.

Heywood, K. J., and Coauthors, 2014: Ocean processes at the Antarctic continental slope. Philos. Trans. Roy. Soc. London, A372, 20130047, https://doi.org/10.1098/rsta.2013.0047.

_ - and Coauthors, 2016: Between the devil and the deep blue sea: the role of the Amundsen Sea continental shelf in exchanges between ocean and ice shelves. Oceanography, 29, 118-129, https://doi.org/10.5670/oceanog.2016.104.

Hotinski, R. M., K. L. Bice, L. R. Kump, R. G. Najjar, and M. A. Arthur, 2001: Ocean stagnation and end-Permian anoxia. Geology, 29, 7-10, https://doi.org/10.1130/0091-7613(2001) $029<0007$ :OSAEPA $>2.0 . \mathrm{CO} ; 2$.

Jackett, D. R., and T. J. McDougall, 1997: A neutral density variable for the world's oceans. J. Phys. Oceanogr., 27, 237-263, https://doi.org/ 10.1175/1520-0485(1997)027<0237:ANDVFT >2.0.CO;2.

Jacobs, S. S., 1991: On the nature and significance of the Antarctic Slope Front. Mar. Chem., 35, 9-24, https://doi.org/10.1016/ S0304-4203(09)90005-6.

Jenkins, A., P. Dutrieux, S. Jacobs, E. J. Steig, G. H. Gudmundsson, J. Smith, and K. J. Heywood, 2016: Decadal ocean forcing and Antarctic ice sheet response: Lessons from the Amundsen Sea. Oceanography, 29, 106-117, https:// doi.org/10.5670/oceanog.2016.103.

Karsten, R. H., and J. Marshall, 2002: Constructing the residual circulation of the ACC from observations. J. Phys. Oceanogr. 32, 3315-3327, https://doi.org/10.1175/1520-0485(2002)032<3315: CTRCOT $>2.0 . \mathrm{CO} ; 2$.

Klinck, J. M., and M. S. Dinniman, 2010: Exchange across the shelf break at high southern latitudes. Ocean Sci., 6, 513-524, https://doi.org/10.5194/os-6-513-2010.

Kusahara, K., and K. I. Ohshima, 2014: Kelvin waves around Antarctica. J. Phys. Oceanogr., 44, 2909-2920, https://doi.org/ 10.1175/JPO-D-14-0051.1.

Lane-Serff, G. F., and P. G. Baines, 1998: Eddy formation by dense flows on slopes in a rotating fluid. J. Fluid Mech., 363, 229-252, https://doi.org/10.1017/S0022112098001013.

Langlais, C. E., S. R. Rintoul, and J. D. Zika, 2015: Sensitivity of Antarctic Circumpolar Current transport and eddy activity to wind patterns in the Southern Ocean. J. Phys. Oceanogr., 45, 1051-1067, https://doi.org/10.1175/JPO-D-14-0053.1.

Large, W. G., and S. G. Yeager, 2009: The global climatology of an interannually varying air-sea flux data set. Climate Dyn., $\mathbf{3 3}$, 341-364, https://doi.org/10.1007/s00382-008-0441-3.

Lee, S.-H., and R. C. Beardsley, 1999: Influence of stratification on residual tidal currents in the Yellow Sea. J. Geophys. Res., 104, 15 679-15 701, https://doi.org/10.1029/1999JC900108.

Li, Q., S. Lee, and A. Griesel, 2016: Eddy fluxes and jet-scale overturning circulations in the Indo-western Pacific Southern Ocean. J. Phys. Oceanogr., 46, 2943-2959, https://doi.org/ 10.1175/JPO-D-15-0241.1.

Loder, J. W., 1980: Topographic rectification of tidal currents on the sides of Georges Bank. J. Phys. Oceanogr., 10, 1399-1416, https:// doi.org/10.1175/1520-0485(1980)010<1399:TROTCO >2.0.CO;2.

Losch, M., D. Menemenlis, J.-M. Campin, P. Heimbach, and C. Hill, 2010: On the formulation of sea-ice models. Part 1: Effects of 
different solver implementations and parameterizations. Ocean Modell., 33, 129-144, https://doi.org/10.1016/j.ocemod.2009.12.008.

Marshall, J., and T. Radko, 2003: Residual-mean solutions for the Antarctic Circumpolar Current and its associated overturning circulation. J. Phys. Oceanogr., 33, 2341-2354, https://doi.org/ 10.1175/1520-0485(2003)033<2341:RSFTAC $>2.0 . C O ; 2$.

— A. Adcroft, C. Hill, L. Perelman, and C. Heisey, 1997a: A finite-volume, incompressible Navier Stokes model for studies of the ocean on parallel computers. J. Geophys. Res., 102, 5753-5766, https://doi.org/10.1029/96JC02775.

- C. Hill, L. Perelman, and A. Adcroft, 1997b: Hydrostatic, quasihydrostatic, and nonhydrostatic ocean modeling. J. Geophys. Res., 102, 5733-5752, https://doi.org/10.1029/96JC02776.

Mathiot, P., H. Goosse, T. Fichefet, B. Barnier, and H. Gallée, 2011 Modelling the seasonal variability of the Antarctic Slope Current. Ocean Sci., 7, 455-470, https://doi.org/10.5194/os-7-455-2011.

Meijers, A. J. S., A. Klocker, N. L. Bindoff, G. D. Williams, and S. J. Marsland, 2010: The circulation and water masses of the Antarctic shelf and continental slope between 30 and $80^{\circ}$ E. Deep-Sea Res. II, 57, 723-737, https://doi.org/10.1016/ j.dsr2.2009.04.019.

Meneghello, G., J. Marshall, J.-M. Campin, E. Doddridge, and M.-L. Timmermans, 2018: The ice-ocean governor: Ice-ocean stress feedback limits Beaufort Gyre spin-up. Geophys. Res. Lett., $\mathbf{4 5}$, 11 293-11 299, https://doi.org/10.1029/2018GL080171.

Menemenlis, D., J.-M. Campin, P. Heimbach, C. Hill, T. Lee, A. Nguyen, M. Schodlok, and H. Zhang, 2008: ECCO2: High resolution global ocean and sea ice data synthesis. Mercator Ocean Quarterly Newsletter, No. 31, Mercator Ocean International, Ramonville Saint Agne, France, 13-21, https://www.mercator-ocean.fr/wp-content/uploads/2015/06/ lettre_31_en.pdf.

Morrison, A. K., and A. M. Hogg, 2013: On the relationship between Southern Ocean overturning and ACC transport. J. Phys. Oceanogr., 43, 140-148, https://doi.org/10.1175/ JPO-D-12-057.1.

Munk, W. H., and E. Palmén, 1951: Note on the dynamics of the Antarctic Circumpolar Current. Tellus, 3, 53-55, https:// doi.org/10.3402/tellusa.v3i1.8609.

Newsom, E. R., C. M. Bitz, F. O. Bryan, R. Abernathey, and P. R. Gent, 2016: Southern Ocean deep circulation and heat uptake in a high-resolution climate model. J. Climate, 29, 2597-2619, https://doi.org/10.1175/JCLI-D-15-0513.1.

Nøst, O. A., M. Biuw, V. Tverberg, C. Lydersen, T. Hattermann, Q. Zhou, L. H. Smedsrud, and K. M. Kovacs, 2011: Eddy overturning of the Antarctic Slope Front controls glacial melting in the Eastern Weddell Sea. J. Geophys. Res., 116, C11014, https://doi.org/10.1029/2011JC006965.

Orsi, A. H., S. S. Jacobs, A. L. Gordon, and M. Visbeck, 2001: Cooling and ventilating the abyssal ocean. Geophys. Res. Lett., 28, 2923-2926, https://doi.org/10.1029/2001GL012830.

Padman, L., S. L. Howard, A. H. Orsi, and R. D. Muench, 2009: Tides of the northwestern Ross Sea and their impact on dense outflows of Antarctic Bottom Water. Deep-Sea Res. II, 56, 818-834, https://doi.org/10.1016/j.dsr2.2008.10.026.

Palóczy, A., S. T. Gille, and J. L. McLean, 2018: Oceanic heat delivery to the Antarctic continental shelf: Large-scale, lowfrequency variability. J. Geophys. Res. Oceans, 123, 76787701, https://doi.org/10.1029/2018JC014345.

Paolo, F. S., L. Padman, H. A. Fricker, S. Adusumilli, S. Howard, and M. R. Siegfried, 2018: Response of Pacificsector Antarctic ice shelves to the El Niño/Southern Oscillation. Nat. Geosci., 11, 121, https://doi.org/10.1038/ s41561-017-0033-0.
Peña-Molino, B., M. S. McCartney, and S. R. Rintoul, 2016: Direct observations of the Antarctic Slope Current transport at $113^{\circ}$ E. J. Geophys. Res. Oceans, 121, 7390-7407, https:// doi.org/10.1002/2015JC011594.

Pritchard, H. D., S. R. M. Ligtenberg, H. A. Fricker, D. G. Vaughan, M. R. van den Broeke, and L. Padman, 2012: Antarctic ice-sheet loss driven by basal melting of ice shelves. Nature, 484, 502-505, https://doi.org/10.1038/nature10968.

Rintoul, S. R., 2018: The global influence of localized dynamics in the Southern Ocean. Nature, 558, 209-218, https://doi.org/ 10.1038/s41586-018-0182-3.

Robertson, R., 2001: Internal tides and baroclinicity in the southern Weddell Sea: 1. Model description. J. Geophys. Res., 106, 27 001-27 016, https://doi.org/10.1029/2000JC000475.

Rocha, C. B., T. K. Chereskin, S. T. Gille, and D. Menemenlis, 2016: Mesoscale to submesoscale wavenumber spectra in Drake Passage. J. Phys. Oceanogr., 46, 601-620, https://doi.org/10.1175/JPOD-15-0087.1.

Sarmiento, J. L., T. D. Herbert, and J. R. Toggweiler, 1988: Causes of anoxia in the world ocean. Global Biogeochem. Cycles, 2 , 115-128, https://doi.org/10.1029/GB002i002p00115.

Schmidtko, S., K. J. Heywood, A. F. Thompson, and S. Aoki, 2014: Multidecadal warming of Antarctic waters. Science, 346, 12271231, https://doi.org/10.1126/science.1256117.

Smith, W. H. F., and D. T. Sandwell, 1997: Global sea floor topography from satellite altimetry and ship depth soundings. Science, 277, 1956-1962, https://doi.org/10.1126/ science.277.5334.1956

Spence, P., S. M. Griffies, M. H. England, A. M. Hogg, O. A. Saenko, and N. C. Jourdain, 2014: Rapid subsurface warming and circulation changes of Antarctic coastal waters by poleward shifting winds. Geophys. Res. Lett., 41, 4601-4610, https://doi.org/10.1002/ 2014GL060613.

— R. M. Holmes, A. M. Hogg, S. M. Griffies, K. D. Stewart, and M. H. England, 2017: Localized rapid warming of West Antarctic subsurface waters by remote winds. Nat. Climate Change, 7, 595-603, https://doi.org/10.1038/nclimate3335.

St-Laurent, P., J. M. Klinck, and M. S. Dinniman, 2013: On the role of coastal troughs in the circulation of warm circumpolar deep water on Antarctic shelves. J. Phys. Oceanogr., 43, 51-64, https://doi.org/10.1175/JPO-D-11-0237.1.

Stewart, A. L., and A. F. Thompson, 2012: Sensitivity of the ocean's deep overturning circulation to easterly Antarctic winds. Geophys. Res. Lett., 39, L18604, https://doi.org/10.1029/ 2012GL053099.

, and - 2013: Connecting Antarctic cross-slope exchange with Southern Ocean overturning. J. Phys. Oceanogr., 43, 1453-1471, https://doi.org/10.1175/JPO-D-12-0205.1.

_, and —, 2015a: Eddy-mediated transport of warm Circumpolar Deep Water across the Antarctic Shelf Break. Geophys. Res. Lett., 42, 432-440, https://doi.org/10.1002/2014GL062281. , and $-2015 \mathrm{~b}$ : The Neutral Density Temporal Residual Mean overturning circulation. Ocean Modell., 90, 44-56, https://doi.org/10.1016/j.ocemod.2015.03.005.

$\longrightarrow$, and — 2016: Eddy generation and jet formation on the Antarctic continental slope. J. Phys. Oceanogr., 46, 3729-3750, https://doi.org/10.1175/JPO-D-16-0145.1.

, and A. M. Hogg, 2017: Reshaping the Antarctic Circumpolar Current via Antarctic Bottom Water export. J. Phys. Oceanogr., 47, 2577-2601, https://doi.org/10.1175/JPO-D-17-0007.1. A. Klocker, and D. Menemenlis, 2018: Circum-Antarctic shoreward heat transport derived from an eddy- and tideresolving simulation. Geophys. Res. Lett., 45, 834-845, https:// doi.org/10.1002/2017GL075677. 
Su, Z., A. L. Stewart, and A. F. Thompson, 2014: An idealized model of Weddell Gyre export variability. J. Phys. Oceanogr., 44, 1671-1688, https://doi.org/10.1175/JPO-D-13-0263.1.

Thompson, A. F., and K. J. Heywood, 2008: Frontal structure and transport in the northwestern Weddell Sea. Deep-Sea Res. I, 55, 1229-1251, https://doi.org/10.1016/j.dsr.2008.06.001.

,,$\ldots$, S. Schmidtko, and A. L. Stewart, 2014: Eddy transport as a key component of the Antarctic overturning circulation. Nat. Geosci., 7, 879-884, https://doi.org/10.1038/ngeo2289.

- A. L. Stewart, P. Spence, and K. J. Heywood, 2018: The Antarctic Slope Current in a changing climate. Rev. Geophys., 56, 741-770, https://doi.org/10.1029/2018RG000624.

Towns, J., and Coauthors, 2014: XSEDE: Accelerating scientific discovery. Comput. Sci. Eng., 16, 62-74, https://doi.org/ 10.1109/MCSE.2014.80.

Vallis, G. K., 2006: Atmospheric and Oceanic Fluid Dynamics: Fundamentals and Large-Scale Circulation. Cambridge University Press, $745 \mathrm{pp}$.

Wang, Q., S. Danilov, H. Hellmer, D. Sidorenko, J. Schroeter, and T. Jung, 2013: Enhanced cross-shelf exchange by tides in the western Ross Sea. Geophys. Res. Lett., 40, 5735-5739, https:// doi.org/10.1002/2013GL058207.

Wang, Y., and A. L. Stewart, 2018: Eddy dynamics over continental slopes under retrograde winds: Insights from a model intercomparison. Ocean Modell., 121, 1-18, https://doi.org/10.1016/ j.ocemod.2017.11.006.

Whitworth, T., A. H. Orsi, S.-J. Kim, W. D. Nowlin, and R. A. Locarnini, 1998: Water masses and mixing near the Antarctic Slope Front. Ocean, Ice, and Atmosphere: Interactions at the Antarctic Continental Margin, S. S. Jacobs and R. F. Weiss, Antarctic Research Series, Vol. 75, Amer. Geophys. Union, 1-27.

Zhao, K. X., A. L. Stewart, and J. C. McWilliams, 2019: Sillinfluenced exchange flows in ice shelf cavities. J. Phys. Oceanogr., 49, 163-191, https://doi.org/10.1175/JPO-D-180076.1 .

Zhou, Q., T. Hattermann, O. A. Nøst, M. Biuw, K. M. Kovacs, and C. Lydersen, 2014: Wind-driven spreading of fresh surface water beneath ice shelves in the Eastern Weddell Sea. J. Geophys. Res. Oceans, 119, 3818-3833, https://doi.org/ 10.1002/2013JC009556. 